\title{
THE RELATIONSHIP BETWEEN CHRONIC STRESS, EMOTION REGULATION AND DEPRESSIVE SYMPTOMS IN HEALTHY OLDER ADULTS
}

\author{
by \\ Vivian Huang \\ Bachelor of Science (Hons.), University of Calgary, 2013
}

\author{
A thesis \\ presented to Ryerson University \\ in partial fulfillment of the requirements for the degree of \\ Master of Arts \\ in the Program of Psychology
}

Toronto, Ontario, Canada, 2016

C (Vivian Huang) 2016 


\section{AUTHOR'S DECLARATION}

I hereby declare that I am the sole author of this thesis. This is a true copy of the thesis, including any required final revisions, as accepted by my examiners.

I authorize Ryerson University to lend this thesis to other institutions or individuals for the purpose of scholarly research

I further authorize Ryerson University to reproduce this thesis by photocopying or by other means, in total or in part, at the request of other institutions or individuals for the purpose of scholarly research.

I understand that my thesis may be made electronically available to the public. 
The Relationship Between Chronic Stress, Emotion Regulation And Depressive Symptoms In Healthy Older Adults

Master of Arts, 2016

Vivian Huang

Psychology

Ryerson University

\begin{abstract}
The current study examined the association between chronic stress (measured in allostatic load or AL), ER, and depressive symptoms in a group of community-dwelling older adults. It was hypothesized that chronic stress levels would mediate the relationship between ER and depressive symptoms. A total of 70 older adults aged 60 and older participated in the study. There were no significant associations found in the main analyses between the AL index and depressive symptoms, as well as no significant relationship was found between ER strategies and AL index, after controlling for age, sex, education, and perceived SES. However, perceived stress significantly mediated the relationship between maladaptive ER strategies and depressive symptoms, and the relationship between adaptive ER strategies and depressive symptoms. Given the small sample size and the lack of variability of the AL index, the study would benefit from a larger sample size to clarify the present results.
\end{abstract}




\section{Acknowledgement}

I would like to thank my supervisor, Dr. Alexandra Fiocco, for her continuous support and guidance. Alex helped me to get through moments when I felt loss and confused. Thank you for your wisdom and kind words. I would also like to thank my supervisory committee member, Dr. Kristin Vickers, for her feedback and support throughout the project, and Dr. Lixia Yang for agreeing to be my external reviewer. I am grateful for all the wonderful suggestions provided by my committee members.

I would also like to thank all the members in the Stress and Healthy Aging Research Laboratory for your support, laughter, and words of encouragement. Especially, Shruti Vyas and Mitra Farzaneh who helped me with data collection. I work with the most amazing team of individuals! I would also like to thank all the participants who have dedicated their time and effort on this project.

I would like to thank my family and friends for their unconditional support throughout my graduate school journey thus far. I would like to thank my wonderful fiancée, Wesley, for his continuous support. He helped me get through every stressful moment and all the ups and downs throughout this time. You kept me grounded and always lent me your ear. I am forever grateful to have you by my side.

Lastly, I would also like to dedicate this work to my grandparents. It was the experience of living and growing up with all of you that have motivated me to pursue a career in geropsychology. To my popo, I love you and thank you for all your wisdoms. To my gongong and yeye, I hope the both of you are happy and at peace whereever you are. 


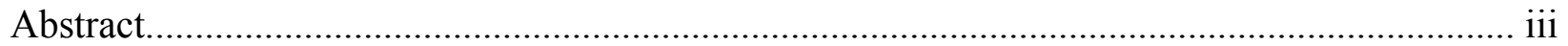

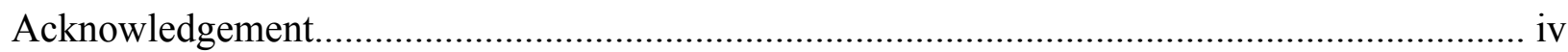

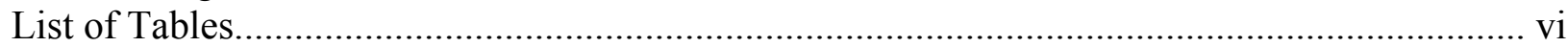

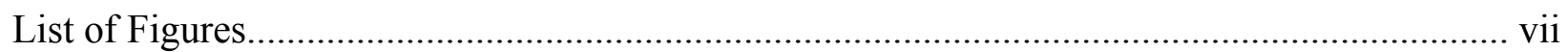

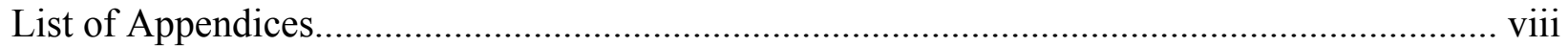

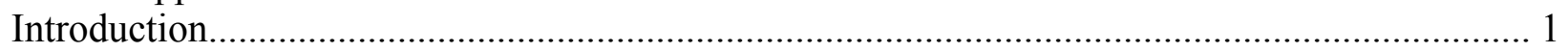

Overview of Depression and Its Impact in Older Adults.................................................... 1

Overview of the Stress Systems....................................................................................... 5

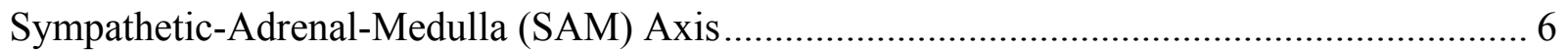

Hypothalamic-Pituitary-Adrenal (HPA) Axis .............................................................. 6

Stress System Dysregulation and the Brain .................................................................... 7

Hypothalamic-Pituitary-Adrenal (HPA) Axis in Depression ............................................... 9

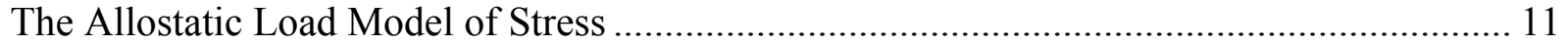

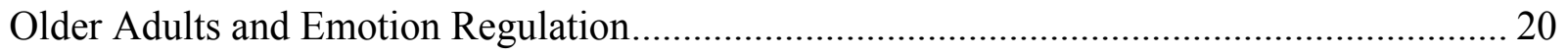

Relationship between Emotion Regulation, Depression and Stress ................................... 24

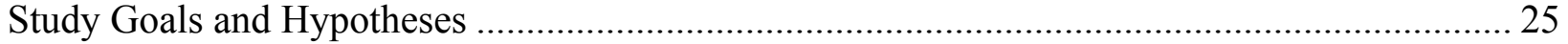

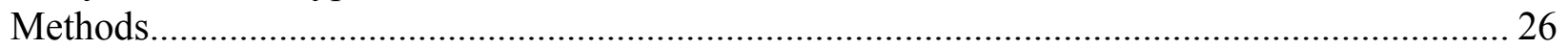

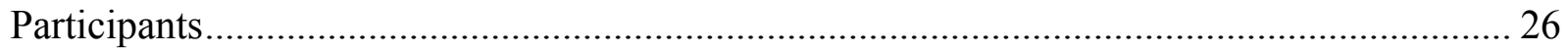

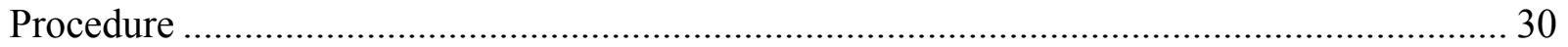

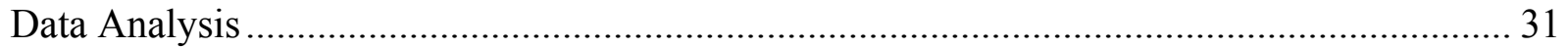

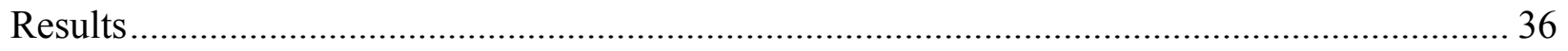

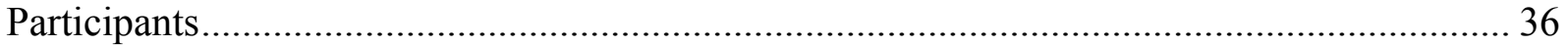

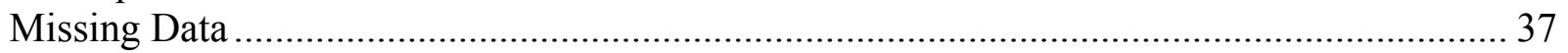

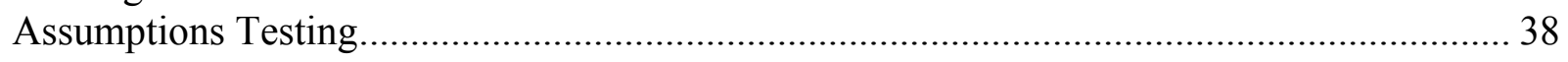

Analysis 1: Association between AL index and depressive symptoms............................... 39

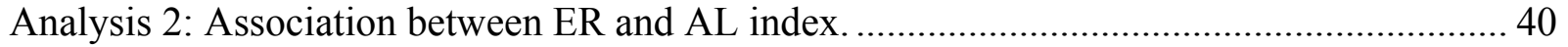

Analysis 3.0: The mediating role of AL in the relationship of ER and depressive symptoms. 41

Exploratory analyses: Examining the interplay between PSS, ER, and depressive symptoms.43

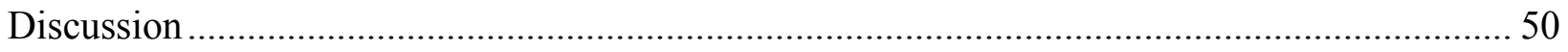

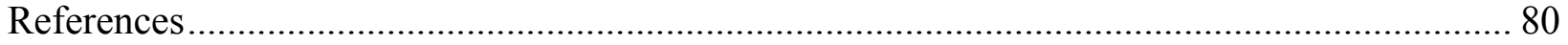




\section{List of Tables}

Table 1: Information on the Sample's Biomarker Levels and Criteria Cut-Off for Each

Biomarker

Table 2: Sample Characteristics and Descriptive Statistics.................................. 36

Table 3: Hierarchical Regression Model of AL and BDI-II Scores........................... 40

Table 4: Hierarchical Regression Model for ER strategies and AL .......................... 41

Table 5: Indirect Mediation Analysis for ER strategies, AL, and BDI-II..................... 41

Table 6: Hierarchical Regression Model of PSS-10 and BDI-II Scores....................................... 44

Table 7: Hierarchical Regression Model for ER strategies and PSS-10 ..................................... 45

Table 8: Indirect Mediation Analyses for ER strategies, PSS-10, and BDI-II scores................... 46 


\section{List of Figures}

Figure 1. Direct and indirect model of the relationship between emotion regulation (ER) strategies, allostatic load (AL), and depressive symptoms.

Figure 2: Hypothesized and alternative models of emotion regulation (ER) strategies, perceived stress, and depressive symptoms. a) Perceived stress mediates the relationship between ER strategies and depressive symptoms; b) Depressive symptoms mediate the relationship between ER strategies and perceived stress. 


\section{List of Appendices}

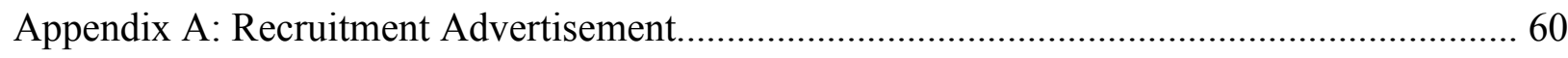

Appendix B: Telephone Screening Questionnaires......................................................... 61

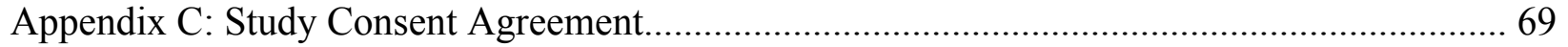

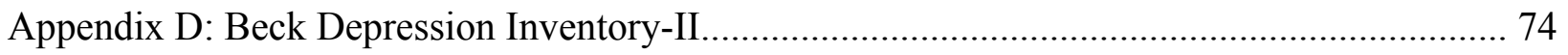

Appnedix E: Cognitive Emotion Regulation Questionnaire .................................................. 76

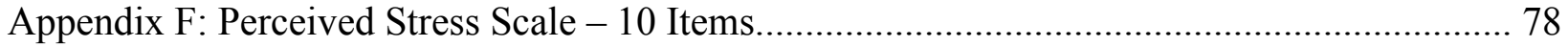

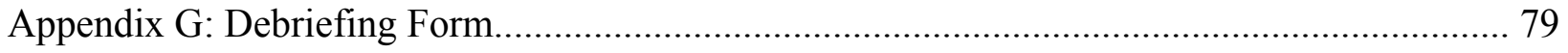


The Relationship between Chronic Stress, Emotion Regulation and Depressive Symptoms in Healthy Older Adults

Depression has been identified as a leading cause of disability worldwide (WHO, 2012). In Canada, it is estimated that 3 to $5 \%$ of older adults suffer from depression and 10 to $15 \%$ of those in the community experience depressive symptoms (CPA, 2014; Meeks, Hahia, Lavretysky, Kulkarni, \& Jeste, 2011). Depression, regardless of severity, is associated with poor physical function, greater healthcare utilization, and an increased risk of suicide (Fisket, Wetherell, \& Gatz, 2009; Meeks et al., 2011). Unfortunately, older adults with depression are often left undiagnosed and untreated (Stanners, Barton, Shakib, \& Winefield, 2013), resulting in accelerated deterioration in physical health and quality of life in this vulnerable population. With an aging population on the rise, it is imperative to elucidate the underlying mechanisms of depression in late life and to promote the well-being and independence of the elderly, who are expected to comprise $25 \%$ of the Canadian population in 2051 (Statistics Canada, 2011). Various factors, such as stress and emotion regulation, have been linked to the onset and maintenance of depression (Aldao, Nolen-Hoeksema, \& Schweizer, 2010; Kendler, Karkowski \& Prescott, 1999). However, the majority of research to date has taken a simplistic approach and has not considered the potential interplay between these factors. It is important to explore the interplay between depression, chronic stress, and emotion regulation to further our understanding of mechanisms that underlie the development and maintenance of late-life depression.

\section{Overview of Depression and Its Impact in Older Adults}

Although not an age-related disorder per se, the prevalence of depression in older adults is on the rise (Baldwin, 2000; Edlund, Lauerer, \& Drayton, 2015). Family members, caregivers, and physicians often overlook depression in older adults due to different symptom presentations 
compared to younger adults. Whereas young adults may present more affective symptoms (e.g., feeling sad), older adults often report feelings of worry and somatic complaints, just to name a few (Stanners et al., 2013). If depression is left untreated, older adults are more likely to attempt and commit suicide compared with young adults (Alexopoulos, 2005; Fisket, Wetherell, \& Gatz, 2009; Szczerbinska, Hirdes, \& Zyczkowska, 2012).

For a diagnosis of depression, regardless of age, individuals must present with either depressed mood or loss of interest or pleasure during the same two-week period and report changes from previous functioning (APA, 2013). Moreover, they must present with at least four of the following symptoms: fluctuation in weight, changes in sleep, psychomotor disturbances, fatigue, feelings of worthlessness, inability to concentrate, and/or recurrent suicidal thoughts (APA, 2013). The aforementioned symptoms must lead to significant functional impairment and symptoms must not be associated with substance use or any other medical condition (APA, 2013). Although there is an increased prevalence of major depression in older adults, recent studies suggest that subclinical depression is more common in community-dwelling older adults (CPA, 2014; Meeks et al., 2011), that is, individuals present with depressive symptoms without meeting full diagnostic criteria for major depressive disorder.

Previous studies have indicated that subclinical depression is associated with poorer social function (Howland et al., 2008), lower quality of life (Goldney, Fisher, Dal Grande, \& Taylor, 2004), more access of healthcare systems (Howland et al., 2008), and greater functional impairment (Rapaport et al., 2002) compared to healthy individuals. Moreover, older adults who experience persistent depressive symptoms have increased risks of disability and mortality over a 4-year period (Murphy et al., 2016). Given the negative impact of subclinical depressive 
symptoms on overall functioning, it is thus imperative to investigate the mechanism that underlies subclinical depression among older adults.

Compared to their younger counterparts, there are some unique symptom expressions in older adults. Depression in older adults has been termed "depression without sadness" (Gallo \& Rabins, 1999, p. 820). Older adults with depression often indicate feelings of emptiness, worry, and loneliness instead of feelings of sadness and/or depressed mood, which are commonly reported in younger individuals (Gallo \& Rabins, 1999). Moreover, they may appear to be quieter, as well as more critical of themselves. Somatization, health complaints, psychomotor disturbances (Albert, Bear-Lehman, \& Burkhardt, 2012; Parker, Roy, Hadzi-Pavlovic, Wilhelm, \& Mitchell, 2001), and delusions are also more common in depressed older adults than their younger counterparts (Alvarez, Urretavizcaya, Benllock, Vallejo, \& Menchon, 2011).

Different symptom presentations may contribute to difficulties in detecting depression in older adults. In addition to a different depression profile, older adults tend to be less knowledgeable about depression than younger adults (Farrer, Leach, Griffiths, Christensen, \& Jorm, 2008) and exhibit more self- and perceived-stigma of depression (Conner et al., 2010; Werner, Stein-Shvachman, \& Heinik, 2009). Thus, older adults are less likely to seek help (e.g., Conner et al., 2010), which may further contribute to depression being undiagnosed and untreated in the elderly population. As such, it is important to educate health professionals on the differences in depressive symptom presentation and potential underlying mechanisms to ensure that adequate treatments are provided for the elderly.

In addition to somatic and psychological disturbances, severe cognitive impairments are also found in older adults due to the combined effect of cognitive aging and depression-related cognitive symptoms (Thomas \& O'Brien, 2008). Subjective cognitive complaints have been 
identified as one of the common clinical features in older adults with depression (Alexopoulos, 2005; Amore et al., 2007). Impairments in information processing speed, executive functions, and visuospatial ability have also been found (Lockwood, Alexopoulos, \& van Gorp, 2002; Nebes et al., 2000). Of these domains, it appears that executive functions are most affected by late-life depression (Koenig, Bhalla, \& Butters, 2014). In particular, executive function deficits are strongly associated with functional decline (Wilkins et al., 2010). For instance, depressed individuals often exhibit negative attention and interpretation biases (Cowden Hindash, \& Amir, 2012; for review see Gotlib \& Joormann, 2010; Mathews \& MacLeod, 2005), cognitive rigidity (Meiran, Diamond, Toder, \& Nemets, 2011), and poor planning (Snyder, 2013). Such deficits not only perpetuate the prognosis of depression, they also have a significant impact on the functioning and well-being of older adults.

Previous research suggests a link between disruption in executive function processes and functional disability in older adults with depression (Alexopoulos et al., 1996). Potter and colleagues (2012) examined the association between attentional shifting and deficits in daily functions in 89 older adults with depression. After controlling for age, sex, education, and depression severity, greater error rates in attentional shifting were associated with greater functional disability (Potter, McQuoid, Payne, Taylor, \& Steffens, 2012). It was suggested that depressed individuals' inability to problem solve in daily activities could be due to poor problem solving skills that are outside of the individual's current abilities. Moreover, executive functions, such as working memory and problem solving abilities, could mediate the relationship between depressive symptoms and the inability to perform daily living tasks (Gallo et al., 2003). Consequently, older depressed individuals tend to exhibit functional impairments in tasks that require detailed encoding and effortful processing. 
Previous research provides strong support for a bidirectional relationship between depression and physical health in the elderly population. It is well established that late-life depression is linked to various chronic health conditions, such as cardiovascular (CVD; e.g., Carney, Freedland, \& Sheps, 2003) and neurological diseases (e.g., dementia; Alexopoulos, 2005), as well as diabetes (Li, Ford, Strine, \& Mokdad, 2008). Depression may further worsen the management and outcomes of these physical conditions as the individual is more likely to engage in unhealthy behaviours (e.g., smoking), display poor adherence to treatment, and/or exhibit underlying physiological changes associated with depression (e.g., increased inflammation in the body; Carney, Freedland, \& Sheps, 2004). Conversely, physical illnesses may serve as an important predictor for the onset of late-life depression due the emotional strain of health deterioration and reduced quality of life that the individual experiences (Golden et al., 2008; Gunn et al., 2012). Overall, depression has a significant impact on the overall well-being of older adults. As indicated, various factors have been identified as being associated with latelife depression. Particularly, prolonged stress exposure and dysregulation of the stress response system have received significant attention over the past three decades.

\section{Overview of the Stress Systems}

Chronic stress has been identified as a risk factor for the onset of depression (McGonagle \& Kessler, 1990). Stress arises when an individual perceives that the environmental demand placed upon him or her is beyond the available resources that the individual possesses (Lazarus, 1966). The stress response is a natural defense mechanism that requires physiological and behavioural adaptations to ensure the well-being of an individual (Ursin \& Erikensen, 2004). There are two main systems involved in the acute stress response: the sympathetic-adrenalmedulla (SAM) axis and the hypothalamic-pituitary-adrenal (HPA) axis (Herman \& Cullinan, 
1997). When individuals are presented with a stressor, the body activates both the SAM and HPA axes to engage in the "fight-or-flight" response (Piazza, Almeida, Dmitrieva, \& Klein, 2010). However, the timing of activation of these two systems differs. Whereas the SAM axis is a fast acting system where its activation and effect lasts from seconds to minutes, the HPA axis is a slower stress response system where its effect can remain from minutes to hours. These two systems have independent functions yet they are intricately connected.

\section{Sympathetic-Adrenal-Medulla (SAM) Axis}

Initially, the amygdala perceives a stimulus as a potential threat and sends a signal to the hypothalamus, which controls the autonomic nervous system and the endocrine system. The hypothalamus stimulates the adrenal medulla for the release of catecholamines (i.e., epinephrine and norepinephrine in humans) through the sympathetic nervous system (SNS; Theirry et al., 1968), which prepares the body to engage in the "fight-or-flight" response, resulting in increased arousal such as elevated heart rate, blood pressure, and metabolic changes (Sapolsky, 1999). Activation of the SAM axis allows the body to increase oxygen and glucose supplies to the brain and muscles. Moreover, it suppresses any non-emergent bodily functions during a stress response (e.g., digestion, reproduction and growth). Once the stressor subsides, the parasympathetic nervous system (PNS) is activated to terminate the subsequent release of catecholamines, thus allowing the body to return to its normal range of functioning (i.e., homeostasis).

\section{Hypothalamic-Pituitary-Adrenal (HPA) Axis}

During an acute stress response, the HPA axis is also activated. Similar to what is found with the SAM axis, the amygdala is activated and sends a signal to the hypothalamus. The hypothalamus releases corticotropin-releasing hormone (CRH; Herman \& Cullinan, 1997) which stimulates the secretion and release of adrenocorticotropic hormone (ACTH) from the pituitary 
glands into the circulatory system which then binds to target cells; including cells of the adrenal cortex which results in the culmination of glucocorticoids (GC; Hennessy \& Levine, 1979), or cortisol in humans. Cortisol maintains elevated blood glucose concentrations and blood pressure during a stress response to ensure that a sufficient amount of energy is provided to all parts of the body (Sapolsky, 1999). Once the stressor subsides, cortisol will bind to GC receptors in the limbic system, the hypothalamus and the pituitary, to inhibit the release of subsequent $\mathrm{CRH}$ and ACTH. This process is referred to as the negative feedback loop, which terminates the production and secretion of cortisol. The negative feedback mechanism allows the body to return to baseline, thus maintaining homeostasis of the organism (Herman \& Cullinan, 1997).

Both systems are activated to enhance attention and prepare the body to interact with the stressor through transient physiological changes (Chrousos \& Gold, 1992). Activation of the stress systems is adaptive in the short run. However, chronic or repeated exposure to stressors leads to overactivation of the SAM and HPA axes. Overtime, elevated levels of stress hormones may result in dysfunction of the stress-sensitive systems and other interconnected biological systems. Chronically increased cortisol concentrations can adversely affect the body and the brain, which is particularly susceptible to the effect of elevated cortisol levels due to the high concentrations of GC receptors in the brain (Pariante \& Lightman, 2008). Consequently, high cortisol levels have negative effects on the regulatory function of cortisol secretion, resulting in impaired cognitive functions (Lyons, Lopez, Yang \& Schatzberg, 2000).

\section{Stress System Dysregulation and the Brain}

Previous studies have demonstrated the adverse effect of repeated stress on the brain (see review, Juster, McEwen, \& Lupien, 2010; Karlamangla, Singer, McEwen, Rowe, \& Seeman, 2002). In particular, the hippocampus, amygdala, and the prefrontal cortex (PFC) are especially 
vulnerable to the effect of stress and increased levels of cortisol (see review Arnsten, 2009;

McEwen, Gould, \& Sakai, 1992; see review Roozendaal, Barsegyan, \& Lee, 2007). The

hippocampus is a malleable brain structure that is involved in learning and memory, whereas the amygdala mediates the physiological and behavioural response towards fear and other emotions (Morris et al., 1998). The prefrontal cortex (PFC) plays a role in working memory and executive functions in general (e.g., decision-making) and during the stress response (Qin, Hermans, van Marle, Luo, \& Fernandez, 2009). Animal and human research suggests that chronic exposure to stress hormones can have a neurotoxic effect on the brain (Landfield, Waymire, \& Lynch, 1978; Lupien et al., 1998). With respect to hippocampal integrity, it has been shown that chronic GC binding can lead to downregulation of receptor function, which may lead to further HPA axis dysregulation (see review Pariante \& Lightman, 2008), evidenced by increased basal cortisol levels. Furthermore, it is suggested that elevated cortisol levels lead to impaired hippocampal neurogenesis (Sapolsky, 2000). Based on the aforementioned links, researchers suggest that dysfunction of the HPA axis in depression may also be associated with alterations in hippocampal structure and volumes (e.g., Sheline et al., 1996; Steffens, McQuoid, Payne, \& Potter, 2011).

Previous research suggests that HPA axis dysregulation and changes in hippocampal volume are linked to depression in at-risk individuals (Dedovic et al., 2010), depressed patients (Axelson et al., 1993), and older adults with elevated depressive symptoms (O'Hara et al., 2007). Increased cortisol levels are also associated with changes in the PFC (Carrion et al., 2010). Given the neurotoxic effect of cortisol, it is plausible that chronic cortisol exposure in the hippocampus and PFC may lead to structural changes and subsequently disrupt cognitive processes that are associated with these stress sensitive brain regions. Previous studies have suggested that young 
and older adults with elevated cortisol levels exhibit declines in memory and executive functions (e.g., Lee et al., 2007; Shields, Bonner, \& Moons, 2015). Given the link between HPA axis dysfunction and structural changes in the hippocampus and PFC, elevated cortisol levels in depressed individuals may lead to cognitive symptoms, including impairments in executive control, attention, memory and thinking abilities such as negative interpretation and attention biases (e.g., Schule, Baghai, Rackwitz, \& Laakmann, 2003; Stetler \& Miller, 2005).

\section{Hypothalamic-Pituitary-Adrenal (HPA) Axis in Depression}

There is a robust association between the HPA axis and depression, evidenced by deviations from the norm in diurnal cortisol and basal cortisol levels (e.g., Murri et al., 2014; Burke, Davis, \& Mohr, 2005). In healthy populations, the diurnal cortisol pattern is generally characterized by a steep increase within the first 30 minutes of awakening followed by a steady decline throughout the day and reaching a trough in the evening (Edwards, Evans, Hucklebridge, \& Clow, 2001; Wust et al., 2000). Depressed patients often have higher levels of cortisol throughout different periods of the diurnal pattern when compared with their healthy counterparts. In particular, a blunted awakening cortisol response (ACR) in the morning has been found in depressed patients (Hinkelmann et al., 2013; Vreeburg et al., 2009). Further, elevated cortisol level during the evening nadir phase has been noted (Vreeburg et al., 2009). Given the difference in morning and evening cortisol secretion, persons with depression have been characterized as displaying a flat cortisol pattern (Fiocco et al., 2006).

Elevated basal cortisol levels have also been found in depressed individuals. Previous studies have examined the linked between HPA dysfunction and depression using the dexamethasone suppression test (DEX). Dexamethasone is a hormone that binds to GC receptors and activates the negative feedback loop of the HPA axis. In turn, dexamethasone suppresses the 
release of ACTH and, subsequently, cortisol (Cole, Kim, Kalman, \& Spencer, 2000). Increased cortisol response (i.e., non-suppression) after dexamethasone administration has been found in depressed patients when compared to healthy individuals (e.g., Bardeleben \& Holsboer, 1989), suggesting overactivation of HPA activity. Moreover, remitted depressed individuals who display an exaggerated cortisol response to the DEX are more likely to relapse (Zobel et al., 2001). These findings have been confirmed by a meta-analysis that reported a large effect size (Hedges' $g=3.22$ ) for heightened basal cortisol levels post dexamethasone administration (Murri et al., 2014). However, other studies have found hypocortisolism in older adults with depressive symptoms (e.g., Oldehinkel et al., 2001; Penninx et al., 2007). Altogether, the aforementioned findings suggest a plausible overactivity of the HPA axis in persons with depression. However, findings are mixed in the current literature, especially in late life (e.g., Bremmer et al., 2007; Penninx et al., 2007).

In addition to the altered diurnal pattern and basal secretion of cortisol, depressed and atrisk individuals also exhibit abnormal cortisol reactivity towards an acute stressor; however, these findings are mixed. Whereas some studies suggested an exaggerated cortisol response to a psychosocial stressor in remitted depressed individuals (Morris, Rao, Wang, \& Garber, 2014), other studies have found blunted cortisol reactivity compared with healthy individuals (Dienes, Hazel, \& Hammen, 2013). Further, blunted cortisol reactivity has been reported as more pronounced in individuals who are older and more severely depressed (Burke et al., 2005). Inconsistent findings in the literature may be due to variability in cortisol secretion (Mason, 1968) and measurement issues that commonly arise from salivary cortisol sampling (Adam \& Kumari, 2009), including time of day, number of samples, and use of sampling device (e.g., Adam \& Kumari, 2009; Kudielka, Broderick, \& Kirschbaum, 2003; Saxbe, 2008). Given the 
variability of cortisol, a more stable and comprehensive measure of stress, especially reflective of chronic stress, is needed to accurately reflect HPA function and its effect on the body.

\section{The Allostatic Load Model of Stress}

In order to effectively respond and adapt to the demands of the external environment, activity of the stress-sensitive systems fluctuates to maintain homeostasis within a changing environment. This adaptation process is termed "allostasis" (Sterling \& Eyer, 1988). Whereas homeostasis is referred to as the regulation of various physiological systems to maintain a stable and relatively constant internal condition in an organism, allostasis allows the organism to maintain its physiological stability by changing its internal milieu to appropriately adapt to environmental demands (Juster, McEwen Lupien, 2010; Sterlin \& Eyer, 1988). Thus, allostasis refers to the dynamic biological set-points that allow the body to adapt to the changing environment, whereas homeostasis is concerned with the static biological set-points that allow physiological systems to maintain their optimal range of function (Schulkin, 2003). Chronic or consistent intermittent activation of the SAM and HPA axes may lead to dysregulation in the primary regulatory systems. As a result, other regulatory systems, namely the immune, cardiovascular, and metabolic systems may alter their normal range of functioning in order to maintain allostasis. The chronic activation and imbalance of these interconnected regulatory systems may result in a "wear and tear" of the organism, called allostatic load (AL; McEwen \& Stellar, 1993).

The AL model comprehensively integrates several interacting regulatory systems and mediators that play a role in allostasis regulation. Given this framework, stress hormones and inflammatory markers have been identified as the primary mediators of allostasis (Juster et al., 2010). These markers reflect the physiological regulatory response to stress. When one 
mediating marker alters its levels in response to stress, other mediating markers will engage in compensatory changes in order to maintain allostasis (McEwen, 2008). Initially, the primary mediators will exert an effect on cellular activity of the regulatory systems in order to maintain allostasis (Juster et al., 2010). The secondary mediators then engage in a compensatory mechanism by altering their own operating ranges in order to maintain homeostasis. These regulatory systems include the cardiovascular and metabolic systems. As the interconnected systems continue to move out of allostatic range, tertiary outcomes ensue, which includes disease/disorder and mortality. Thus, by measuring the primary and secondary mediators, researchers can then examine the effect of chronic stress and the "wear and tear" of the regulatory systems on health outcomes.

The MacArthur Studies of Successful Aging was the first study to validate the composite AL index using the following biomarkers: 12 hour urinary cortisol, epinephrine, norepinephrine; serum dehydroepiandrosterone-sulfate (DHEA-S), total cholesterol, high density lipoprotein (HDL) cholesterol; plasma glycosylated hemoglobin; systolic and diastolic blood pressure; and waist to hip ratio (Seeman, Singer, Rowe, Horwitz, \& McEwen, 1997). The original biomarkers only included stress hormones as the primary mediators. Since then, subsequent studies have incorporated immune makers to improve knowledge of AL progression and the significance and predictability of the AL index in identifying various health outcomes.

At 2.5-year and 7-year follow-up of the MacArthur Studies of Successful Aging cohort, the AL index was found to significantly predict health outcome (Seeman et al., 1997; Seeman, McEwen, Rowe, \& Singer, 2001). Specifically, baseline AL significantly predicted the onset of physical and cognitive decline, as well as the risk of mortality in participants (Seeman et al, 2001). Importantly, the AL index was a better predictor of health outcomes at follow-up 
compared with any individual marker within the composite score (Seeman et al., 2001). This finding highlights the importance of using a comprehensive measure of stress physiology rather than a single unitary measure, such as cortisol.

Other studies have further demonstrated AL as a significant predictor in other health and functional outcomes (e.g., Goldman et al., 2006; Gruenewald, Seeman, Karlamangla, \& Sarkisian, 2009; Karlamangla, Singer, McEwen, Rowe, \& Seeman, 2002; Vieta et al., 2013) and in late-life mortality (Gruenewald et al., 2006; Seeman, McEwen, Rose, \& Singer, 2001). Again, these studies have confirmed the comprehensive AL index as a better predictor of health and functional outcomes, and mortality risk than the individual components of the AL index (e.g., Karlamangla, Singer, McEwen, Rowe, \& Seeman, 2002; McEwen, 2003).

Few studies have recently examined AL in relation to depression. The Social Environment and Biomarkers of Aging Study (SEBAS; Goldman et al., 2006; Seplaki, Goldman Weinstein, \& Lin, 2006) was one of the first studies to examine the link between the dysfunctions of multiple physiological systems and depression in a group of 972 Taiwanese older adults. The authors incorporated an inflammatory marker (i.e., interleukin-6) to provide a more comprehensive AL summary measure. A significant relationship was found between increased AL index and global depressive symptoms (Seplaki et al., 2006). However, due to the cross-sectional and correlational research design, it was difficult to conclude that increased AL is a risk for the development of depression. Goldman and colleagues (2006) expanded on the findings of Seplaki et al. (2006) by looking at the longitudinal measure of AL indices and selfreported depressive symptoms in the same group of participants from the SEBAS. Higher baseline AL index was associated with greater depressive symptom severity three years later. 
This finding lent supporting evidence to the notion that multiple physiological system dysfunctions contribute to the onset of depression.

Recent studies sought to replicate the findings of the SEBAS studies. Juster and colleagues (2011) examined the association of AL to acute and long-term (3-and 6-year) measures of depressive symptoms in 58 healthy, community-dwelling older adults (mean age of 67.55 years). In this study, researchers only used seven biomarkers in comparison to the 10 that were originally proposed in the MacArthur Studies. After controlling for age and gender, increased AL was significantly related to acute depressive symptoms, but not to the 3- and 6-year depressive symptoms. However, due to the insufficient numbers of AL biomarkers, researchers were unable capture the overall dysregulation and abnormal activities of all the interconnected systems. In turn, Juster and colleagues (2011) failed to replicate the longitudinal findings of Goldman et al., (2006), which is the association between AL and depressive symptoms in older adults over a 3-year period.

In another recent study, Kobrosly and colleagues (2013) examined the relationship between AL and global depressive symptom severity, as well as the somatic and affective symptoms in a sample of 2045 healthy older adults. The researchers utilized different biomarkers from the original measures that were validated in the MacArthur Studies and did not include any primary mediators in the study design (i.e., neuroendocrine and inflammatory markers). Controlling for age and gender, increased AL index was associated with increased overall depressive symptom severity. Similarly, somatic and affective symptoms were significantly correlated with the AL index. Out of the two symptom domains, a stronger relationship was found in somatic symptoms and AL. Furthermore, in comparison to the "no depression to mild depression" severity, increased AL was associated with greater risk of having more severe 
depression. Although the findings of the study suggest a relationship between AL and different domains of depressive symptoms, results should be interpreted with caution, as none of the primary mediators were included in this study. To improve on their study design, Kobrosly and colleagues (2014) conducted a similar study in a sample of 125 older adults from the Mindfulness to Improve Elders' Immune and Health Status (MIEIHS) study. In this study, a neuroendocrine measure (i.e., two-day salivary cortisol collection) and an inflammatory marker (i.e., interleukin-6) were included in the AL index. After adjusting for age, gender, education, estimated annual income, exercise frequency, and antidepressant use, a significant positive relationship was found between AL index and the three depressive symptoms. Although similar biomarkers and AL score calculations were used as the MacArthur Studies, some of the original biomarkers were not included in this study, including DHEA-s, plasma glycosylate hemoglobin, epinephrine, and norepinephrine measures.

Taken together, a positive relationship has been found between AL and depressive symptoms in elderly individuals. Yet, due to methodological limitations, findings in the existing literature may not accurately reflect chronic allostatic dysregulation in the interconnected regulatory systems. The AL markers used in previous studies fail to include at least one of the primary mediators (e.g., neuroendocrine and inflammatory markers). As recommended by Seeman and colleagues (1997), having both primary AL mediators provides a better and more accurate reflection of AL status. Furthermore, these studies do not take into account various psychological factors that may contribute to the pathogenesis of depression. In particular, individuals' ability to effectively regulate their emotions is suggested to play an important role in the onset and maintenance of depression (Joormann \& Siemer, 2011). 


\section{Overview of Emotion Regulation}

Emotion regulation (ER) is a set of processes that determine the experience and expression of an emotional response to an event (Gross, 1998a). When an individual reacts to an event, emotions such as joy and sadness may be elicited (Gross \& Munoz, 1995). The way that an individual feels, acts, and physiologically responds to a perceived situation depends on the utilization of ER strategies (Ekman, 1992). According to Gross's (1998a) process model of emotion regulation, once an individual becomes aware of the emotion that he or she is experiencing, different ER strategies can be implemented to allow the individual to alter the magnitude and intensity of an emotional experience or expression (Gross \& Jazaieri, 2014). By using ER strategies different emotional responses and outcomes can be elicited (Gross, 2015).

There are five classes of ER strategies (Gross, 1998a): Situation selection is a strategy that will determine whether or not an individual will encounter a situation that will likely produce an emotional response; Situation modification is a strategy that is used to alter individuals' surrounding environment in an effort to alter their emotions; Attentional deployment is a strategy that directs individuals' attention in order to change their emotional response; Cognitive change is a strategy that may alter individuals' emotion by changing the meaning of the situation; Lastly, response modulation is a strategy that individuals may use to alter the way that they feel, act, and physiologically respond to the situation at hand.

These strategies are divided into two broad distinctions: antecedent- and responsefocused ER strategies. Antecedent-focused ER occurs relatively early in the emotion generative process and is concerned with the modulation that takes place prior to the onset of a certain emotion (Gross, 1998b; Gross \& Munoz, 1995). Reappraisal is a form of an antecedent-focused strategy, and involves the attempt to attenuate the emotional impact by changing the 
interpretation of an emotional event. Response-focused ER takes place later in the emotion generative process where an individual may attempt to modify their response after an emotion is already elicited. Expressive suppression is an example of response-focused ER, and involves preventing the outward expression of emotions. Depending on the individual, elicited emotions and the context of the situation, ER strategies can be further characterized as adaptive or maladaptive (Aldao, 2013; Garnefski, Kraaij, \& Spinhoven, 2001). In the context of depression, it is suggested that reappraisal is an adaptive strategy as it is associated with an increase in positive affect and reduced negative affect, as well as increased well-being (Gross \& John 2003); whereas expressive suppression is a maladaptive ER strategy and is often associated with sustained negative affect (Ehring, Tuschen-Caffier, Schnülle, Fischer, \& Gross, 2010).

Previous studies suggest that emotion dysregulation contributes to the onset and maintenance of depression (Campbell-Sills \& Barlow, 2007; Kovasc, Joormann, \& Gotlib, 2008). Specifically, depressed individuals are unable to regulate positive emotions effectively, resulting in a prolonged experience of sadness and depressed mood (Joormann, 2010). Furthermore, persons with depression often engage in maladaptive ER strategies and have difficulties in implementing adaptive strategies (Aldao et al., 2010). For instance, studies have shown that patients with depression often engage in rumination (Olatunji, Naragon-Gainey, \& Wolitzky-Taylor, 2013), which is a maladaptive ER strategy where individuals engage in persistent, repetitive negative thoughts (Nolen-Hoeksema, 1991). Rumination often leads to sustained negative mood (Nolen-Hoeksema, Morrow, \& Fredrickson, 1993), greater negative cognitions (Ciesla \& Roberts, 2007), and impairment in effective problem solving (Watkins \& Moulds, 2005). It has been suggested that biased attention, memory, and interpretation processes 
in depression lead to more frequent use of maladaptive ER strategies, such as rumination (Joormann \& Siemer, 2011).

Cognitive theories of depression suggest that individuals' thoughts, interpretations, attitudes, and manners in which they attend to and recall events play a role in their emotional state (e.g., Siemer, Mauss, \& Gross, 2007). Compared to their healthy counterparts, depressed individuals often exhibit negative biased interpretation towards ambiguous stimuli (Mogg, Bradbury, \& Bradley, 2006; Wisco \& Nolen-Hoeksema, 2010), experience difficulties disengaging from negative stimuli (Joormann \& Gotlib, 2007; Koster, Leyman, DeRaedt, \& Crombez, 2006), and exhibit elevated mood-congruent memory recall bias (Koster, De Raedt, Leyman, \& De Lissnyder, 2010). That is, depressed individuals are more likely to recall memories that are congruent with their mood state, resulting in recalling more negative memories than positive ones. It has been suggested that deficits in cognitive control processes underlie the negative cognitive biases in depression (Joormann, 2010). Similar attentional, interpretation, and memory biases have been found in subclinical depression (Everaert, Duyck, \& Koster, 2014).

Cognitive control processes allow individuals to flexibly respond and adjust their behavioural and emotional response to changing situations by selecting and renewing the content of working memory (Hasher, Zacks, \& May, 1999; Joormann \& Siemer, 2011). Given the limited capacity of working memory, cognitive control processes ensure that working memory functions efficiently by limiting access of information and removing any information that is no longer relevant to the focus of attention (Hasher et al., 1999). It has been suggested that cognitive control processes contain several components (Friedman \& Miyake, 2004) that are involved in 
different stages of information processing, such as attention and interpretation of information (Hasher et al., 1999).

Indeed, different cognitive abilities have been associated with emotional response and ER. For instance, Tang and Schmeichel (2014) found that reduced inhibitory control predicted greater negative emotional responsivity. Gyurak and colleagues (2012) have indicated that verbal ability is positively associated with suppression, a maladaptive ER strategy, above and beyond age and level of cognitive function. Further, working-memory capacity (Schmeichel, Vokokhov, \& Demaree, 2008) and set-shifting costs (McRae et al., 2012) exhibit a positive association with individuals' ability to engage in reappraisal, an adaptive ER strategy. Malooly, Genet, and Siemer (2013) extended McRae et al.'s (2012) findings and further suggested that individuals' flexibility in processing emotionally-valenced materials contributes to their ability to effectively engage in adaptive ER strategies, such as cognitive reappraisal. Overall, it is plausible that with reduced cognitive flexibility, individuals may be less able to engage in adaptive ER strategies (e.g., reappraisal) and thus likely to engage in the habitual use of maladaptive ER strategies (e.g., rumination; Joormann \& Siemer, 2011). Consequently, decreased cognitive control and increased use of maladaptive ER strategies lead to the persistent negative affect that depressed individuals experience.

Studies of depressed and previously depressed individuals suggest that reduced inhibition of negative material is associated with greater use of rumination and expressive suppression, and less use of reappraisal (Joormann, 2006; Joormann \& Gotlib, 2008; Joormann \& Gotlib, 2010). Thus, habitual use of maladaptive ER strategies may sustain negative mood and dampen recovery from negative emotions. Similar to depression-related cognitive deficits, age-related cognitive decline, such as inefficient inhibition of irrelevant information (Hasher, Quig, \& May, 
1997), may further contribute to further dysregulation of emotions and prolong the experience of negative emotions, especially in older adults.

\section{Older Adults and Emotion Regulation}

Research suggests that older adults appear to be motivated to regulate their emotions in order to stay emotionally close with those whom they care about (Carstensen et al., 1999; Mather \& Knight, 2005). It is suggested that older adults can maintain a sense of positive emotional well-being and self-esteem (Carstensen, 1995). This is referred to as the positivity effect where older adults show preference for positive over negative information in attention and memory (Mather \& Carstensen, 2005). While numerous studies have provided support for the positivity effect in older adults (Carstensen et al., 2011), a recent meta-analysis revealed that older adults exhibit the positivity effect only when information processing is unconstrained (Reed, Chan, \& Mikels, 2014). Once restrictions (e.g., divided attention) are imposed on how information should be processed, older adults show equal preference across stimuli (Knight, Seymour, Gaunt, Baker, Nesmith, \& Mather, 2007).

It is also suggested that older adults regulate their emotion more effectively than their younger counterparts (e.g., Allard \& Kensinger, 2014; Brassen, Gamer, \& Bhuchel, 2011). For instance, diary studies have shown that older adults are more likely to avoid situations that may elicit negative emotions, such as social conflicts or stressful situations (Birditt, Fingerman, \& Almeida, 2005; Stawski, Almeida, Sliwinski, \& Smyth, 2008). Thus, older adults appear to be better at employing situation selection as their preferred form of ER strategy in order to modulate the initial stages when an emotion is elicited. However, once the selectivity of the situation is removed, such as coping with chronic health conditions or stressors that are 
uncontrollable, the ER advantages that older adults possess dissipates (Charles, Piazza, Luong, \& Almeida, 2009).

Neuroimaging studies have also provided evidence for age differences in ER (e.g., Opitz, Rauch, Terry, \& Urry, 2012; St. Jacques, Dolcos, \& Cabeza, 2010; Winecoff, LaBar, Madden, Cabeza, \& Huttel, 2011). Studies using functional magnetic resonance imaging (fMRI) have shown that older adults display greater neural activation while engaging in cognitively demanding ER strategies, such as cognitive reappraisal, compared to younger adults (Allard \& Kensinger, 2014). Furthermore, temporal differences have been observed between the two age groups while engaging in ER. While older adults show heighten neural activity at the peak of negative stimuli, younger adults display greater activity during the onset of the stimuli (Allard \& Kensinger, 2014). It is suggested that the differences in the degree and timing of neural activation during ER might be reflective of limited cognitive resources in older adults. This is especially pronounced when older adults engage in adaptive ER strategies that are more cognitively taxing (e.g., Allard \& Kensinger, 2014).

Given that adaptive ER strategies require a significant amount of cognitive control resources, some older adults may be less able to engage in these ER strategies due to age-related cognitive decline (Opitz, Rauch, Terry, \& Urry, 2012; von Hippel, Vasey, Gonda, \& Stern, 2008). As a result, some older adults may be less effective at inhibiting irrelevant negative thoughts and may engage in more maladaptive ER strategies relative to adaptive strategies (Urry \& Gross, 2010). Consequently, age-related cognitive deficits and increased use of maladaptive ER strategies may have an adverse effect on the emotional well-being of older adults.

Similar to younger persons with depression, older adults with depression are more likely to engage in maladaptive ER compared with healthy controls (Kraaij, Pruymboom, \& Garnefski, 
2002). Von Hippel and colleagues (2008) found that executive dysfunction was associated with depressive symptoms, which was mediated by rumination (von Hippel et al., 2008). Older adults with elevated depressive symptoms also engage in other maladaptive ER strategies, such as catastrophizing (Kraaij et al., 2002). Similar to young adults with depression, depressed older adults are less likely to engage in adaptive ER strategies to reduce negative emotions (Smoski et al., 2014). Age-related declines in executive function may lead to a reduction in cognitive flexibility that is required in order to employ adaptive ER strategies. With less effective use of adaptive ER strategies, individuals may be at greater risk of developing and maintaining depressive symptoms.

\section{Stress and Emotion Regulation}

Stressful situations can give rise to negative emotions (Lazarus \& Folkman, 1984). In turn, negative emotions may affect our physiological functioning. Thus, the way that individuals regulate their emotions could have an impact on physiological reactivity (Gross \& Levenson, 1997). Gross and Levenson (1993) examined the effect of suppression on physiological responsivity, measured by skin conductance and finger pulse amplitude. Participants watched a film that elicited the emotion of disgust. They were instructed to either watch the film freely or suppress their feelings. Results showed that participants in the suppression condition had greater skin conductance reactivity and greater decrease in finger pulse amplitude, suggesting greater SAM axis reactivity to the film clip compared to the control group. The heightened physiological response that suppression may evoke in response to emotional stimuli has been replicated with other negative emotions, such as sadness (Gross \& Levenson, 1997) and embarrassment (Harris, 2001). Some studies have also examined the effect of suppression and HPA axis reactivity. Lam and colleagues (2009) examined the relationship between trait suppression and cortisol reactivity 
during a psychosocial stressor. Participants with higher scores on trait suppression exhibited heightened cortisol reactivity compared to those who scored lower on this trait. Thus, findings suggest that suppression is associated with greater acute stress responsivity.

Rumination is another maladaptive ER strategy that may elicit an exaggerated acute stress response. Previous studies have found that individuals who tend to ruminate show sustained blood pressure elevation (Johnson, Lavoie, Bacon, Carlson, \& Campbell, 2012) and non-acclimatization of the HPA axis after repeated stress exposure (Gianferante et al., 2014). Increased and prolonged cortisol levels and inflammatory responses to an acute stressor have also been found in those who ruminate habitually (Zoccola, Figueroa, Rabideau, Woody, \& Benencia, 2014). In terms of basal HPA activity, higher trait rumination scores, in combination with high role ambiguity (i.e., unclear about job requirements and standards), have been associated with elevated evening cortisol levels in a group of white-collar workers 3.5 years later (Rydstedt, Cropley, \& Devereux, 2011). Ryerdstedt and colleagues (2011) suggested that rumination might serve as a moderator in the relationship between work-related stress and physiological strain outcomes. Altogether, the aforementioned findings suggest that rumination plays an important role in stress physiology.

Although consistent findings have been found for heightened stress reactivity and the utilization of maladaptive ER strategies, mixed findings for adaptive ER strategy use and acute stress reactivity have been noted. Some studies suggest that reappraisal dampens SAM axis activity (measured by cardiovascular measures; Carlson, Dikecligil, Greenberg, \& MujicaParodi, 2012; Jamieson, Nock, \& Mendes, 2012), while other studies using HPA axis measures have shown either heightened cortisol responsivity (Lam et al., 2009) or reduced cortisol responsivity (Carlson et al., 2012) when individuals implement adaptive ER strategies. The 
mixed findings may be due to the intra-individual variability of SAM and HPA measures. Due to the adverse effect of stress and chronic stress exposure on the physiological milieu of the organism, it is worthwhile to examine the relationship between ER and chronic stress using a comprehensive measure, namely AL.

\section{Relationship between Emotion Regulation, Depression and Stress}

Emerging studies have examined the relationship between ER, stress and depressive symptoms. Stewart and colleagues (2013) examined the relationship between rumination and cortisol level in a sample of adolescents with depression. They found that rumination was associated with greater cortisol levels after stress exposure in depressed adolescents compared to non-depressed adolescents. In addition, distraction, a maladaptive ER strategy, was associated with lower post-stressor cortisol levels in the depressed group (Stewart, Mazurka, Bond, WynneEdwards, \& Harkness, 2013). It has also been reported that undergraduate students who experience greater interpersonal stress report more ER difficulties and elevated depressive symptoms (Moriya \& Takahashi, 2013). Furthermore, maladaptive ER strategies appear to mediate the relationship between interpersonal stress and depression (Moriya \& Takahashi, 2013). Altogether, these findings suggest that impaired cortisol reactivity after stress exposure might underlie the relationship between maladaptive ER strategies and depression. However, this relationship has not been investigated in older adults. Further, no studies to date have evaluated the association between chronic biological stress, ER strategies and depressive symptomology. Given that age-related cognitive decline may reduce the effectiveness and the use of adaptive ER strategies, it is plausible that emotion dysregulation may contribute to elevated chronic stress levels and sustained negative emotions in older adults. 


\section{Study Goals and Hypotheses}

With an aging population and depression prevalence on the rise, it is imperative to study factors that contribute to the underlying physiological and psychological mechanisms of depression in older adults. Given the paucity of research on AL and ER in older adult populations, the interplay between ER, depression and chronic stress (measured by AL) in older adults remains unclear. Moreover, the association between ER and stress physiology has only been examined in the context of acute stress within adolescent and young adult populations. Given the methodological limitations in previous studies, such as the absence of at least one primary mediator, having both primary AL mediators (neuroendocrine and immune biomarkers) will provide a more comprehensive and accurate reflection of AL and the outcomes of interest. To address current gaps in the literature, the objectives of the proposed study are three-fold:

1. To determine the association between AL and depressive symptoms in communitydwelling older adults. Hypothesis: Based on past research, it is hypothesized that higher AL measurement will be associated with higher self-report depressive symptoms.

2. To determine the relationship between ER strategies and AL in community-dwelling older adults. Hypothesis: Based on the acute stress literature, it is hypothesized that older adults who endorse more maladaptive ER strategies and less adaptive ER strategies will exhibit a higher AL index.

3. To determine whether AL mediates the relationship between ER and depressive symptoms in community-dwelling older adults. Hypothesis: It is hypothesized that AL will partially mediate the relationship between ER and depressive symptoms in community-dwelling older adults. 


\section{Methods}

\section{Participants}

The current study is part of a larger ongoing study that examines the predictive roles of various biopsychosocial factors in differentiating high and low cognitive performance in older adults aged 60 years and older. For the current study, a power calculation was conducted based on study objective 3 via G*Power (Faul, Erdfelder, Lang \& Chuner, 2007; with small effect size, a priori $\alpha=.05 . \beta=.80$, two-tailed), which resulted in a recommended sample size of 135 participants.

Participants were recruited from the community using community advertisement, online advertisement posting (e.g., Kijiji, Craigslist, etc.), community knowledge translation events (e.g., library talks), and the Ryerson Senior Participant Pool (i.e., a database of older community members who can volunteer in research studies across laboratories at Ryerson). For recruitment material see Appendix A. The study was approved by Ryerson Research Ethics Board (REB \#2014-164). Written informed consent was obtained from all participants prior to their participation.

Eligibility criteria. Older adult men and women were included in the study if they were aged 60 years and older, reported normal or corrected vision and/or hearing, and were a native English speaker or acquired English prior to the age of 12. Participants were excluded if they reported conditions that would significantly impair cognitive performance on tests for the larger study, including past or current history of neurological condition (e.g. dementia, Parkinson's disease), learning disability, uncontrolled medical conditions (e.g., non-medicated hypo/hyperthyroidism, diabetes, etc.), alcohol/substance abuse, bipolar disorder, hallucination and/or delusion symptoms, experienced a concussion or head injury in the last year, or received 
general anesthesia in the last year. Participants were also excluded if they had participated in any cognitive or neuropsychological testing within the last year, or were actively participating in any formal brain training activities (e.g., Lumosity).

To date, 126 individuals have been contacted and screened for eligibility criteria. Of these, 74 participants met the inclusion criteria and participated in the study (mean age $=67.31$, $S D=6.49$, range: $60-87)$. Of the 74 participants, four participants were not included in the current analysis as the urine sample results were not received within the current time limit. Thus, a total of sample size of 70 participants was included in the current analysis.

\section{Measures}

As part of a larger study, participants completed a battery of neurocognitive tasks and psychosocial questionnaires. Measures that are specific to the current proposal include:

The Beck Depression Inventory - II (BDI-II). The BDI-II is a 21-item self-report depressive symptomatology measure (Beck, Steer, \& Brown, 1996). Each item is answered on a 4-point severity scale (ranged from 0 to 3 ), with a higher score indicating greater depression severity. The BDI-II exhibits high internal consistency $(\alpha=0.86)$ in a community-dwelling older adult sample (Segal, Coolidge, Cahill, \& O'Riley, 2008), as well as in geriatric depressed patients ( $\alpha=0.89$; Steer, Rissmiller, \& Beck, 2000). The BDI-II also demonstrated good discrimination and convergent validity has also been found among community-dwelling older adults (Segal, Coolidge, Cahill, \& O’Riley, 2008). The BDI-II demonstrated excellent internal consistency in the current sample $(\alpha=.93)$.

The Cognitive Emotion Regulation Questionnaire (CERQ). The CERQ is a self-report questionnaire consisting of 36 items (Garnefski, Kraaij, \& Spinhoven, 2002). The CERQ assesses nine different cognitive ER strategies, including 1) self-blame, which refers to thoughts 
of blaming yourself for what you have experienced; an example item is "I feel that I am the one to blame for it"; 2) acceptance, referring to thoughts of resigning to what has happened; an example item is "I think that I have to accept that this has happened"; 3) rumination, which refers to reoccurring negative thoughts and feelings; an example item is "I often think about how I feel about what I have experienced"; 4) positive refocusing, referring to thinking of other, enjoyable matters instead of the actual event; an example is "I think of nicer things than what I have experienced"; 5) refocus on planning, which refers to thinking about the steps required to deal with the task at hand; an example item is "I think of what I can do best"; 6) positive reappraisal, which refers to assigning a positive meaning to the event; an example item is "I think I can learn something from the situation"; 7) putting into perspective, which refers to decreasing the importance of the event in comparison to other events; an example item is "I think that it all could have been much worse"; 8) catastrophizing, referring to emphasizing the terror of the event; an example item is "I often think that what I have experienced is much worse than what others have experienced"; and 9) other-blame, which refers to thoughts of blaming others for what you have experienced; an example item is "I feel that others are to blame for it." Each strategy consists of 4 items. Each item is scored on a 4-point frequency scale (ranged from 1 to 5), with higher scores indicating more frequent use of that particular ER strategy. Each subscale has demonstrated high internal consistency in the elderly population, with Cronbach's alpha values ranging from 0.77 to 0.82 . Previous studies have also demonstrated convergent and discriminant validity of the CERQ (e.g., Martin \& Dahlen, 2005). The CERQ subscales have demonstrated adequate to good internal consistencies in the current analysis, with Crobach's alpha values ranging from .67 to .85 . 
The Perceived Stress Scale -10 (PSS-10). The PSS-10 (Cohen et al., 1983) is a 10-item self-report measure that assesses the subjective level of stress that individuals are experiencing within the last month. Each item is answered on a 5-point Likert-type frequency scale, with scores ranging from 0 (Never) to 4 (Very often). The scale also contains four reverse response items, in which the scores of the positively stated items needed to be reverse coded. Individual scores were then summed up to provide the total scores of participants' perception of stress. Higher total PSS-10 scores are reflective of greater levels of perceived stress. The PSS-10 has demonstrated as a reliable measure among older adults (Ezzati et al., 2014) and a valid measure of perceived stress (Roberti, Harrington, \& Storch, 2006). In the current study, the PSS-10 demonstrated excellent internal consistency $(\alpha=.92)$.

The Allostatic Load Index. The current study used a total of 16 biomarkers to create the composite AL index. The primary AL mediators include biomarkers from the neuroendocrine and the immune system, and secondary AL mediators include biomarkers from the cardiovascular and metabolic systems. Neuroendocrine biomarkers that were used in the current study included 24-hour urinary cortisol level, which is an index of 24-hour HPA axis activity; 24-hour urinary epinephrine and norepinephrine levels, which reflect 24-hour SAM activity; and dehydroepiandrosterone-sulphate (DHEA-S), which exerts an antagonistic function on the HPA axis (Seeman et al., 1997). Immune biomarkers included C-reactive protein (CRP), an inflammatory marker; insulin-like growth factor (IGF-1), a stimulator of systemic growth and marker of oxidative stress (Holzenberger et al., 2003); fibrinogen, a protein involved in blood coagulation that plays a pro-inflammtory role (see review, Davalos \& Akassoglou, 2012); and albumin, a protein involved in the regulation of intravascular osmotic pressure with antioxidant properties (see review, Taverna, Marie, Mira, \& Guidet, 2013). Cardiovascular biomarkers of the 
current study included systolic and diastolic blood pressure (SBP and DBP). Biomarkers of the metabolic system included serum levels of high-density lipoprotein (HDL) cholesterol and total cholesterol, to assess lipid levels; glycosylated haemoglobin (HbA1c), which reflects glucose metabolism; insulin, which is an index of glucose and lipid metabolism; plasma creatinine, which is an index of metabolic function; and waist-to-hip ratio (WHR), which is an index of adipose tissue deposition. All the plasma biomarkers were collected and analyzed at the CORE laboratory at the St. Michael's Hospital, whereas the urinary biomarkers were sent to the CORE laboratory for analysis after collection.

\section{Procedure}

A screening questionnaire was administered on the phone to determine the eligibility of participants (Appendix B). Eligible participants were invited to meet the researcher at the CORE laboratory, an outpatient blood clinic, at St. Michael's Hospital for 12-hour fasting morning blood sample collection. Prior to the testing day, participants were instructed to refrain from eating 12-hours prior to the scheduled appointment time. To ensure that participants did not fast beyond 12 hours, all testing sessions began between 8:00 AM and 10:00 AM. Participants provided written informed consent prior to sample collection (Appendix C). After blood sample collection, participants were given two plastic bottles to take home for two, 24-hour urine collections (one for urinary catecholamine levels and another for urinary cortisol levels), which were returned to the laboratory approximately one week later. Following blood draw at St. Michael's hospital, the researcher and participant returned to the Stress and Healthy Aging Research (StAR) lab, where a light snack was provided to the participants before proceeding to the testing protocol. Participants then underwent a cognitive battery and completed a set of psychosocial questionnaires, which contained questionnaires relevant to the current study 
(Appendix D, E, and F). Upon study completion, participants were debriefed on the purpose of the study (Appendix G).

\section{Data Analysis}

All analyses were performed using SPSS version 23.0 (IBM, 2015). Assumptions of normality were assessed for all self-report measures in the current analysis (BDI-II, CERQ, and PSS-10). Skewness and kurtosis values were assessed to determine whether z-scores exceed the absolute values of 1.96, which is indicative of significant skew or kurtosis in data (Field, 2014). The Kolmogorov-Smirnov test was also conducted to check for normal distribution of data. To ensure homogeneity of variance, Levene's test was conducted. An alpha level of $p<.05$ (twotailed) was used to test all a priori hypotheses.

To compute the composite AL index, biomarker values that fell within the high-risk 75th percentile with respect to the overall sample distribution were categorized as 1 and those in the blow the highest 75th percentile were categorized as 0, except for DHEA-S, HDL cholesterol, IGF-1 and albumin (Seeman et al., 1997). Individuals in the lower 25th percentile on DHEA-S, HDL cholesterol, IGF-1, and albumin measures were categorized as 1 and individuals with DHEA-S HDL, IGF-1, and albumin values above the $25^{\text {th }}$ percentile were categorized as 0 (Seeman et al., 1997; Kobrosly et al., 2014). All biomarker values were aggregated to create an overall $\mathrm{AL}$ index (ranging from 0 to 16), with higher values indicating greater dysfunction in the interconnected regulatory systems. Table 1 presents the actual criterion cut-off for each of the 16 biomarkers. Previous studies have validated the current AL index computation method and have yielded comparable results using other methods, such as using clinical cut-off values (Howard \& Sparks, 2016; Juster et al., 2011; Seeman et al., 2001). 
Table 1. Information on the Sample's Biomarker Levels and Criteria Cut-Off for Each Biomarker.

\begin{tabular}{|c|c|c|c|}
\hline & Biomarker (Unit) & Mean $(S D)$ & Criterion cut-off \\
\hline \multicolumn{4}{|l|}{ Highest quartile } \\
\hline & Urinary cortisol (nmol/d) & $63.02(80.08)$ & $\geq 68.00$ \\
\hline & Urinary epinephrine (nmol/d) & $20.93(12.36)$ & $\geq 24.50$ \\
\hline & Urinary norepinephrine (nmol/d) & $195.10(81.94)$ & $\geq 235.25$ \\
\hline & $\mathrm{CRP}(\mathrm{mg} / \mathrm{L})$ & $3.92(11.47)$ & $\geq 2.70$ \\
\hline & $\mathrm{SBP}(\mathrm{mm} \mathrm{Hg})$ & $131.84(17.32)$ & $\geq 143.83$ \\
\hline & $\mathrm{DBP}(\mathrm{mm} \mathrm{Hg})$ & $80.89(8.44)$ & $\geq 86.67$ \\
\hline & Plasma creatinine $(\mu \mathrm{mol} / \mathrm{L})$ & $77.32(16.19)$ & $\geq 87.25$ \\
\hline & Fibrinogen $(\mathrm{g} / \mathrm{L})$ & $3.07(0.75)$ & $\geq 3.35$ \\
\hline & Total cholesterol-HDL ratio & $3.74(1.19)$ & $\geq 4.30$ \\
\hline & HbAlc $(\%)$ & $5.63(0.81)$ & $\geq 5.78$ \\
\hline & Insulin $(\mathrm{pmol} / \mathrm{L})$ & $53.39(61.32)$ & $\geq 57.50$ \\
\hline & WHR & $0.91(0.07)$ & $\geq 0.97$ \\
\hline \multicolumn{4}{|l|}{ Lowest quartile } \\
\hline & DHEA-S $(\mu \mathrm{mol} / \mathrm{L})$ & $2.53(1.99)$ & $\leq 1.30$ \\
\hline & HDL cholesterol (nmol/L) & $1.38(0.39)$ & $\leq 1.06$ \\
\hline & $\mathrm{IGF}-1(\mu \mathrm{g} / \mathrm{L})$ & $123.41(35.78)$ & $\leq 101.25$ \\
\hline & Albumin $(\mathrm{g} / \mathrm{L})$ & $41.88(6.11)$ & $\leq 41.00$ \\
\hline
\end{tabular}

Note. All values reported were non-imputed data.

Hypothesis 1: Association between AL index and depressive symptoms. Adjusting for age (years), sex (female or male), education attainment (years), and perceived socioeconomic status (SES), which were covariates identified in previous literature (e.g., Crimmins, Johnston, Hayward, \& Seeman, 2003; Steffens et al., 2000; Upchurch et al., 2015), a hierarchical multiple regression was conducted, regressing BDI-II on AL.

Hypothesis 2: Association between ER and AL index. Adjusting for the same covariates, a hierarchical multiple regression was conducted between AL index and all nine of the CERQ strategies.

\section{Hypothesis 3: The mediating role of $A L$ in the relationship between $E R$ and}

depressive symptoms. Adjusting for the same covariates, Preacher and Hayes's (2008) bootstrap method of indirect mediation was conducted between the AL index, the BDI-II, and 
each of the CERQ strategy score to examine the mediating role of AL in the relationship between ER and depressive symptoms. The PROCESS macro on SPSS developed by Hayes (2013) was used to test the mediation model. The macro tests mediation models by comparing the observed indirect effect against 5000 bootstrapped resamples (Hayes, 2009). Each simulated parallel dataset is constructed by random sampling from the observed dataset with replacement. Based on the distribution of the resampled datasets, $95 \%$ confidence intervals (CI) were generated for the different effects being examined (i.e., the total, direct, and indirect effect). If the CI does not include zero, the indirect mediation is significantly different than zero (Hayes 2013; Preacher \& Hayes, 2008).

Researchers have suggested examining other equivalent mediation models to rule out possible statistical equivalency (Gelfand, Mensinger, \& Tenhave, 2009; Pek \& Hoyle, 2015). Although the theoretical background has been established for the current hypothesized mediation model, alternative mediation analyses were computed to rule out alterative models. The alternative explorative model entailed depressive symptoms as the mediator, ER strategies as the independent variable, and AL as the outcome variable. Figure 1 depicts the hypothesized mediation model between AL, ER strategies, and depressive symptoms. 


\section{a) Direct relationship between ER and depressive symptoms}

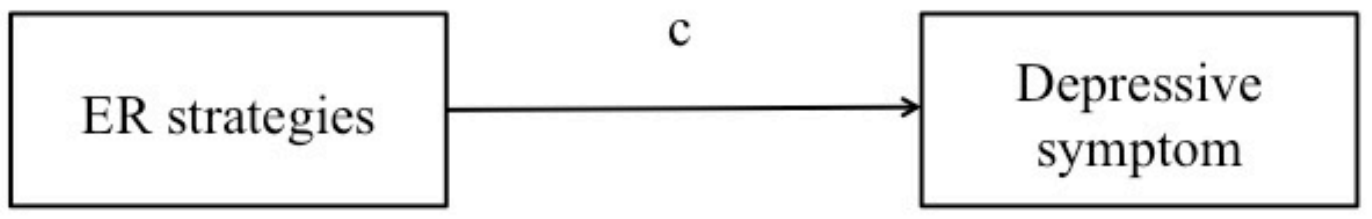

\section{b) Indirect effect of ER and Depressive symptoms through AL}

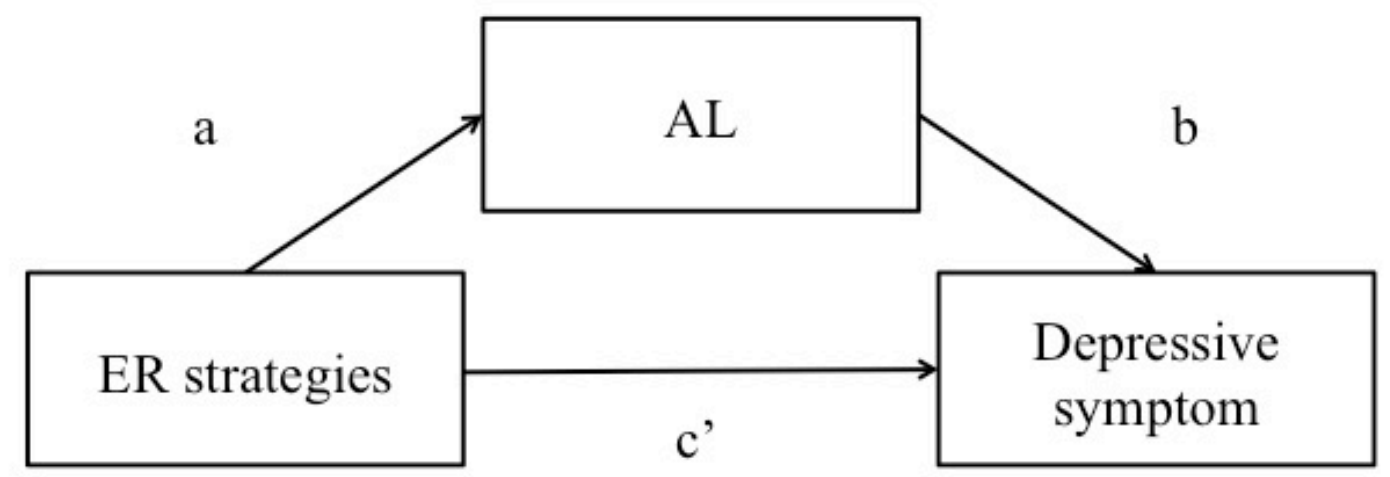

Figure 1. Direct and indirect model of the relationship between emotion regulation (ER) strategies, allostatic load (AL), and depressive symptoms.

Exploratory analyses. In order to further understand the relationship between stress and depressive symptoms, it is imperative to also examine the perceived levels of stress and its relationship with depressive symptoms. Thus, the current study also conducted additional analysis with perceived levels of stress to provide a more comprehensive understanding of the link between chronic stress and depressive symptom in older adults. Adjusting for the same covariates, hierarchical multiple regressions were conducted to examine the relationship between BDI-II and PSS-10, as well as PSS-10 and CERQ scores. Finally, using the PROCESS macro, an indirect mediation analysis was conducted to examine the mediating role of perceived stress 
level (PSS-10) in the relationship between ER strategies and depressive symptoms in the current sample of community-dwelling older adults. 


\section{Results}

\section{Participants}

The majority of the sample was Caucasian (80.0\%), had medium level of perceived SES $(68.6 \%)$, and were never depressed based on self-report and the phone screen questionnaire $(80.0 \%)$. Approximately half of the sample was female $(52.9 \%)$ and retired $(55.7 \%)$. Of the 70 participants, 8 participants did not provide urine samples. Among the participants who provided urine samples $(n=62)$, the average collection began at 9:07AM $(S D=2.30$; range $=1: 30 \mathrm{AM}$ to $4: 43 \mathrm{PM})$ for the first sample and $8: 50 \mathrm{AM}(S D=2.31$, range $=1: 30 \mathrm{AM}$ to $2: 07 \mathrm{PM})$ for the second sample. Overall, participants reported an average of $7.10(S D=8.24)$ and considered as non-depressed based on the cut-off scores proposed by previous studies (Beck et al., 1996; Cameron et al., 2011); the cut-off for mild depression is 14 , for moderate depression 20 , and for severe depression 29 (Beck et al., 1996; Cameron et al., 2011). Table 2 provides a detail summary of sample characteristics, as well as the mean total scores and standard deviations of the untransformed values for all the variables.

Table 2. Sample Characteristics and Descriptive Statistics.

\begin{tabular}{lc}
\hline & Total sample $(N=70)$ \\
\hline Age $(S D)$ & $67.33(6.50)$, range: $60-87$ \\
Education $(S D)$ & $16.12(2.77)$, range: $10-29$ \\
Female $(\%)$ & $37(52.9)$ \\
Ethnicity $(\%)$ & $56(80.0)$ \\
Caucasian & $5(7.1)$ \\
Chinese & $2(2.9)$ \\
Black & $4(5.7)$ \\
East Asian & $3(4.3)$ \\
Pacific Islanders & $13(18.6)$ \\
Retirement status $(\%)$ & $39(55.7)$ \\
Not retired & $18(25.7)$ \\
Retired & \\
Semi-retired & $19(27.1)$
\end{tabular}


Medium

High

Depression status (\%)

Never depressed

Currently depressed

Previously depressed

BDI-II $(S D)$

Depression level $^{a}$

Non-depressed (\%)

Mild depression

Moderate depression

Severe depression

CERQ

Self blame $(S D)$

Acceptance $(S D)$

Rumination $(S D)$

Positive refocusing $(S D)$

Refocus planning $(S D)$

Positive reappraisal $(S D)$

Putting into perspective $(S D)$

Catastrophizing $(S D)$

Other blame $(S D)$

PSS-10 (SD)

AL Index $(S D)$
48 (68.6)

$3(4.3)$

$56(80.0)$

$12(17.1)$

$2(2.9)$

$7.10(8.24)$

$57(81.4)$

$6(8.6)$

$6(8.6)$

$1(1.4)$

$8.61(3.09)$

$10.90(3.06)$

$10.16(3.33)$

$9.91(3.40)$

$13.70(3.66)$

$13.19(3.82)$

$12.26(3.59)$

$7.29(3.49)$

$7.04(2.37)$

$12.54(7.53)$

3.84 (2.14)

Note. East Asian included Indian, Pakistani, etc.; Pacific Islander included Filipinos, etc.;

Depression status was based on self report of mental and physical health history on the phone screening questionnaire; BDI-II = Beck Depression Inventory-II; CERQ = Cognitive Emotion Regulation Questionnaire; PSS-10 = Perceived Stress Scale - 10 item; AL Index = Allostatic load index; $\mathrm{a}=$ depression level cut-off scores based cut-off scores proposed by Beck, Steer \& Brown (1996) and Cameron et al. (2011).

\section{Missing Data}

Missing data points for self-report measures were less than $1 \%$ of participants' self-report item scores. The individual mean imputation was used to estimate missing data points, as suggested by the questionnaire manuals. Missing data for biomarker values were greater than $10 \%$, specifically for the 24-hour urinary cortisol $(n=10,14.3 \%)$, epinephrine $(n=9,12.9 \%)$, and norepinephrine values $(n=8,11.4 \%)$, whereas the missing data value for CRP was $1.4 \%(n$ $=1$ ). Accordingly, the multiple imputation procedure in SPSS (v.23.0) was used to impute the 
aforementioned biomarker values. This method of missing data point estimation has been recommended elsewhere (Sterne et al., 2009).

Variables in the imputation model included all variables used in the AL index calculation. Furthermore, age was used as an auxiliary variable in the imputation model. Fourteen imputed datasets were created. The AL index was calculated with and without the imputed values of CRP, cortisol, epinephrine, and norepinephrine levels. A paired sample $t$-test was conducted to examine the differences of the AL indices with the non-imputed and imputed biomarker values. The analysis revealed that there were no significant differences between the two AL indices. Furthermore, all analyses were conducted with the imputed and non-imputed AL indices to assess whether imputed values significantly differ with outcome variables. There were no substantial differences in the analyses between the imputed and non-imputed AL indices. Thus, only the non-imputed AL index was used for the subsequent analyses.

\section{Assumptions Testing}

The skewness and kurtosis analyses revealed that the total scores for the BDI-II, CERQ Self-blame, Rumination, Positive refocusing, and Other-blame subscales were all positively skewed, whereas the total CERQ Catastrophizing was leptokurtic. Further, a KolmogorovSmirnov test was conducted to test for normality of distribution in current data. The test indicated that the distribution of all measures significantly differed from normal distribution $(D[70]=.11-.23, p<.05)$, except for CERQ Putting into perspective subscale $(D[70]=.086, p$ $=.20)$ and PSS-10 $(D[70]=.081, p=.20)$.

To assess for the assumption of homogeneity of variance, a Levene's test was conducted. The analyses revealed that variance did not differ significantly between completers and those who did not provide the urine samples on all measures $(F[1,68]=.02-3.44, p>.05)$. Given 
that the data violated assumptions of normality, BDI-II scores, CERQ Self-blame, Rumination, and Other-blame subscales scores were log transformed; the CERQ Acceptance, Positive refocusing, Refocus planning, Positive reappraisal, and Catastrophizing subscales scores were square root transformed to ensure the assumption of normality. All analyses were conducted with non-transformed and transformed data to assess whether these transformations were significantly related to the outcome variable. Transformation of data was not significantly associated with outcome. Thus, only the non-transformed data were used for the subsequent analyses.

The AL index was also assessed for frequency and central tendency. The AL index of the current sample ranged from 1 to $10(M=3.96, S D=2.14)$ and slight positive skewness was found (Skewness $=.801$, Kurtosis $=.287$ ), with $51.4 \%$ of the sample had AL indices $\leq 3$ and $48.6 \%$ had $\mathrm{AL}$ indices $\geq 4$. The $\mathrm{AL}$ index was not transformed given that the raw values reflect the accurate levels of physiological dysfunctions among participants.

\section{Analysis 1: Association between AL index and depressive symptoms.}

Adjusting for age, sex, education attainment level, and perceive SES levels, a hierarchical regression was conducted to examine the association between AL index and depressive symptoms. The Durbin-Watson statistic of 1.86 indicated that the current regression analysis did not violate the assumption of independent errors. The variance inflation factor (VIF) was examined to assess for multicollinearity between predictors, and was deemed to be within the acceptable range (range $=1.01$ to 1.19$)$ according to Field (2014).

The fully adjusted regression model revealed that all covariates and the AL index combined significantly accounted for $18 \%$ of variance in depressive symptom scores, $F(5,64)=$ $2.75, p=.03$. However, the AL index was not significantly associated with depressive symptom scores $($ beta $=.01, t(68)=.08, p=.94)$. All of covariates combined accounted for $17 \%$ of the 
variance in BDI-II scores; however, perceived SES level was the driving factor in this association (beta $=-0.39, t(68)=-3.24, p=.002$ ), where every 0.39 unit decrease in perceived SES was associated with a unit increase in depressive symptom scores. See table 3 for model details.

Table 3. Hierarchical Regression Model of AL and BDI-II Scores.

\begin{tabular}{lccc}
\hline & $B$ & $S E B$ & $\beta$ \\
\hline Step 1 & & & .06 \\
Age & .08 & .15 & -.08 \\
Gender & -1.31 & 1.86 & -.09 \\
Education & -.28 & .35 & $-.39^{*}$ \\
Perceived SES & -6.22 & 1.88 & .07 \\
\hline Step 2 & & & -.08 \\
\hline Age & .08 & .15 & -.09 \\
Gender & -1.36 & 1.98 & $-.39 *$ \\
Education & -.28 & .35 & -.01 \\
Perceived SES & -6.20 & 1.91 & .48 \\
AL & .04 & & \\
\hline Notes. Step $1: R^{2}=.18, F(4,65)$ & $=3.49, p=.012 ;$ Step $2: R^{2}=.18, F(5,64)=2.75, p=.03$. \\
$* p<.01$ & & &
\end{tabular}

\section{Analysis 2: Association between ER and AL index.}

As planned, a hierarchical regression was conducted to examine the relationship between the nine ER strategy scores and the AL index. The assumption of independent errors was not violated as suggested by the Durbin-Watson statistics (1.89) in the current regression models. Furthermore, the VIF values revealed no significant multicollinearity issues.

The fully adjusted model accounted for $24.2 \%$ of variance in AL index. However, the model was not statistically significant, $F(13,56)=1.38, p=.20$. Moreover, none of the ER strategies were associated with the AL index. Covariates in the model (Step 1) accounted for $16.0 \%$ of variance in chronic biological stress, $F(4,65)=3.10, p=.02$. Specifically, sex was significantly associated with the AL index (beta $=0.29, t(68)=2.22, p=.03)$, where males were more likely to have greater chronic biological stress than females. See table 4 for model details. 
Table 4. Hierarchical Regression Model for ER strategies and AL.

\begin{tabular}{lccc}
\hline & $B$ & $S E B$ & $\beta$ \\
\hline Step 1 & & & .08 \\
Age & .03 & .04 & $.31^{*}$ \\
Gender & 1.34 & .49 & -.13 \\
Education & .10 & .09 & -.15 \\
Perceived SES & -.64 & .49 & .01 \\
\hline Step 2 & & .05 & $.29 *$ \\
\hline Age & .003 & .55 & -.16 \\
Gender & 1.22 & .10 & -.10 \\
Education & -.12 & .60 & .02 \\
Perceived SES & -.37 & .11 & .13 \\
Self Blame & .02 & .11 & .02 \\
Acceptance & .09 & .09 & .18 \\
Rumination & .02 & .10 & -.22 \\
Positive Refocusing & .11 & .18 & -.16 \\
Refocus Planning & -.13 & .17 & .005 \\
Positive Reappraisal & -.09 & .09 & -.17 \\
Putting into Perspectives & .003 & .11 & .01 \\
Catastrophizing & -.10 & .16 & .09 \\
Other Blame & .009 & &
\end{tabular}

\section{Analysis 3.0: The mediating role of $A L$ in the relationship of ER and depressive symptoms.}

Adjusting for age, sex, education, and perceived SES, bootstrap mediation analyses reveal no significant relationship between each ER strategy and depressive symptoms through AL. See Table 5 for model details.

Table 5. Indirect Mediation Analysis for ER strategies, AL, and BDI-II.

\begin{tabular}{llcc}
\hline Model & & $\beta$ & $p$ \\
\hline Hypothesized model & & & \\
Self Blame $\rightarrow$ AL $\rightarrow$ BDI-II & Self Blame $\rightarrow$ AL & .06 & .47 \\
& AL $\rightarrow$ BDI-II & -.04 & .94 \\
& Self-Blame $\rightarrow$ BDI-II & .55 & .08 \\
Indirect effect & $-.01,95 \%$ CI [-.22,.04] & & \\
Acceptance $\rightarrow$ AL $\rightarrow$ BDI-II & Acceptance $\rightarrow$ AL & .03 & .73 \\
& AL $\rightarrow$ BDI-II & .04 & .93 \\
Acceptance $\rightarrow$ BDI-II & -.07 & .85 \\
Indirect effect & $-.002,95 \%$ CI [-.05,.10] & & \\
Rumination $\rightarrow$ AL $\rightarrow$ BDI-II & Rumination $\rightarrow$ AL & -.03 & .73
\end{tabular}




\begin{tabular}{|c|c|c|c|}
\hline & $\mathrm{AL} \rightarrow \mathrm{BDI}-\mathrm{II}$ & .13 & .76 \\
\hline & Rumination $\rightarrow$ BDI-II & 1.23 & $<.001$ \\
\hline Indirect effect & $-.003,95 \%$ CI $[-.06, .06]$ & & \\
\hline \multirow[t]{3}{*}{ Positive refocusing $\rightarrow \mathrm{AL} \rightarrow$ BDI-II } & Positive refocusing $\rightarrow \mathrm{AL}$ & .02 & .74 \\
\hline & $\mathrm{AL} \rightarrow \mathrm{BDI}-\mathrm{II}$ & -.24 & .63 \\
\hline & Positive refocusing $\rightarrow$ BDI-II & -.35 & .23 \\
\hline Indirect effect & $.000,95 \%$ CI $[-.15, .06]$ & & \\
\hline \multirow[t]{3}{*}{ Refocus planning $\rightarrow$ AL $\rightarrow$ BDI-II } & Refocusing planning $\rightarrow \mathrm{AL}$ & -.11 & .11 \\
\hline & $\mathrm{AL} \rightarrow \mathrm{BDI}-\mathrm{II}$ & -.20 & .68 \\
\hline & Refocus planning $\rightarrow$ BDI-II & -.66 & .01 \\
\hline Indirect effect & $.02,95 \%$ CI $[-.06, .20]$ & & \\
\hline \multirow[t]{3}{*}{ Positive reappraisal $\rightarrow$ AL $\rightarrow$ BDI-II } & Positive reappraisal $\rightarrow \mathrm{AL}$ & -.10 & .16 \\
\hline & $\mathrm{AL} \rightarrow \mathrm{BDI}-\mathrm{II}$ & -.25 & .57 \\
\hline & Positive reappraisal $\rightarrow$ BDI-II & -.90 & $<.001$ \\
\hline Indirect effect & $.02,95 \%$ CI $[-.04, .17]$ & & \\
\hline \multirow{4}{*}{$\begin{array}{l}\text { Putting into perspectives } \rightarrow \mathrm{AL} \rightarrow \mathrm{BDI}- \\
\mathrm{II}\end{array}$} & Putting into perspectives $\rightarrow \mathrm{AL}$ & -.061 & .40 \\
\hline & $\mathrm{AL} \rightarrow \mathrm{BDI}-\mathrm{II}$ & -.05 & .92 \\
\hline & Putting into persepctives $\rightarrow$ BDI-II & -.48 & .09 \\
\hline & $.003,95 \%$ CI $[-.07, .13]$ & & \\
\hline \multirow[t]{3}{*}{ Catastrophizing $\rightarrow$ AL $\rightarrow$ BDI-II } & Catastrophizing $\rightarrow \mathrm{AL}$ & -.06 & .44 \\
\hline & $\mathrm{AL} \rightarrow \mathrm{BDI}-\mathrm{II}$ & -.26 & .51 \\
\hline & Catastrophizing $\rightarrow$ BDI-II & 1.32 & $<.001$ \\
\hline Indirect effect & $-.02,95 \%$ CI $[-.19, .04]$ & & \\
\hline \multirow[t]{3}{*}{ Other blame $\rightarrow$ AL $\rightarrow$ BDI-II } & Other blame $\rightarrow \mathrm{AL}$ & -.08 & .43 \\
\hline & $\mathrm{AL} \rightarrow \mathrm{BDI}-\mathrm{II}$ & .17 & .71 \\
\hline & Other blame $\rightarrow$ BDI-II & 1.11 & .004 \\
\hline Indirect effect & $-.01,95 \% \mathrm{CI}[-.23, .06]$ & & \\
\hline \multicolumn{4}{|l|}{ Alternative Model } \\
\hline \multirow[t]{3}{*}{ Self Blame $\rightarrow$ BDI-II $\rightarrow$ AL } & Self Blame $\rightarrow$ BDI-II & .56 & .07 \\
\hline & BDI-II $\rightarrow$ AL & -.003 & .94 \\
\hline & Self-Blame $\rightarrow$ AL & .06 & .47 \\
\hline Indirect effect & $-.01,95 \%$ CI $[-.09, .03]$ & & \\
\hline \multirow[t]{3}{*}{ Acceptance $\rightarrow$ BDI-II $\rightarrow$ AL } & Acceptance $\rightarrow$ BDI-II & -.06 & .85 \\
\hline & $\mathrm{BDI}-\mathrm{II} \rightarrow \mathrm{AL}$ & .003 & .93 \\
\hline & Acceptance $\rightarrow$ AL & .03 & .73 \\
\hline Indirect effect & $-.002,95 \%$ CI $[-.03, .02]$ & & \\
\hline \multirow[t]{3}{*}{ Rumination $\rightarrow$ BDI-II $\rightarrow$ AL } & Rumination $\rightarrow$ BDI-II & 1.23 & $<.001$ \\
\hline & BDI-II $\rightarrow$ AL & .01 & .76 \\
\hline & Rumination $\rightarrow \mathrm{AL}$ & -.04 & .65 \\
\hline Indirect effect & $.02,95 \%$ CI $[-.07, .17]$ & & \\
\hline \multirow[t]{3}{*}{ Positive refocusing $\rightarrow$ BDI-II $\rightarrow$ AL } & Positive refocusing $\rightarrow$ BDI-II & -.36 & .22 \\
\hline & BDI-II $\rightarrow$ AL & -.02 & .63 \\
\hline & Positive refocusing $\rightarrow \mathrm{AL}$ & .02 & .81 \\
\hline Indirect effect & $.006,95 \%$ CI $[-.02, .04]$ & & \\
\hline \multirow[t]{2}{*}{ Refocus planning $\rightarrow$ BDI-II $\rightarrow$ AL } & Refocusing planning $\rightarrow$ BDI-II & -.37 & .22 \\
\hline & 42 & & \\
\hline
\end{tabular}




\begin{tabular}{llcc} 
& BDI-II $\rightarrow$ AL & .003 & .93 \\
& Refocus planning $\rightarrow$ AL & .002 & .98 \\
Indirect effect & $-.001,95 \%$ CI [-.04, .03] & & \\
Positive reappraisal $\rightarrow$ BDI-II $\rightarrow$ AL & Positive reappraisal $\rightarrow$ BDI-II & -.88 & $<.001$ \\
& BDI-II $\rightarrow$ AL & -.02 & .57 \\
& Positive reappraisal $\rightarrow$ AL & -.11 & .13 \\
Indirect effect & $.02,95 \%$ CI [-.03, .10] & & \\
Putting into perspectives $\rightarrow$ BDI-II $\rightarrow$ & Putting into perspectives $\rightarrow$ BDI-II & -.47 & .08 \\
AL & BDI-II $\rightarrow$ AL & -.003 & .92 \\
& Putting into perspectives $\rightarrow$ AL & -.07 & .40 \\
Indirect effect & $.002,95 \%$ CI [-.03,.06] & & \\
Catastrophizing $\rightarrow$ BDI-II $\rightarrow$ AL & Catastrophizing $\rightarrow$ BDI-II & 1.31 & $<.001$ \\
& BDI-II $\rightarrow$ AL & .03 & .51 \\
Indirect effect & Catastrophizing $\rightarrow$ AL & -.09 & .31 \\
Other blame $\rightarrow$ BDI-II $\rightarrow$ AL & $.03,95 \%$ CI [-.08, .23] & & \\
& Other blame $\rightarrow$ BDI-II & 1.10 & .004 \\
BDI-II $\rightarrow$ AL & .01 & .71 \\
Indirect effect & Other blame $\rightarrow$ AL & -.10 & .38 \\
\hline
\end{tabular}

Analysis 3.1: Alternative model testing: Depressive symptom as the mediator in the relationship between ER strategies and subjective stress levels. To rule out the alternative model, additional mediation analyses were conducted to examine whether depressive symptoms mediate the relationship between ER strategies and chronic biological stress. The analysis revealed that BDI-II scores did not significantly mediate the relationship between ER strategies and $\mathrm{AL}$ index. See Table 5 for model details.

\section{Exploratory analyses: Examining the interplay between PSS, ER, and depressive} symptoms.

The association between subjective stress levels and depressive symptom. Controlling for age, sex, education, and perceived SES, a hierarchical regression was conducted to examine the relationship between PSS-10 and BDI-II. The Durbin-Watson statistics (1.63) and VIF values (around 1) revealed that the current model met the assumptions of independent errors and no 
issues of collinearity. The adjusted model revealed that PSS-10 scores significantly accounted for $57.2 \%$ of variance in BDI-II scores, $F((5,64)=17.13, p<.001$. Specifically, a 0.67 unit increase in the PSS-10 scale was associated with a unit increase in BDI-II $(t(68)=7.69, p<$ $.001)$. See Table 6 .

Table 6. Hierarchical Regression Model of PSS-10 and BDI-II Scores.

\begin{tabular}{lccc}
\hline & $B$ & $S E B$ & $\beta$ \\
\hline Step 1 & & & .06 \\
Age & .08 & .15 & -.08 \\
Gender & -1.31 & 1.86 & -.09 \\
Education & -.28 & .35 & $-.39^{* *}$ \\
Perceived SES & -6.22 & 1.88 & .07 \\
\hline Step 2 & & & -.03 \\
\hline Age & .09 & .11 & -.03 \\
Gender & -.40 & 1.35 & $-.18^{*}$ \\
Education & -.09 & .26 & $.67 * * *$ \\
Perceived SES & -2.94 & 1.43 & .10 \\
PSS-10 & .74 & & \\
\hline Notes. Step $1: R^{2}=.18, F(4,65)=3.49, p=.012 ;$ Step $2: R^{2}=.57, F(5,64)=17.12, p<.001$. \\
$* p<.05, * * p<.01, * * * p<.001$ & &
\end{tabular}

The association between subjective stress levels and ER strategies. Adjusting for the aforementioned covariates, all nine ER strategies of the CERQ significant accounted for 55.4\% of variance in PSS-10, $F(13,56)=5.35, p<.001$. The Durbin-Watson statistics $(2.22)$ and VIF values (around 1) revealed that the assumptions of independent errors and collinearity were not violated. Specifically, the Positive Reappraisal subscale had a significant negative relationship $(\beta=-0.71, t(68)=-3.09, p=.003)$, where a 0.71 unit increase in Positive Reappraisal was associated with a unit decrease in PSS-10. Moreover, the Rumination subscale was significantly associated with PSS-10 $(\beta=.46, t(68)=4.09, p<.001)$, which indicated that a 0.46 unit increase in Rumination was associated with a unit increase in PSS-10. See Table 7. 
Table 7. Hierarchical Regression Model for ER strategies and PSS-10.

\begin{tabular}{lccc}
\hline & $B$ & $S E B$ & $\beta$ \\
\hline Step 1 & & & \\
Age & -.01 & .14 & -.01 \\
Gender & -1.24 & 1.75 & -.08 \\
Education & -.27 & .33 & -.10 \\
Perceived SES & -4.46 & 1.77 & -.31 \\
\hline Step 2 & & .13 & -.12 \\
\hline Age & -.14 & 1.48 & -.07 \\
Gender & -.1 .01 & .27 & -.04 \\
Education & -.10 & 1.60 & -.15 \\
Perceived SES & -2.15 & .29 & .08 \\
Self Blame & .20 & .30 & -.02 \\
Acceptance & .04 & .25 & $.46^{* *}$ \\
Rumination & 1.03 & .29 & -.03 \\
Positive Refocusing & -.07 & .49 & .33 \\
Refocus Planning & .67 & .45 & $-.71^{*}$ \\
Positive Reappraisal & -1.39 & .25 & .08 \\
Putting into Perspectives & .16 & .30 & .09 \\
Catastrophizing & .18 & .42 & -.03 \\
Other Blame & -.09 & & \\
\hline Notes. Step 1: $R^{2}=.12, F(4,65)$ & $2.28, p=.07 ;$ Step $2: R^{2}=.55, F(13,56)=5.35, p<.001$. \\
$* p<.01, * * p<.001$ & & &
\end{tabular}

\section{The relationship between ER strategies and depressive symptoms: subjective stress}

as the mediator. Adjusting for age, sex, education, and perceived SES, nine separate bootstrap indirect mediation analyses were conducted to examine the mediating role of PSS-10 in the relationship between each of the ER strategies and depressive symptoms.

Maladaptive ER strategies. A partial indirect effect of subjective stress was found for the relationship between Rumination and depressive symptoms $(0.71,95 \%$ CI $[0.43,1.14])$, accounting for $60.2 \%$ of the variance in depressive symptoms $(F(6,63)=15.88, p<.001)$. Further, subjective stress partially mediated the relationship between Catastrophizing and depressive symptoms $(0.50,95 \% \mathrm{CI}[0.22,0.84])$, where the mediational model accounted for $65.9 \%$ of the variance in depressive symptoms $(F(6,63)=20.33, p<.001)$. Finally, a partial indirect effect of subjective stress level was found for the relationship between Other Blame and 
depressive symptoms $(0.55,95 \% \mathrm{CI}[0.04,1.13])$, accounting for $59.5 \%$ of variance in depressive symptoms $(F(6,63)=15.46, p<.001)$. The relationship between Self Blame and depressive symptoms was not significantly mediated through subjective stress $(0.19,95 \%$ CI [$0.25,0.69])$. See Table 8 .

Table 8. Indirect Mediation Analyses for ER strategies, PSS-10, and BDI-II scores.

\begin{tabular}{|c|c|c|c|}
\hline \multicolumn{2}{|l|}{ Model } & \multirow[t]{2}{*}{$\beta$} & \multirow[t]{2}{*}{$p$} \\
\hline Hypothesized model & & & \\
\hline \multirow{3}{*}{ Self Blame $\rightarrow$ PSS-10 $\rightarrow$ BDI-II } & Self Blame $\rightarrow$ PSS- 10 & .27 & .36 \\
\hline & PSS-10 $\rightarrow$ BDI-II & .72 & $<.001$ \\
\hline & Self-Blame $\rightarrow$ BDI-II & .36 & .11 \\
\hline Indirect effect & $.19,95 \%$ CI $[-.25, .69]$ & & \\
\hline \multirow[t]{3}{*}{ Acceptance $\rightarrow$ PSS-10 $\rightarrow$ BDI-II } & Acceptance $\rightarrow$ PSS- 10 & -.13 & .65 \\
\hline & PSS-10 $\rightarrow$ BDI-II & .73 & $<.001$ \\
\hline & Acceptance $\rightarrow$ BDI-II & .07 & .75 \\
\hline Indirect effect & $-.10,95 \%$ CI $[-.07, .05]$ & & \\
\hline \multirow[t]{3}{*}{ Rumination $\rightarrow$ PSS-10 $\rightarrow$ BDI-II } & Rumination $\rightarrow$ PSS-10 & 1.17 & $<.001$ \\
\hline & PSS-10 $\rightarrow$ BDI-II & .60 & $<.001$ \\
\hline & Rumination $\rightarrow$ BDI-II & .52 & .03 \\
\hline Indirect effect & $.71,95 \%$ CI $[.43,1.14]$ & & \\
\hline \multirow[t]{4}{*}{ Positive refocusing $\rightarrow$ PSS-10 $\rightarrow$ BDI-II } & Positive refocusing $\rightarrow$ PSS- 10 & -.44 & .11 \\
\hline & PSS-10 $\rightarrow$ BDI-II & .73 & $<.001$ \\
\hline & Positive refocusing $\rightarrow$ BDI-II & -.03 & .89 \\
\hline & $-.33,95 \%$ CI $[-.83, .14]$ & & \\
\hline \multirow{4}{*}{ Refocus planning $\rightarrow$ PSS- $10 \rightarrow$ BDI-II } & Refocusing planning $\rightarrow$ PSS- 10 & -.47 & .09 \\
\hline & PSS-10 $\rightarrow$ BDI-II & .70 & $<.001$ \\
\hline & Refocus planning $\rightarrow$ BDI-II & -.26 & .25 \\
\hline & $-.33,95 \% \mathrm{CI}[-.87, .10]$ & & \\
\hline \multirow[t]{3}{*}{ Positive reappraisal $\rightarrow$ PSS- $10 \rightarrow$ BDI-II } & Positive reappraisal $\rightarrow$ PSS- 10 & -.79 & .001 \\
\hline & PSS-10 $\rightarrow$ BDI-II & .66 & $<.001$ \\
\hline & Positive reappraisal $\rightarrow$ BDI-II & -.37 & .08 \\
\hline Indirect effect & $-.52,95 \%$ CI $[-.98,-.20]$ & & \\
\hline \multirow[t]{4}{*}{$\begin{array}{l}\text { Putting into perspectives } \rightarrow \text { PSS- } 10 \rightarrow \\
\text { BDI-II }\end{array}$} & $\begin{array}{l}\text { Putting into perspectives } \rightarrow \text { PSS- } \\
10\end{array}$ & -.24 & .34 \\
\hline & PSS-10 $\rightarrow$ BDI-II & .72 & $<.001$ \\
\hline & Putting into perspectives $\rightarrow$ BDI-II & -.25 & .20 \\
\hline & $-.18,95 \%$ CI $[-.60, .22]$ & & \\
\hline \multirow[t]{3}{*}{ Catastrophizing $\rightarrow$ PSS-10 $\rightarrow$ BDI-II } & Catastrophizing $\rightarrow$ PSS-10 & .86 & .001 \\
\hline & PSS-10 $\rightarrow$ BDI-II & .57 & $<.001$ \\
\hline & Catastrophizing $\rightarrow$ BDI-II & .78 & $<.001$ \\
\hline Indirect effect & $.50,95 \%$ CI $[.22, .84]$ & & \\
\hline \multirow[t]{2}{*}{ Other blame $\rightarrow$ PSS- $10 \rightarrow$ BDI-II } & Other blame $\rightarrow$ PSS- 10 & .80 & .03 \\
\hline & PSS-10 $\rightarrow$ BDI-II & .69 & $<.001$ \\
\hline
\end{tabular}




\begin{tabular}{|c|c|c|c|}
\hline Indirect effect & $\begin{array}{l}\text { Other blame } \rightarrow \text { BDI-II } \\
.55,95 \% \text { CI }[.04,1.13]\end{array}$ & .56 & .06 \\
\hline \multicolumn{4}{|l|}{ Alternative Model } \\
\hline \multirow[t]{3}{*}{ Self Blame $\rightarrow$ BDI-II $\rightarrow$ PSS-10 } & Self Blame $\rightarrow$ BDI-II & .56 & .07 \\
\hline & BDI-II $\rightarrow$ PSS-10 & .66 & $<.001$ \\
\hline & Self-Blame $\rightarrow$ PSS-10 & -.10 & .64 \\
\hline Indirect effect & $.37,95 \%$ CI $[-.04, .97]$ & & \\
\hline \multirow[t]{3}{*}{ Acceptance $\rightarrow$ BDI-II $\rightarrow$ PSS-10 } & Acceptance $\rightarrow$ BDI-II & -.06 & .85 \\
\hline & BDI-II $\rightarrow$ PSS-10 & .65 & $<.001$ \\
\hline & Acceptance $\rightarrow$ PSS-10 & -.13 & .54 \\
\hline Indirect effect & $-.04,95 \%$ CI $[-.49, .44]$ & & \\
\hline \multirow{3}{*}{ Rumination $\rightarrow$ BDI-II $\rightarrow$ PSS-10 } & Rumination $\rightarrow$ BDI-II & 1.23 & $<.001$ \\
\hline & BDI-II $\rightarrow$ PSS-10 & .53 & $<.001$ \\
\hline & Rumination $\rightarrow$ PSS-10 & .52 & .02 \\
\hline Indirect effect & $.65,95 \%$ CI $[.27,1.20]$ & & \\
\hline \multirow[t]{3}{*}{ Positive refocusing $\rightarrow$ BDI-II $\rightarrow$ PSS-10 } & Positive refocusing $\rightarrow$ BDI-II & -.36 & .22 \\
\hline & BDI-II $\rightarrow$ PSS-10 & .64 & $<.001$ \\
\hline & Positive refocusing $\rightarrow$ PSS-10 & -.21 & .30 \\
\hline Indirect effect & $-.23,95 \%$ CI $[-.70, .18]$ & & \\
\hline \multirow[t]{3}{*}{ Refocus planning $\rightarrow$ BDI-II $\rightarrow$ PSS-10 } & Refocusing planning $\rightarrow$ BDI-II & -.64 & .01 \\
\hline & BDI-II $\rightarrow$ PSS-10 & .63 & $<.001$ \\
\hline & Refocus planning $\rightarrow$ PSS-10 & -.16 & .40 \\
\hline Indirect effect & $-.40,95 \%$ CI $[-.76,-.08]$ & & \\
\hline \multirow[t]{3}{*}{ Positive reappraisal $\rightarrow$ BDI-II $\rightarrow$ PSS-10 } & Positive reappraisal $\rightarrow$ BDI-II & -.88 & $<.001$ \\
\hline & BDI-II $\rightarrow$ PSS-10 & .60 & $<.001$ \\
\hline & Positive reappraisal $\rightarrow$ PSS-10 & -.26 & .18 \\
\hline Indirect effect & $-.53,95 \%$ CI $[-.89,-.24]$ & & \\
\hline \multirow{3}{*}{$\begin{array}{l}\text { Putting into perspectives } \rightarrow \text { BDI-II } \rightarrow \\
\text { PSS-10 }\end{array}$} & Putting into perspectives $\rightarrow$ BDI-II & -.47 & .09 \\
\hline & BDI-II $\rightarrow$ PSS-10 & .65 & $<.001$ \\
\hline & $\begin{array}{l}\text { Putting into perspectives } \rightarrow \text { PSS- } \\
10\end{array}$ & .06 & .75 \\
\hline Indirect effect & $-.31,95 \%$ CI $[-.68, .02]$ & & \\
\hline \multirow[t]{3}{*}{ Catastrophizing $\rightarrow$ BDI-II $\rightarrow$ PSS-10 } & Catastrophizing $\rightarrow$ BDI-II & 1.31 & $<.001$ \\
\hline & BDI-II $\rightarrow$ PSS-10 & .65 & $<.001$ \\
\hline & Catastrophizing $\rightarrow$ PSS-10 & .02 & .95 \\
\hline Indirect effect & $.85,95 \%$ CI $[.46,1.44]$ & & \\
\hline \multirow[t]{3}{*}{ Other blame $\rightarrow$ BDI-II $\rightarrow$ PSS-10 } & Other blame $\rightarrow$ BDI-II & 1.10 & .004 \\
\hline & BDI-II $\rightarrow$ PSS-10 & .65 & $<.001$ \\
\hline & Other blame $\rightarrow$ PSS-10 & .09 & .76 \\
\hline Indirect effect & $.71,95 \%$ CI $[.05,1.33]$ & & \\
\hline
\end{tabular}

Adaptive ER strategies. Controlling for the aforementioned covariates, a complete indirect effect of subjective stress levels was found in the relationship between Positive 
Reappraisal and depressive symptoms (-0.52, 95\% CI [-0.98, -0.20]), where both Positive Reappraisal and PSS-10 accounted for 59.3\% of variance in depressive symptom $(F(6,63)=$ $15.27, p<.001)$. No significant mediations were found for the other four adaptive ER strategies (i.e., Acceptance, Positive Refocusing, Refocus Planning, Putting into Perspectives) and depressive symptoms through subjective stress levels (see Table 8).

\section{Alternative model testing: Depressive symptoms as the mediator in the relationship} between ER strategies and subjective stress. Additional mediation analyses were conducted the rule out the alternative model between subjective stress, ER strategies, and depressive symptoms, using depressive symptoms as the mediator.

Maladaptive ER strategies. A significant partial indirect effect of depressive symptoms was found for the relationship between Rumination and subjective stress levels $(0.65,95 \% \mathrm{CI}$ $[0.27,1.20])$, where Rumination and BDI-II accounted for $58.1 \%$ of variance in subjective stress $(F(6,63)=14.57, p<.001)$. It was also found that depressive symptoms completely mediated the relationship between Catastrophizing and subjective stress levels $(0.85,95 \%$ CI $[0.46,1.44])$, accounting for $54.4 \%$ of variance in subjective stress levels $(F(6,63)=12.54, p<.001)$. Furthermore, depressive symptoms completely mediated the relationship between Other Blame and subjective stress level through depressive symptoms $(0.71,95 \%$ CI $[0.05,1.33])$. The Other Blame model accounted for $54.5 \%$ of variance in subjective stress levels $(F(6,63)=12.58, p<$ .001). No significant indirect effect was found between Self Blame, depressive symptoms, and subjective stress levels $(0.37,95 \%$ CI $[-0.02,0.97])$. See Table 8 for model details.

Adaptive ER strategies. A significant complete indirect effect of depressive symptoms was found for the relationship between Positive Reappraisal and subjective stress levels ( -0.53 , $95 \%$ CI $[-0.89,-0.24])$, accounting for $55.7 \%$ of variance in subjective stress while controlling 
for the aforementioned covariates $(F(6,63)=13.23, p<.001)$. Furthermore, depressive symptoms also completely mediated the relationship between Refocus Planning and perceived stress levels (-.40, 95\% CI [-.76, -.08]), accounting for $54.9 \%$ of variance in subjective stress levels $(F(6,63)=12.81, p<.001)$, adjusting for the aforementioned covariates. No significant indirect effect of depressive symptom was found between the remaining three adaptive ER strategies and subjective stress levels (see Table 8). 


\section{Discussion}

Depressive symptoms have a significant impact on the physical, cognitive, and emotional well-being among older adults. With an expanding aging population and the prevalence of depressive symptoms among older adults on the rise, it is imperative to examine factors that underlie the development of depression in late life. Exposure to chronic stress has been identified as a risk factor for the onset of depression. Furthermore, strategies that are used to regulate individuals' emotions have also been linked to the development and maintenance of depression. Although studies have investigated the relationship between chronic biological stress (or physiological dysfunctions) and depressive symptoms, as well as the link between ER and depression, few studies have examined these factors in a single model. The current study sought to examine the relationship between ER, chronic biological stress, and depressive symptoms among community-dwelling older adults. Specifically, the mediating role of AL in the relationship between ER and depressive symptoms was of primary interest.

Previous studies have demonstrated that AL is significantly associated with the onset of depressive symptoms using longitudinal (e.g., Goldman, 2006; Juster et al., 2011; Kobrosly et al., 2013) and cross-sectional designs (Kobrosley et al., 2014). For example, Kobrosly and colleagues (2014) examined the relationship between AL, global, affective, and somatic depressive symptoms in a group of 125 older adults using a cross-sectional design. In this study, the AL index was calculated using average diurnal salivary cortisol slope, interleukin-6 (an inflammatory marker), IGF-1, resting heart rate, WHR, SBP and DBP. The range of AL index for Kobrosly and colleges (2014) ranged from zero to six (with a possible maximum value of seven), with a mean of 1.7 and a median of 2. Controlling for age, sex, education, estimated annual income, average weekly level of physical activity and antidepressant medication use, 
Kobrosly and colleagues (2014) found that higher AL was associated with more global, affective and somatic depressive symptoms. Similar to the current study, Kobrosly et al. (2014) demonstrated restrictive range within their AL index. Moreover, a medium effect size $(\beta=1.21)$ was found for the association between $\mathrm{AL}$ index and global depressive symptoms.

Inconsistent with previous studies, no significant association was found between AL and depressive symptoms in the current study. Whereas Kobrosly et al. (2014) had a total of 125 participants; the present study had a sample size of only 70 participants. Due to low statistical power, the small sample size could contribute to inconsistent findings and failure to detect the hypothesized association. Another possible explanation for the discrepant results may be a result of sample characteristics (discussed further below).

According to coping theory by Lazarus and Folkman (1984), individuals who engage in maladaptive ER strategies experience greater stress than those who engage in adaptive strategies. It was hypothesized that increased adaptive ER strategies would associate with lower AL, whereas increased maladaptive ER strategies would associate with higher AL. This hypothesis was not supported in the present study, which is inconsistent with previous research that indicate level of self-reported stress is associated with cognitive ER strategies Rumination, Positive Reappraisal and Self Blame (Martin \& Dahlen, 2005). Furthermore, studies using objective measures of acute stress have shown that maladaptive ER strategies such as rumination are associated with prolonged acute stress reactivity, measured by cortisol and inflammatory marker secretions (Zoccola et al., 2014; Zoccola et al., 2008).

Given that this was the first study to examine the relationship between ER strategies and chronic biological stress measured by AL, future studies should further examine this link. In the context of the aforementioned null findings and limitations, the mediation analyses with $\mathrm{AL}$ as a 
mediator in the relationship between ER strategies and depressive symptoms were not significant. Similarly, the alternative model also revealed null findings.

Although none of the proposed hypotheses were supported, two important study limitations are likely the reason for null findings: sample size and sample characteristics. First, the analyses were conducted using a relatively small sample size of 70 participants. As suggested by the power analysis, in order to detect a small to medium effect size, a minimal sample of 135 was required. Second, the current sample was relatively healthy, high functioning and active members of the community, all of which may suggest lower physiological dysfunction. Although the current AL index included a more complex composition of biological indicators of chronic stress compared with previous studies, the current sample presented with restrictive range for the mean AL index value and thus lacked the required variability, especially for values in the higher range of the AL index. As such, the sample size must be increased to meet power calculations and recruitment strategies must focus on including older adults with poorer health and functional status to expand the higher level (i.e., greater dysfunction) of the AL range.

To provide a more comprehensive evaluation of the relationship between stress and depressive symptoms, additional analyses were conducted to examine the relationship between subjective stress levels, ER strategies, and depressive symptoms. It was found that subjective stress level was significantly associated with depressive symptoms, after controlling for age, sex, education, and perceived SES. However, it is worth mentioning that perceived SES remained as a significant factor of depressive symptoms after PSS-10 was added into the model. This mirrors the findings of the AL and depressive symptoms model, which suggests that financial difficulties contribute to the onset of depressive symptoms within the current sample. Previous studies have found that lower SES is associated with higher levels of AL (e.g., Gruenewald et al., 2012). It is 
plausible that subjective financial difficulties serve as a form of stress that underlies the link between perceived SES levels and depressive symptoms. Recent studies have indicated that subjective SES is more predictive of health outcomes than objective SES such as education and income levels (e.g., Adler, Epel, Castellazzo, \& Ickovics, 2000; Cohen et al., 2008; SinghManoux, Marmot, \& Adler, 2005). Furthermore, the inverse relationship between SES (both subjective and objective) and various health outcomes has been consistently documented in the literature, including depression (e.g., Hu, Adler, Goldman, Weinstein, \& Seeman, 2005; Lorant et al., 2003).

Consistent with previous findings in undergraduate students (Martin \& Dahlen, 2005; Miklosi, Martos, Szabo, Kocsis-Bogar, \& Forintos, 2014), the present findings revealed that greater engagement of Rumination was associated with more perceived stress levels, whereas more engagement of Positive Reappraisal was associated with less subjective stress among older adults. The relationship between Positive Reappraisal and depressive symptoms was completely mediated by subjective stress levels, after controlling for a priori covariates. Moreover, the model accounted for more than half of the variance in depressive symptoms. This suggests that the relationship between Positive Reappraisal and depressive symptoms is significantly explained by subjective stress.

Older adults who engage in adaptive ER strategies are less likely to experience depressive symptoms. However, given the negative effect of stress on cognitive function (e.g., Lupien et al., 1999; Qin et al., 2009), increased levels of perceived stress may attenuate the protective nature of adaptive ER strategies on depressive symptoms. Similarly, Miklosi and colleagues (2014) found that greater perceived stress levels were associated with high levels of anxiety through lower use of adaptive ER strategies in a group of undergraduate students. Given 
that adaptive ER strategies require greater executive function processes such as set-shifting (Etkin, Buchel, \& Gross, 2015; Zelazo \& Cunningham, 2007), the negative effect of stress on cognitive function may impair adaptive ER strategies used. Moreover, the uncontrollable and unpredictable nature of perceived stress may also inhibit the use of adaptive strategies, which further contribute to increased anxiety and stress (Miklosi et al., 2014).

The alternative model revealed that depressive symptoms fully mediated the relationship between Positive Reappraisal and subjective stress, as well as Refocus Planning and subjective stress. Previous studies have indicated that adaptive ER strategies are associated with a decrease in both perceived stress levels (e.g., Miklosi et al., 2014) and negative mood (e.g., Aldao et al., 2010). Thus, the current study provides preliminary support that depressive symptom levels mediate the relationship between adaptive cognitive ER strategies and subjective stress levels. Specifically, the alternative model for Refocus Planning explained the relationship of adaptive ER-depressive symptoms-subjective stress better than the hypothesized model, considering that the indirect mediation effect was not found in the hypothesized model. This suggests that older adults who often think about the steps that are required for the task at hand (i.e., Refocus Planning) experience lower perceived stress. However, once they experience depressive symptoms, the protective effect of Refocus Planning as a form of adaptive ER strategy is no longer effective. This attenuating effect may be a result of the limited cognitive resources experienced by individuals with depression. Given that adaptive ER strategies require greater cognitive resources (Etkin et al., 2015; Zelazo \& Cunningham, 2007), depression-related cognitive dysfunction may limit the ability for older adults to engage in Refocus Planning, consequently increasing levels of perceived stress. 
The alternative model of Positive Reappraisal may further explain the link between Positive Reappraisal, perceived stress, and depressive symptoms more accurately compared to the hypothesized model. However, the alternative model accounted for a smaller portion of the variance than the hypothesized model, after controlling for a priori covariates. Therefore, it is possible that other factors were not accounted for in the current model, specifically within the stress-depressive symptom link.

Partial indirect mediating effects were found in the relationships between Rumination, Catastrophizing, and Other Blame depressive symptoms through perceived stress, after controlling for covariates. Each of the maladaptive ER models accounted for a significant amount of variance in depressive symptoms. This suggests that the relationship between each of these maladaptive ER strategies and depressive symptoms is partially explained by perceived stress. Previous studies have identified both maladaptive ER strategies and stress as risk factors for depressive symptoms (Aldao et al., 2010; Kendler, et al., 1999). Consistent with previous research, maladaptive ER strategies are also associated with greater levels of perceived stress (Miklosi et al., 2014). Increased experience of stress has been associated with reduced cognitive load (see Sandi, 2013). Given that maladaptive ER strategies require fewer cognitive resources (Zelazo \& Cunningham, 2007), when combined with additional levels of perceived stress due to poor coping, maladaptive ER strategies are more readily engaged in, given that cognitive resources are already limited when individuals are exposed to stress (Miklosi et al., 2014). Thus, the engagement of maladaptive ER strategies in combination with greater perceived stress may further contribute to an increase in negative mood. The present findings were similar to Miklosi et al.'s (2014) findings where the relationship between perceived stress and anxiety levels were mediated by maladaptive ER strategies. They suggested that the negative impact of stress, 
mainly the uncontrollable and unpredictable nature of stress, further facilitates the use of maladaptive ER strategies due to the need for fewer cognitive resources. Thus, the habitual use of maladaptive ER strategies could lead to the onset, as well as the maintenance, of negative mood, which may further result in the onset of depression.

Similar to adaptive ER strategies, the alternative models revealed that depressive symptoms fully mediated the relationship between Catastrophizing-perceived stress, and Other Blame-perceived stress, whereas depressive symptoms only partially mediated the relationship between Rumination and perceived stress. Given that maladaptive ER strategies are associated with increased perceived stress levels, the presence of depressive symptoms further contributes to the negative influence of maladaptive ER and enhances the level of perceived stress. Thus, the current study provides preliminary evidence for an indirect effect of depressive symptoms in the relationship between maladaptive ER strategies and perceived stress level. Similar to adaptive strategies, the alternative model of maladaptive ER strategies accounted for less of the variance in subjective stress after controlling for the a priori covariates. It is plausible that additional moderators or mediators are present in the current model of maladaptive ER strategies, especially within the stress-depressive symptom link.

Overall, it appears that two models containing ER strategies, perceived stress, and depressive symptoms can be constructed (see Figure 2). It is worth mentioning that contrary to the AL index, perceived stress levels were normality distributed, indicating that there is variability within the level of stress being experience within current sample. However, the PSS10 only requires participants to report the levels of stress that they experience within the last month. As such, the questionnaire does not adequately capture the construct of chronic stress. Thus, the current mediation models of ER strategies-depressive symptoms-perceived stress 
should be interpreted with caution. Nonetheless, the current findings involving perceived stress enhances current knowledge in understanding the mechanisms that underlie the three constructs in a group of older adults.
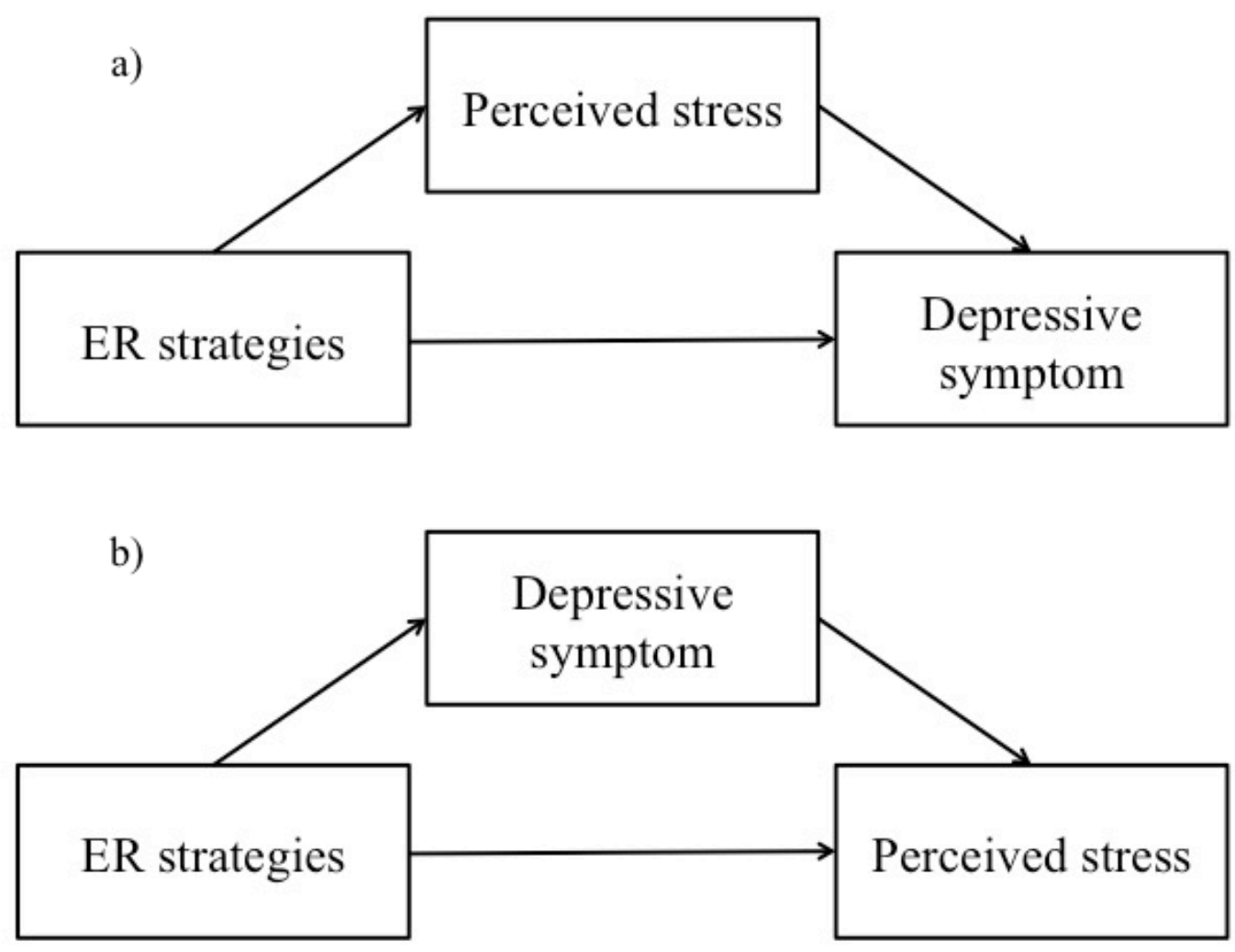

Figure 2. Hypothesized and alternative models of emotion regulation (ER) strategies, perceived stress, and depressive symptoms. a) Perceived stress mediates the relationship between ER strategies and depressive symptoms; b) Depressive symptoms mediate the relationship between ER strategies and perceived stress.

As mentioned above, the primary limitation of the current study was the relatively small sample size. The present study did not contain sufficient statistical power to detect the hypothesized relationship. Recruitment and testing is still underway. Second, the present sample is healthy and actively engaged in the community, which has restricted the range of the $\mathrm{AL}$ index for the current analyses. Furthermore, the original exclusion criteria were too stringent and were 
not designed to capture the variability of chronic biological stress or physiological dysfunctions in the population. Only healthy individuals were included at the beginning stages of the study, which further contributed to the lack of variability of biomarker values and the AL index found in the present study. Compliance with biomarker sampling may also be questioned. It is unknown whether all participants closely adhered to the two 24-hour urine collection procedures. Due to the diurnal variability of stress hormones, it is plausible that non-compliance with sampling may result in faulty stress hormone measurement. Furthermore, four participants' catecholamine values were falsely lower due to inaccurate acid concentrations in the urine collection containers provided by St. Michael's Hospital. As a result, this may further influence the estimate of participants' catecholamine levels. Consequently, the AL index may not accurately represent the chronic "wear and tear" of the primary mediators of the physiological system.

A final study limitation is the study design. Although theoretically sound covariates were controlled as potential determinants of depressive symptoms and stress levels (both in objective and objective stress), the cross-sectional design prevented the identification of causal relations, especially within the perceived stress mediation models. Furthermore, since the onset of stress and depressive symptoms cannot be temporally separated, the alternative explanations for the ER-perceived stress-depressive symptoms cannot be ruled out. Given that older adults' level of executive function is associated with ER, it would have been informative to include that information in the current analyses. However, due to the purpose and the scope of the current study, the information was not included. Future studies should include the executive function level as part of the model. 
Overall, the study's main hypotheses were not supported. However, additional analyses provided some interesting insight into the ER-perceived stress-depressive symptoms interplay among older adults. Despite the aforementioned limitations, the current study was the first to examine the relationship between chronic biological stress, ER, and depressive symptoms in older adults, using the bootstrap indirect mediation analysis. It was also the first study to examine the relationship between chronic biological stress (measured by AL), depressive symptoms, and all nine cognitive ER strategies. Given that the recruitment and testing is still underway, the study has the potential to elucidate novel pathways that underlie the three constructs. 


\section{RYERSON}

UNIVERSITY

\section{AGING and the BRAIN}

A study that examines the impact of biological, psychological and social factors on brain health in older adults

OLDER ADULT RESEARCH PARTICIPANTS NEEDED!!!

Ages: 60 YEARS AND OLDER

\section{Participation includes 2 testing sessions:}

1. Blood, urine and saliva collection to measure biological markers of stress and aging followed by a testing session that will assess memory, attention, speed of processing, language, mood, and lifestyle behaviors. This session will take an estimated total of 4 hours.

2. Undergo a non-invasive test that measures your brain activity while at rest and during an activity, lasting an estimated total of 3 hours.

Eligible participants will be reimbursed for their participation.

If interested, please call

(416) 979-5000 ext 3233

or

Email: star.lab@psych.ryerson.ca 


\section{Appendix B}

\section{Phone Screening Questionnaire}

Researcher: To determine your eligibility for the study, I will now ask you a few questions about demographic and health information. This confidential information will be securely stored in our database and is restricted to members of the research team. You do not have to answer any questions that you are uncomfortable with; however, you may be excluded based on the information you choose to withhold.

\section{DEMOGRAPHIC QUESTIONS}

\begin{tabular}{|c|c|}
\hline Age: & \\
\hline Sex: (Do you identify as male or female) & $\mathrm{M}$ \\
\hline Ethnicity (e.g., Caucasian, Hispanic, etc.): & \\
\hline Country of birth: & \\
\hline $\begin{array}{l}\text { Country/countries of descent (i.e., where you } \\
\text { would trace your ancestry to): }\end{array}$ & \\
\hline Languages you speak: & \\
\hline $\begin{array}{l}\text { If English is not your mother tongue, at what age } \\
\text { did you learn to speak English? } \\
\text { (Exclude if learned English after age 12) }\end{array}$ & \\
\hline Handedness: & Right ___ Left ___ Ambidextrous \\
\hline Do you drive? & $\begin{array}{l}\text { No __ Yes } \\
\text { If no, do you have a driver's licence? }\end{array}$ \\
\hline Are you retired? & $\begin{array}{l}\text { No } \_ \text {Yes } \\
\text { If yes, in what year did you retire? }\end{array}$ \\
\hline How many years of education do you have? & \\
\hline $\begin{array}{l}\text { Do you participate in a regular exercise program? } \\
\text { (i.e. anything that increases heart rate } 3 \mathrm{x} / \text { week; e.g. } \\
\text { aerobics, swimming, walking) }\end{array}$ & $\begin{array}{l}\text { No } \\
\text { Yes (describe) }\end{array}$ \\
\hline Have you ever had any cognitive or & No \\
\hline
\end{tabular}




\begin{tabular}{|l|l|}
\hline Eeuropsychological testing? & Yes (reason) \\
E.g., with a psychologist or for a study & \\
\hline $\begin{array}{l}\text { Are you actively participating in any sort of formal } \\
\text { brain training activities, e.g., Lumosity, Brain } \\
\text { Metrix? }\end{array}$ & No last year) \\
If Yes, how long (in months)? & Yes \\
& Duration : \\
\hline
\end{tabular}

\section{HEALTH-RELATED QUESTIONS}

\section{Have you ever had any of the following?}

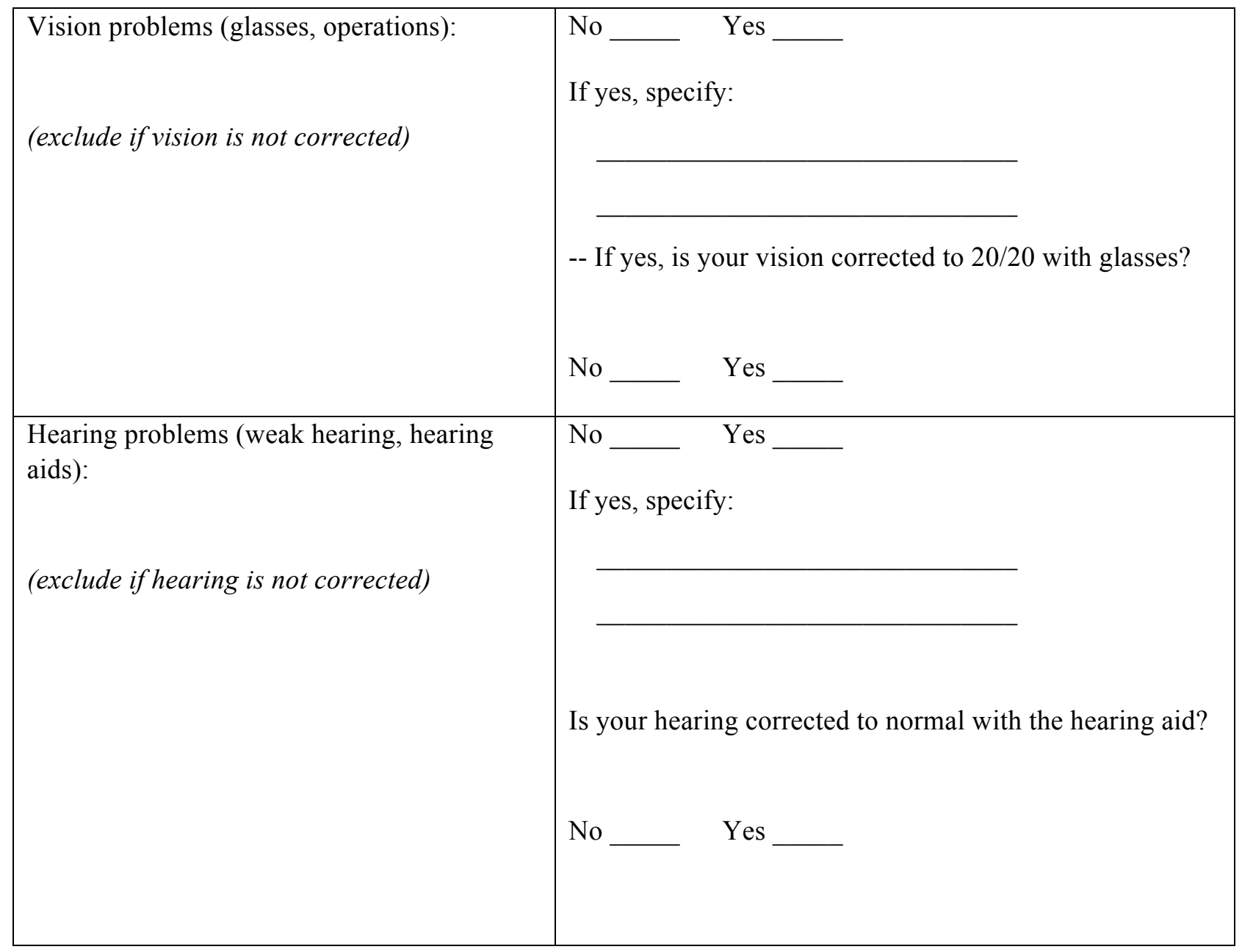




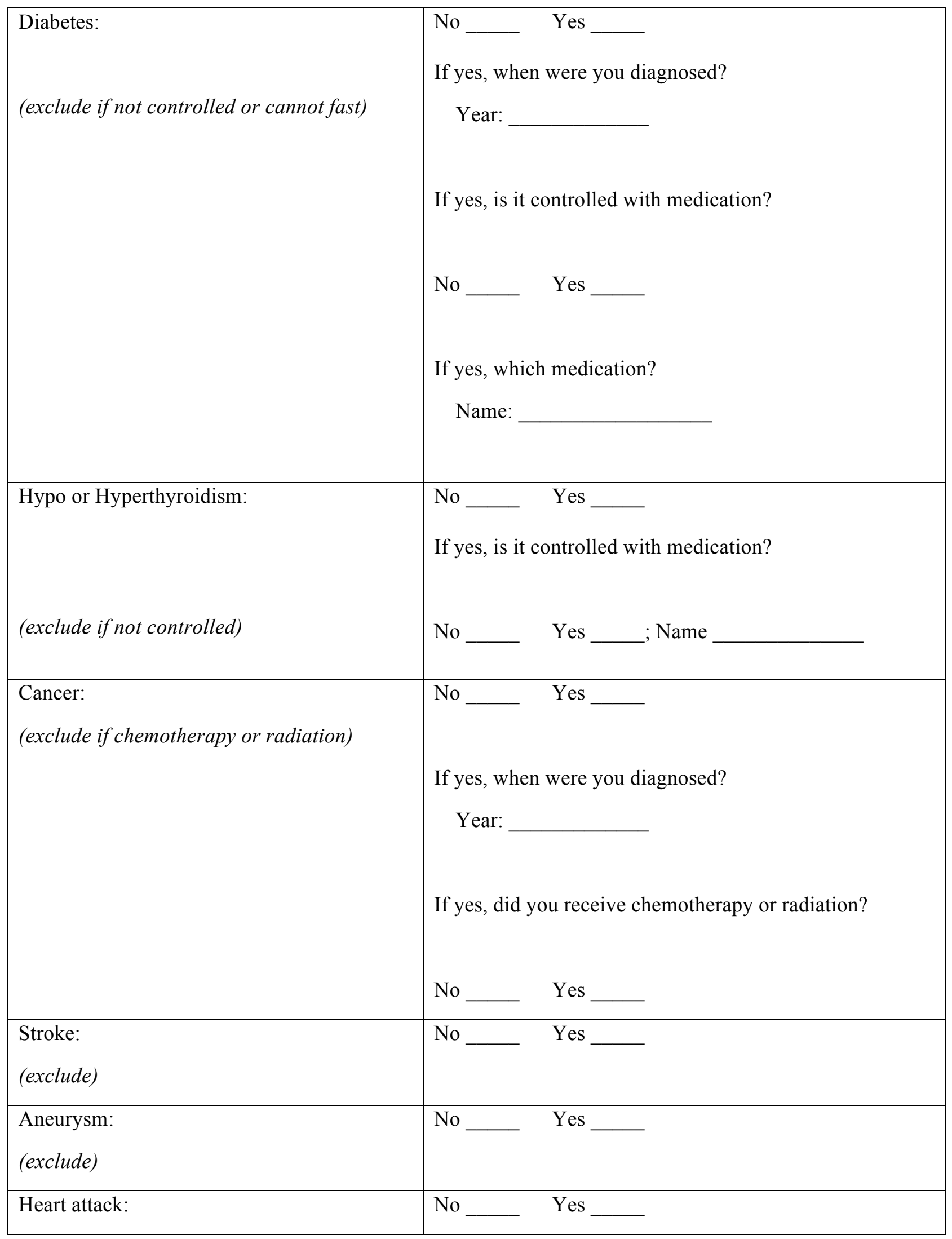




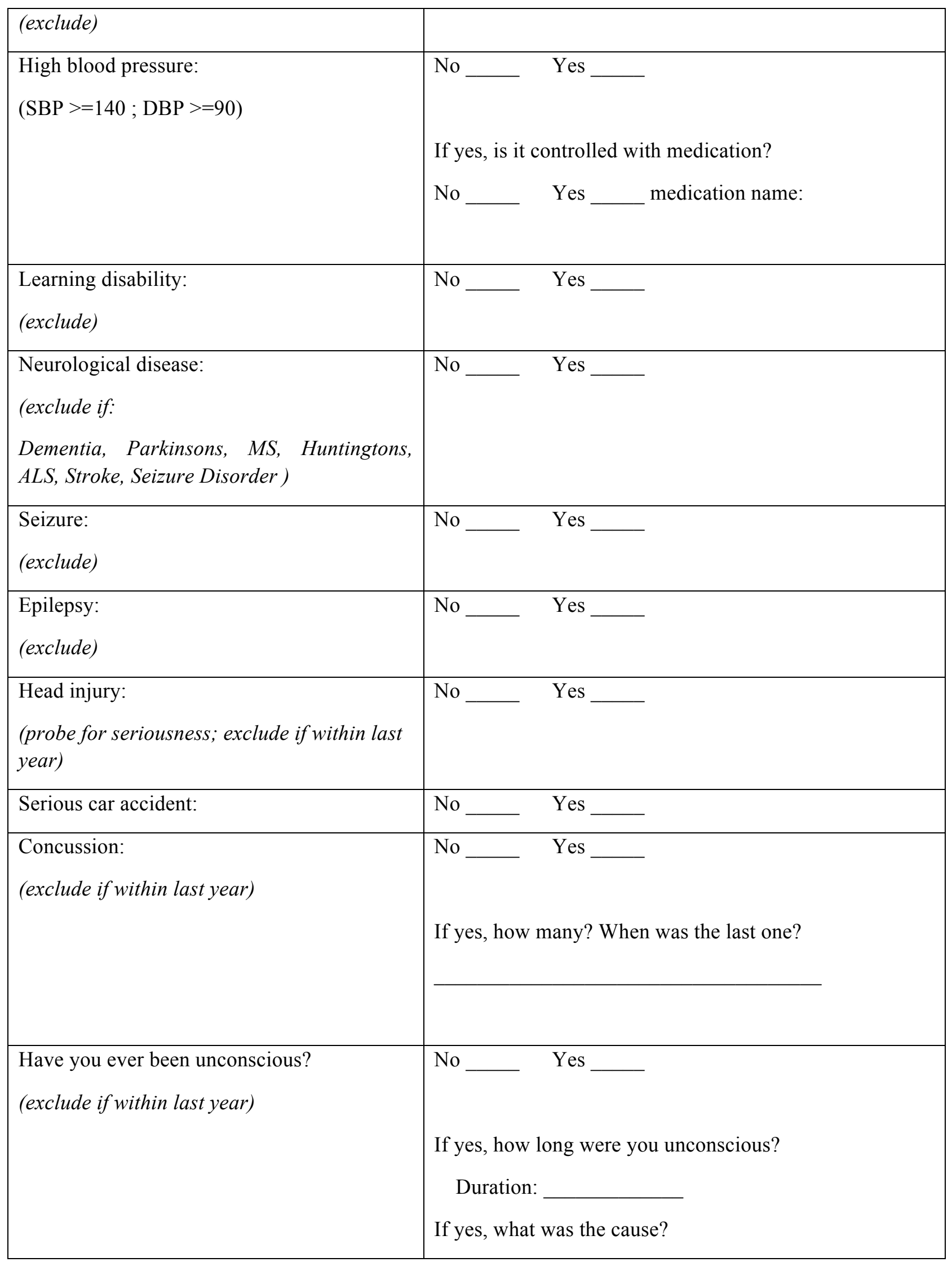




\begin{tabular}{|c|c|}
\hline & Cause: \\
\hline $\begin{array}{l}\text { Have you ever had surgery that required } \\
\text { general anesthesia? } \\
\text { (exclude if within last year) }\end{array}$ & $\begin{array}{l}\text { No _ Yes } \\
\text { If yes, when did you have this procedure? } \\
\text { Year: }\end{array}$ \\
\hline Have you gone through menopause? & $\begin{array}{l}\text { No } \_ \text {Yes } \\
\text { If yes, when }\end{array}$ \\
\hline $\begin{array}{l}\text { Are you currently taking any hormone } \\
\text { replacement therapy? }\end{array}$ & No __ Yes \\
\hline $\begin{array}{l}\text { Are you on any other medications or do you } \\
\text { have another medical condition we have not } \\
\text { spoken about? }\end{array}$ & $\begin{array}{l}\text { No __ Yes _ } \\
\text { If yes, what are they called and what is each one for? } \\
\text { Name: __ Reason: } \\
\text { Name: } \quad \text { Reason: } \\
\text { Name: } \quad \text { Reason: }\end{array}$ \\
\hline
\end{tabular}

\section{Psychiatric disorder}

Next I am going to ask you some questions about your mood and behaviours in the last few months

\begin{tabular}{|c|c|}
\hline $\begin{array}{l}\text { Substance abuse: } \\
\text { (Alcohol use): } \\
\text { In the last } 6 \text { months, have you had } 5 \text { or more } \\
\text { alcoholic drinks on one occasion? }\end{array}$ & $\begin{array}{l}\text { No _ Yes } \\
\text { If yes, how frequently? } \\
\text { drinking caused a problem for you, or has any objected to } \\
\text { it? } \quad \text { (If yes, exclude) }\end{array}$ \\
\hline $\begin{array}{l}\text { (Illegal/recreational drug use): } \\
\text { In the last } 6 \text { months, have you used } \\
\text { recreational drugs? }\end{array}$ & $\begin{array}{l}\text { No } \_ \text {Yes } \\
\text { If yes, how frequently? } \\
\text { caused a problem for you, or has anyone objected to it? } \\
\text { (if yes, exclude) }\end{array}$ \\
\hline $\begin{array}{l}\text { (Prescription medication): } \\
\text { In the last } 6 \text { months, have you taken a lot }\end{array}$ & $\begin{array}{l}\text { No __ Yes } \\
\text { If yes, how frequently? } \\
\text { use caused a problem for you, or has anyone objected to } \\
\text { it? } \quad \text { (if yes, excluse) }\end{array}$ \\
\hline
\end{tabular}




\begin{tabular}{|c|c|}
\hline $\begin{array}{l}\text { more of a prescribed medicine than you were } \\
\text { supposed to? }\end{array}$ & \\
\hline $\begin{array}{l}\text { (Hallucinations): } \\
\text { Has there been any time over the last } 6 \\
\text { months when you have heard voices that } \\
\text { other people couldn't hear, seen things that } \\
\text { other people couldn't see, or smelled things } \\
\text { that other people couldn't smell? }\end{array}$ & $\begin{array}{l}\mathrm{No} \_ \text {Yes } \\
\text { (If yes, exclude) }\end{array}$ \\
\hline $\begin{array}{l}\text { (Delusion) } \\
\text { In the last } 6 \text { months, have you thought that } \\
\text { someone was out to get you or is plotting } \\
\text { behind your back? }\end{array}$ & $\begin{array}{l}\text { No } \_ \text {Yes } \\
\text { (If yes, exclude) }\end{array}$ \\
\hline $\begin{array}{l}\text { (Manic symptoms): } \\
\text { In the last } 6 \text { months, has there been a time } \\
\text { when you felt so happy, "high", excited or } \\
\text { hyper that other people thought you were not } \\
\text { your normal self, or you were so hyper that } \\
\text { you started getting into trouble? }\end{array}$ & $\begin{array}{l}\text { No } \_ \text {Yes } \\
\text { (If yes, exclude) }\end{array}$ \\
\hline $\begin{array}{l}\text { Panic attack: } \\
\text { Have you ever had a panic attack, when you } \\
\text { suddenly felt frightened or anxious or } \\
\text { suddenly developed a lot of symptoms such } \\
\text { as breaking out in a sweat, breathing heavily } \\
\text { or irregularly, or your heart pounding or } \\
\text { racing? }\end{array}$ & $\begin{array}{l}\text { No } \_ \text {Yes } \\
\text { (If yes, exclude) }\end{array}$ \\
\hline $\begin{array}{l}\text { GAD: } \\
\text { In the last } 6 \text { months, have you been } \\
\text { particularly nervous or anxious more than } \\
\text { you normally would? }\end{array}$ & $\begin{array}{l}\mathrm{No} \_\mathrm{Yes} \\
\text { (If yes, exclude) }\end{array}$ \\
\hline $\begin{array}{l}\text { OCD: } \\
\text { Have you ever been bothered by thoughts } \\
\text { that didn't make any sense and kept coming } \\
\text { back to you even when you tried not to have } \\
\text { them? }\end{array}$ & $\begin{array}{l}\text { No } \_ \text {Yes } \\
\text { (If yes, exclude) }\end{array}$ \\
\hline $\begin{array}{l}\text { Was there ever anything that you had to do } \\
\text { over and over again and couldn't resist } \\
\text { doing, like washing your hands again and } \\
\text { again, counting up to a certain number, or }\end{array}$ & $\begin{array}{l}\mathrm{No}_{\text {(If yes, exclude) }} \\
\text { Yes }\end{array}$ \\
\hline
\end{tabular}




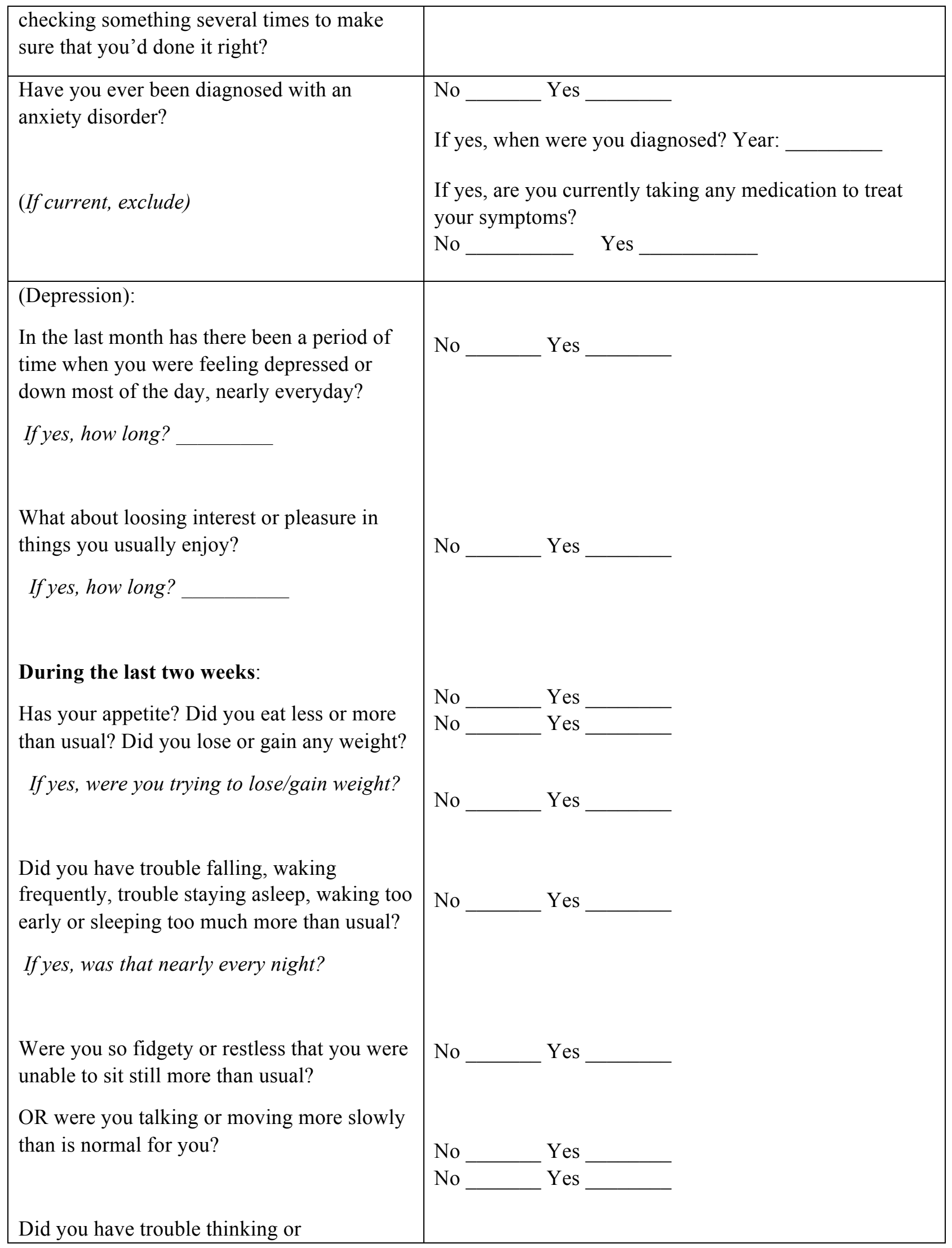




\begin{tabular}{|c|c|}
\hline $\begin{array}{l}\text { concentrating? } \\
\text { If yes, was this more difficult than usual? }\end{array}$ & \\
\hline $\begin{array}{l}\text { Have you ever been diagnosed with } \\
\text { depression? } \\
\text { (If current, exclude; If current controlled by } \\
\text { medication include) }\end{array}$ & $\begin{array}{l}\text { No _ } \quad \text { Yes } \\
\text { If yes, when are you diagnosed? Year: } \\
\text { If yes, are you currently taking any anti-depressant or } \\
\text { medication to treat your symptoms? } \\
\text { No } \quad \text { Yes }\end{array}$ \\
\hline
\end{tabular}




\section{Appendix C}

\section{RYERSON UNIVERSITY}

\section{Consent Agreement}

\section{The Biopsychosocial Profile of High and Low Cognitive Performance in Older Adults}

You are being asked to participate in a research study. Before you give your consent to be a volunteer, it is important that you read the following information and ask as many questions as necessary to be sure you understand what you will be asked to do.

\section{Investigators:}

Principal Investigator: Dr. Alexandra J. Fiocco, PhD., Department of Psychology, Ryerson University Co-Investigator: Vivian Huang, BSc., Department of Psychology, Ryerson University Collaborators: Dr. Ben Dyson, PhD., Department of Psychology, Ryerson University, Dr. Judes Poirier, PhD., CQ. McGill University, Centre for Studies in Aging

\section{Purpose of the Study:}

Cognitive function, such as memory, is an important health factor, especially in late life. The effect of stress on cognitive function has received a lot of attention over the past 20 years; it is suggested that exposure to high levels of stress hormones over a person's lifespan plays a significant role in the aging process and may contribute to declines in cognitive function, such as memory. With an aging population on the rise, and an expected increase in dementia cases, prevention is key! By understanding the biological, psychological and social factors association with good and poor mental function, prevention programs may be developed, specifically created to change these factors.

The purpose of this study is to assess the individual and interacting effects of biological, psychological and social factors in their association with cognitive performance. Biological factors will include Apolipoprotein E gene status and biological markers of stress, including cortisol and norepinephrine. Psychological factors will include personality and lifestyle behaviours such as exercise and smoking status. Finally, social factors will include marital status and social network (i.e. size of social network and time spent in social environments). The goal is to see which of these factors are most predictive of cognitive function in older adults.

Seventy older adults between the ages of 60 and 80 will be recruited for the study. To be eligible for this study, you must have confirmed, in a phone screening, that you do not have any of the following: recent diagnosed mental disorder or mood disorder, cancer/chemotherapy, neuropsychological testing in past year, stroke, diabetes, significant vision or hearing problems. Participants who meet inclusion criteria will complete two testing sessions. In the first session, participants will undergo a blood draw and urine sample (blood analyses of cholesterol and glucose levels will be made available to the participant), saliva 
sample (for genetic information) and neuropsychological testing (i.e. completion of cognitive tests and psychological questionnaires). Approximately one week later, participants will return to the laboratory for a second testing session that will include undergoing electroencephalogray (EEG), which is a noninvasive technique that measures your brain activity.

\section{Description of the Study:}

As a participant, you will be asked to come to the Stress and Healthy Aging Research Lab at Ryerson University for 2 sessions. You will be asked to sign this consent form before the first session and bring it with you to the first testing session. If you forget to bring the consent form on the day of testing, a copy will be made available, ready to sign.

\section{First Testing Session:}

As a participant, you will meet the study's research assistant at Saint Michael's Hospital in the morning in a fasting state (12 hours fasting) and will provide blood and urine for the measurement of biological markers including lipid levels, glucose and cortisol. In addition, a saliva sample will be taken for the genetic analysis of the APOE gene - this gene is involved in the transport of cholesterol. Following blood draw, you will be escorted to the Stress and Healthy Aging Research Lab where you will be provided a light snack (i.e. low glycemic protein bar and water/juice) before beginning the neuropsychological testing (i.e. tasks and questionnaires assessing things such as memory) session. The testing session will take approximately 2.5 hours. During this time, you will be asked to complete tasks that assess things like your memory, attention and thinking abilities (maximum 2 hours). You will also be asked to complete questionnaires that assess your mood and daily living habits (maximum 20 minutes). Depending on the wait time for blood draw and your speed in answering questions, this testing session is anticipated to last approximately 4 hours maximum.

\section{Second Testing Session:}

After completing session one, you will be asked to return to the Stress and Healthy Aging Research Lab where you will be asked to undergo EEG to assess your brain activity while at rest and during a memory task. This session will last a maximum of 2.5 hours. The EEG entails placing a cap on your head. The cap will have electrodes embedded in it, which is what measures your brain activity along the scalp. A special gel is used to insert the electrodes into the cap and some of this gel will likely spill onto your hair. You can wash your hair at the research facility, either with your own shampoo/conditioner, or with that which will be provided.

\section{What is Experimental in this Study:}

Participants will be asked to undergo testing on two separate occasions during which they will be exposed to biological (i.e. providing blood, urine and saliva), cognitive (i.e. completing various tasks assessing things like memory and attention) and brain imaging (i.e. EEG) testing.

\section{What is Genetic Testing:}

As everyone is born with a unique set of genes, a genetic test is an analysis used to look at a person's genetic makeup. Molecular genetic tests (or gene tests) study single genes or short lengths of DNA to identify variations or mutations that are associated with certain phenotypes (e.g. eye colour, height, 
muscle growth, personality etc). Genetic testing for this study will be performed on saliva instead of the common use of blood as it is less invasive and provides the same level of accuracy for results. The cells in your saliva will be extracted to get information on your DNA and the genes embedded in your DNA. Using special techniques, we can examine the structure of the genes that make up your DNA. For example, the APOE gene can come in 3 different forms: e2, e3, and e4. These different genetic forms, or variants, can determine how the proteins in your body function.

Genetic testing is still in an early stage and thus the genetic variants we are interested in are not diagnostic. Participants will not have access to their genetic results and all samples will not have any identifying information on it. Once you have completed the study and your personal identifying information has been destroyed, there will be no way to link you to the DNA results.

\section{Storage of DNA sample:}

A saliva sample will be taken which involves swabbing the inside of your cheek. Samples will be sent to a laboratory that specializes in genetic analyses (Laboratory of Dr. Judes Poirier at McGill University, Montreal QC). No identifying information will be sent with your sample. The DNA from the cell lines will be stored for up to 7 years at the McGill Centre for Studies in Aging Stress following publication of results, after which all viable samples will be destroyed. During this time, and as research funds become available, the sample may be re- analyzed for additional genetic markers of interest (e.g. COMP, Brainderived Neurotrophic Factor) that are associated with cognitive function and stress in older adults (but are not diagnostic of disease).

\section{Confidentiality, Storage and Safekeeping of DNA Samples:}

Your sample will be coded so that we will protect the confidentiality of the sample by assigning it a specific study code. Once you have completed the study, all of your identifying information will be destroyed and no link can be made between your identity and your samples/data. This means that we will not have access to any results from genetic testing, nor will any third party as there is no identifiable link between the sample and yourself. All data and viable samples will be securely stored up to 7 years following publication of results, after which all material will be properly destroyed.

\section{Risks or Discomforts:}

Some of the cognitive tasks (e.g. memorizing a list of words) may be challenging, causing frustration or fatigue; however, we emphasize that you are not expected to get everything correct and that we only ask you to try your best. Should you feel uncomfortable during the testing session and while filling out psychological questionnaires, you may take a break before moving on, or stop altogether.

Physical discomfort may arrive during the blood draw. Although a professional technician will be drawing blood, there is always the risk of bruising. This commonly occurs when it is difficult to find a good vein to draw from. However, this discomfort is short lived and no greater than what you would normally expect from a yearly physical. Common with blood draw, there may be a small amount of bleeding when blood is taken from a vein and there may be slight discomfort and bruising or redness that will usually disappear in a few days.

Although this study does not assess diagnostic genetic markers of disease, concern may pertain to the possibility that the results can affect a person's ability to obtain health, life, disability or long-term care 
insurance. However, it must be stressed that your sample will not have any identifying information on it. A study code will be used to identify your data (i.e. cognitive and psychological test scores, blood, saliva). All identifying information that links you to your data will be destroyed once you have completed the study.

\section{Benefits of the Study:}

Participants will be properly compensated for their time in the study (100\$ total). In addition, upon request, participants will be provided with the results of the blood test from Saint Michael's Hospital (including cholesterol and glucose readings, which are important to monitor). As the genetic marker under evaluation is not a diagnostic tool, participants will not be told their carrier status. While there are no other direct benefits of participating in this study, your participation in this study is extremely valuable in helping researchers understand what contributes to healthy aging.

\section{Confidentiality:}

All data collected for this study, including salivary, urine and blood samples, will remain confidential. Research records will be kept in a cabinet file to which only the principal investigator of this study as well as her research assistants will possess the key. Data will be coded in order to prevent any assistant from making a link between a participant's name and test results, thus maintaining confidentiality of all test results. Once data is collected, identifying information (e.g name, contact information) will be destroyed. All coded data, including saliva and blood samples, will be securely stored up to 7 years following publication of results, after which all material will be properly destroyed. We will destroy all identifying information, including name and telephone numbers, following the second session.

\section{Costs and/or Compensation for Participation:}

Participants will be compensated $100 \$$ in total: $50 \$$ following the first session and $50 \$$ following the second session. This amount will compensate for cost of time and travel to and from Ryerson University.

\section{Voluntary Nature of Participation:}

Participation in this study is voluntary. Your choice of whether or not to participate will not influence your future relations with Ryerson University. If you decide to participate, you are free to withdraw your consent and to stop your participation at any time without penalty or loss of benefits to which you are allowed.

At any particular point in the study, you may refuse to answer any particular question or stop participation altogether. If you decide to stop participating, all information that you provided before stopping will remain confidential in a secured database at Ryerson University and used for future analyses for up to 7 years. If you chose to withdraw before the final session, and thus before destroying your personal information, you may request to have your data removed from the database.

\section{What will be done if "abnormal" findings/results are obtained:}

The tests that you will complete are not "diagnostic" - i.e. no diagnosis can be made with the tests that are administered or the genes that are assayed. However, if there is anything about your performance on the tasks, questionnaires, or blood analytes (e.g. high cholesterol) that raise a concern for us, we will discuss 
it with you.

\section{Questions about the Study:}

If you have any questions about the research now, please ask. If you have questions later about the research, you may contact the principal investigator: Alexandra J. Fiocco via phone (416-979-5000 ext 3008) or email (afiocco@psych.ryerson.ca).

If you have questions regarding your rights as a human subject and participant in this study, you may contact Dr. Lynn Lavallee (Chair) or Toni Fletcher (REB Coordinator) of the Ryerson University Research Ethics Board for information via phone (416-979-5042) or email (rebchair@ryerson.ca). You may also write them at:

\section{Research Ethics Board c/o Office of the Vice President, Research and Innovation Ryerson University 350 Victoria Street, Toronto, ON M5B 2K3}

\section{Agreement:}

Your signature below indicates that you have read the information in this agreement and have had a chance to ask any questions you have about the study. Your signature also indicates that you agree to be in the study and have been told that you can change your mind and withdraw your consent to participate at any time. You have been given a copy of this agreement.

You have been told that by signing this consent agreement you are not giving up any of your legal rights.

Name of Participant (please print)

Signature of Participant

Date

Signature of Investigator/Study Coordinator

Date

\section{Dissemination of Results:}

If you agree to participate in the study, are you interested in learning about the results of the study in a final report? If so, please provide your mailing or email address below:

Email

Mailing 


\section{Appendix D}

\section{BDI-II}

Date:

Instructions: This questionnaire consists of 21 groups of statements. Please read each group of statements carefully, and then pick out the one statement in each group that best describes the way you have been feeling during the past two weeks, including today. Circle the number beside the statement you have picked. If several statements in the group seem to apply equally well, circle the highest number for that group. Be sure that you do not choose more than one statement for any group, including Item 16 (Changes in Sleeping Pattern) or Item 18 (Changes in Appetite).

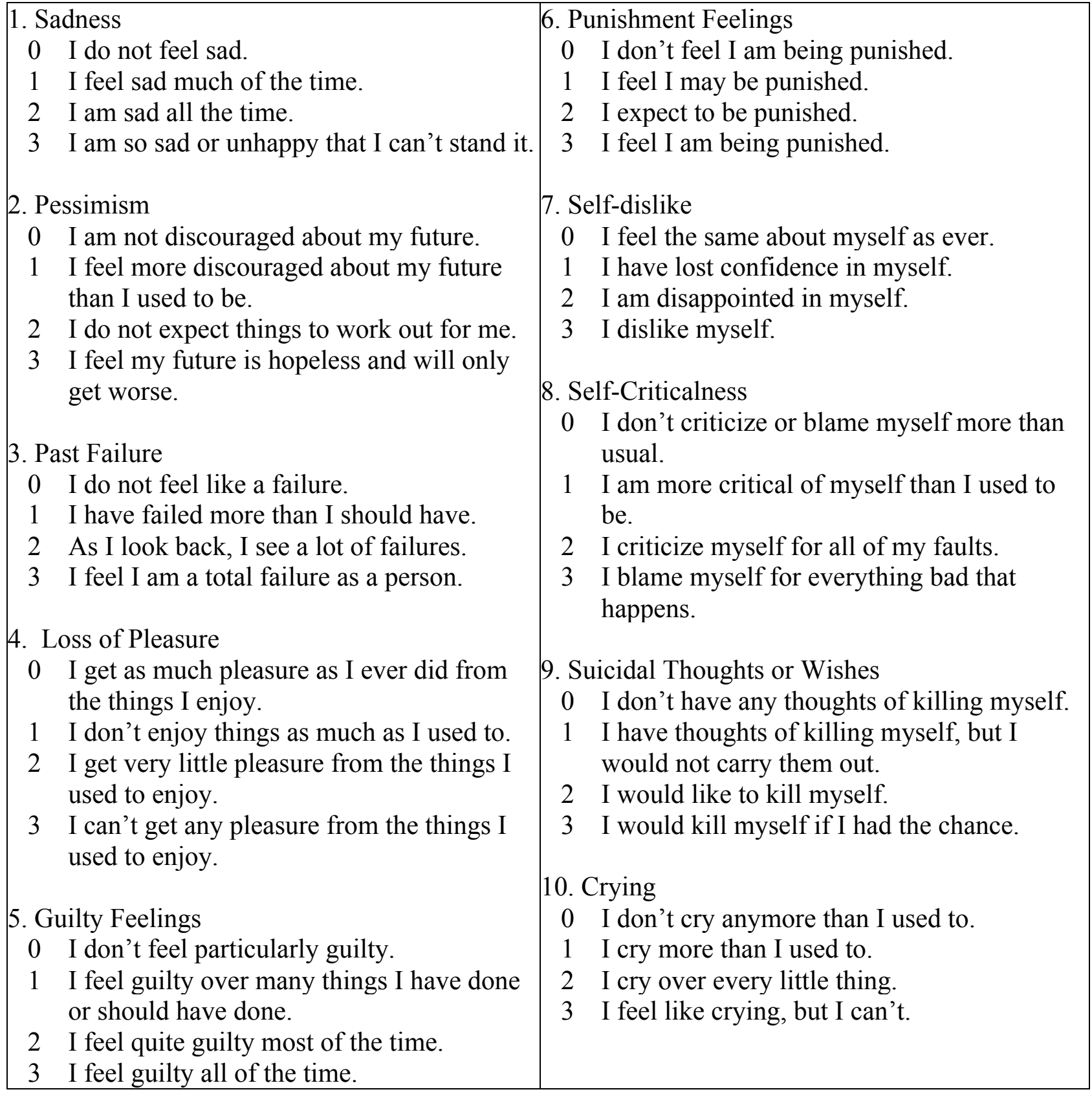




\begin{tabular}{|c|c|c|c|c|}
\hline \multicolumn{2}{|c|}{ 11. Agitation } & \multicolumn{3}{|c|}{ 17. Irritability } \\
\hline & I am no more restless or wound up than usual. & 0 & I am no more irritable than usual. & \\
\hline 1 & I feel more restless or wound up than usual. & 1 & I am more irritable than usual. & \\
\hline 2 & I am so restless or agitated that it's hard to stay still. & 2 & I am much more irritable than usual. & \\
\hline moving & I am so restless or agitated that I have to keep & \multicolumn{3}{|c|}{3 I am irritable al the time. } \\
\hline \multicolumn{2}{|c|}{ or doing something. } & \multicolumn{3}{|c|}{ 18. Changes in Appetite } \\
\hline \multicolumn{2}{|c|}{ 12. Loss of Interest } & \multicolumn{3}{|c|}{$\begin{array}{ll}0 & \text { I have not experienced any change in my appetite. } \\
\text { 1a } & \text { My appetite is somewhat less than usual. }\end{array}$} \\
\hline 0 & I have not lost interest in other people or activities. & \multicolumn{3}{|c|}{$1 \mathrm{~b}$ My appetite is somewhat greater than usual. } \\
\hline 1 & $\begin{array}{l}\text { I am less interested in other people or things than } \\
\text { before. }\end{array}$ & \multicolumn{3}{|c|}{ 2a My appetite is much less than before. } \\
\hline 2 & $\begin{array}{l}\text { I have lost most of my interest in other people or } \\
\text { things. }\end{array}$ & \multicolumn{3}{|c|}{ 3a I have no appetite at all. } \\
\hline 3 & It's hard to get interested in anything. & & & \\
\hline 3 & It's hard to get interested in a & \multicolumn{3}{|c|}{ 19. Concentration Difficulty } \\
\hline \multicolumn{2}{|c|}{ 13. Indecisiveness } & \multicolumn{3}{|c|}{ I can't concentrate as well as usual. } \\
\hline 0 & I make decisions about as well as ever. & \multicolumn{3}{|c|}{2 It's hard to keep my mind on anything for very long. } \\
\hline 1 & I find it more difficult to make decisions than usual. & \multicolumn{3}{|c|}{3 I find I can't concentrate on anything. } \\
\hline 2 & $\begin{array}{l}\text { I have much greater difficulty in making decisions } \\
\text { than I used to. }\end{array}$ & \multicolumn{3}{|c|}{ 20. Tiredness or Fatigue. } \\
\hline 3 & I have trouble making any decisions. & $\begin{array}{l}0 \\
1\end{array}$ & \multicolumn{2}{|c|}{$\begin{array}{l}\text { I am no more tired or fatigued than usual. } \\
\text { I get more tired or fatigued more easily than usual. }\end{array}$} \\
\hline \multicolumn{2}{|c|}{ 14. Worthlessness } & \multicolumn{3}{|c|}{ I am } \\
\hline 0 & I do not feel I am worthless. & & used & \\
\hline & $\begin{array}{l}\text { I don't consider myself as worthwhile and useful as } \\
\text { I used to. }\end{array}$ & \multirow[t]{2}{*}{3} & \multicolumn{2}{|c|}{$\begin{array}{l}\text { I am too tired or fatigued to do most of the things I } \\
\text { used to do. }\end{array}$} \\
\hline 2 & I feel more worthless as compared to other people. & & & \\
\hline 3 & I feel utterly worthless. & \multicolumn{3}{|c|}{ 21. Loss of Interest in Sex } \\
\hline 15. L & oss of Energy & & & my interest in \\
\hline 0 & I have as much energy as ever. & 1 & I am less interested in sex than I used $t$ & to be. \\
\hline 1 & I have less energy than I used to have. & 2 & I am much less interested in sex now. & \\
\hline 2 & I don't have enough energy to do very much. & 3 & I have lost interest in sex completely. & \\
\hline 3 & I don't have enough energy to do anything. & & & \\
\hline 16. C & hang & & & \\
\hline & $\begin{array}{l}\text { I have not experienced any change in my sleeping } \\
\text { pattern. }\end{array}$ & & & \\
\hline 1a & I sleep somewhat more than usual. & & & Subtotal Page 2 \\
\hline $1 \mathrm{~b}$ & I sleep somewhat less than usual. & & & \\
\hline $2 \mathrm{a}$ & I sleep a lot more than usual. & & & Subtotal Page 1 \\
\hline $2 \mathrm{~b}$ & I sleep a lot less than usual. & & & \\
\hline $3 \mathrm{a}$ & I sleep most of the day. & & & 1otal Score \\
\hline $3 b$ & $\begin{array}{l}\text { I wake up 1-2 hours early and can't get back to } \\
\text { sleep. }\end{array}$ & & & \\
\hline
\end{tabular}




\section{Appendix E}

\section{CERQ}

(C) Garnefski, Kraaij \& Spinhoven, 2001

\section{How do you cope with events?}

Everyone gets confronted with negative or unpleasant events now and then and everyone responds to them in his or her own way. By the following questions you are asked to indicate what you generally think, when you experience negative or unpleasant events.

1. 1 feel that I am the one to blame for it

2. I think that I have to accept that this has happened

3. I often think about how I feel about what I have experienced

4. I think of nicer things than what I have experienced

5. I think of what I can do best

6. I think I can learn something from the situation

7. I think that it all could have been much worse

8. I often think that what I have experienced is much worse than

$\begin{array}{cc}\text { (almost) } & \text { some- } \\ \text { never } & \text { times }\end{array}$

$\begin{array}{ll}\text { regu- } & \text { (almost) } \\ \text { larly often } & \text { always }\end{array}$
what others have experienced

9. I feel that others are to blame for it

10. I feel that I am the one who is responsible for what has happened

11. I think that I have to accept the situation

12. I am preoccupied with what I think and feel about what I have experienced

13. I think of pleasant things that have nothing to do with it

14. I think about how I can best cope with the situation

15. I think that I can become a stronger person as a result of what has happened

16. I think that other people go through much worse experiences

17. I keep thinking about how terrible it is what I have experienced

18. I feel that others are responsible for what has happened

19. I think about the mistakes I have made in this matter

20. I think that I cannot change anything about it

21. I want to understand why I feel the way I do about what I have experienced

22. I think of something nice instead of what has happened

23. I think about how to change the situation

24. I think that the situation also has its positive sides

25. I think that it hasn't been too bad compared to other things

26. I often think that what I have experienced is the worst that can happen to a person

27. I think about the mistakes others have made in this matter

28. I think that basically the cause must lie within myself

29. I think that I must learn to live with it

30. I dwell upon the feelings the situation has evoked in me

31. I think about pleasant experiences

32. I think about a plan of what I can do best

33. I look for the positive sides to the matter

34. I tell myself that there are worse things in life 
35. I continually think how horrible the situation has been

36. I feel that basically the cause lies with others

$\begin{array}{lllll}1 & 2 & 3 & 4 & 5 \\ 1 & 2 & 3 & 4 & 5\end{array}$

Thank you for filling out the questionnaire! 


\section{Appendix F}

\section{Perceived Stress Scale}

The questions in this scale ask you about your feelings and thoughts during the last month. In each case, you will be asked to indicate by circling how often you felt or thought a certain way.

\section{$0=$ Never $\quad 1=$ Almost Never $\quad 2=$ Sometimes $\quad 3=$ Fairly Often $\quad 4=$ Very Often}

1. In the last month, how often have you been upset because of something that happened unexpectedly?

2. In the last month, how often have you felt that you were unable to control the important things in your life?

$\begin{array}{lllll}0 & 1 & 2 & 3 & 4\end{array}$

3. In the last month, how often have you felt nervous and "stressed"?

$\begin{array}{lllll}0 & 1 & 2 & 3 & 4\end{array}$

3. In the last month, how often have you felt nervous and "stressed?

$\begin{array}{lllll}0 & 1 & 2 & 3 & 4\end{array}$

4. In the last month, how often have you felt confident about your ability to handle your personal problems?

5. In the last month, how often have you felt that things were going your way?

6. In the last month, how often have you found that you could not cope with all the things that you had to do?

7. In the last month, how often have you been able to control irritations in your life?

$\begin{array}{lllll}0 & 1 & 2 & 3 & 4\end{array}$

8. In the last month, how often have you felt that you were on top of things?

9. In the last month, how often have you been angered because of things that were outside of your control?

10. In the last month, how often have you felt difficulties were piling up so high that you could not overcome them? 


\section{Appendix G}

\section{DEBRIEFING FORM}

Evaluating Biopsychosocial Profile of High and Low Cognitive Performers in Late Life.

Thank you for participating in this study. Your time and effort are much appreciated.

This study investigates the association between biopsychosocial factors (i.e. the combination of biological and psychosocial factors) and cognitive function in older adults. Cognitive function includes memory, attention, and speed of processing (or how quickly you can do certain tasks). You were asked to complete a few tests of cognitive function and to fill out questions related to your mood, personality and lifestyle behaviors. You also provided bodily fluids to measure biological markers of stress, called the allostatic load (AL) index, and genetic variance in a gene that is hypothesized to associate with brain health. You also underwent an electroencephalography (EEG) procedure where your brain activity was measured while at rest and while performing an attention task. Overall, we predict that older adults who display a negative AL index and psychosocial factors associated with poor brainhealth (e.g. sedentary, poor nutrition, low social support) will perform more poorly on cognitive tasks, which will also be found in brain activity patterns measured by the EEG. We also predict that certain biological and psychosocial factors will interact to create a biopsychosocial profile that can differentiate between high and low cognitive performance. This study has received ethics clearance through the Psychology Department Research Ethics Committee at Ryerson University. If you have any questions about this study or concerns about your participation in this study, please contact Dr. Alexandra Fiocco at 416-979-5000-3008 or afiocco@psych.ryerson.ca. If you are interested in knowing how to receive a summary of the study findings, please call the Stress and Healthy Aging Research Lab at 416-979-5000-3233. If you have any concerns about the ethical procedures of this study, please contact the Chair of the Ryerson University Research Ethics Board at 416-979-5042 or rebchair@ryerson.ca.

Thank you again! 


\section{References}

Adam, E. K., \& Kumari, M. (2009). Assessing salivary cortisol in large-scale, epidemiological research. Psychoneuroendocrinology, 34, 1423-1436. doi: 10.1016/j.psyneuen.2009.06.011

Adler, N. E., Epel, E. S., Castellazzo, G., \& Ickovics, J. R. (2000). Relationship of subjective and objective social status with psychological and physiological functioning: Prelininary data in healthy white women. Health Psychology, 19, 586-592. doi: 10.1037/0278-6133.19.6.586

Albert, S. M., Bear-Lehman, J., \& Burkhardt, A. (2012). Mild depressive symptoms, selfreported disability, and slowing across multiple functional domains. International Psychogeriatrics, 24, 253-260. doi: 10.1017/S1041610211001499

Aldao, A. (2013). The future of emotion regulation research: Capturing context. Perspectives on Psychological Science, 8, 155 - 172. doi: 10.1177/1745691612459518

Aldao, A., Nolen-Hoeksema, S., \& Schweizer, S. (2010). Emotion-regulation strategies across psychopathology: A meta-analytic review. Clinical Psychology Review, 30, 217-237. doi: 10.1016/j.cpr.2009.11.004

Alexopoulos, G. S. (2005). Depression in the elderly. The Lancet, 365, 1961 - 1970. doi: $10.1016 / \mathrm{S} 0140-6736(05) 66665-2$

Allard, E. S., \& Kensinger, E. A. (2014). Age-related differences in neural recruitment during the use of cognitive reappraisal and selective attention as emotion regulation strategies. Frontiers in Psychology, 5, 1 - 10. doi: 10.3389/fpsyg.2014.00296

Alvarez, P., Urretavizcaya, M., Benlloch, L., Vallejo, J., \& Menchõn, J. M. (2011). Early- and late-onset depression in the older: No differences found within the melancholic subtype. International Journal of Geriatric Psychiatry, 26, 615-621. doi: 10.1002/gps.2571 
American Psychiatric Association. (2013). Diagnostic and statistical manual of mental disorders (5th ed.). Washington, DC: Author.

Amore, M., Tagariello, P., Laterza, C., \& Savoia, E. M. (2007). Beyond nosography of depression in elderly. Archives of Gerontology and Geriatrics, 44, 13-22. doi:10.1016/j.archger.2007.01.003

Arnsten, A. F. T. (2009). Stress signalling pathways that impair prefrontal cortex structure and function. Nature Reviews Neuroscience, 10, 410 - 422. doi: 10.1038/nrn2648

Axelson, D. A., Doraiswamy, P. M., McDonald, W. M., Boyko, O. B., Tupler, L. A., Patterson, L. J., Nemeroff, C. B., ... \& Krishnan, K. R. R. (1993). Hypercortisolemia and hippocampal changes in depression. Psychiatry Research, 47, 163 - 173. doi: 10.1016/01651781(93)90046-J

Baldwin, R. C. (2000). Poor prognosis of depression in elderly people: Causes and actions. Annals of Medicine, 32, 252 - 256. doi: 10.3109/07853890009011769

Ball, T, M., Ramsawh, H. J., Campbell-Sills, L., Paulus, M. P., \& Stein, M. B. (2013). Prefrontal dysfunction during emotion regulation in generalized anxiety and panic disorders. Psychological Medicine, 43, 1475 - 1586. doi: 10.1017/S0033291712002383

Bardeleben, U., \& Holsboer, F. (1989). Cortisol response to a combined dexamethasone human corticotrophin releasing hormone challenge in patients with depression. Journal of Neuroendocrinology, 1, 485-488. doi: 10.1111/j.1365-2826.1989.tb00150.x

Barry, L. C., Murphy, T. E., \& Gill, T. M. (2011). Depressive symptoms and functional transitions over time in older persons. The American Journal of Geriatric Psychiatry, 19, 783 - 791. doi: 10.1097/JGP.0b013e3181ff6669 
Baune, B. T., Smith, E., Reppermund, S., Air, T., Samaras, K., Lux, O., Brodaty, H., Sachdev, P., \& Trollor, J. N. (2012). Inflammatory biomarkers predict depressive, but not anxiety symptoms during aging: The prospective Sydney Memory and Aging Study. Psychoneuroendocrinology, 37, 1521 - 1530. doi: 10.1016/j.psyneuen.2012.02.006

Beck, A. T., \& Bredemeier, K. (2016). A unified model of depression: Integrating clinical, cognitive, biological, and evolutionary perspectives. Clinical Psychological Science. doi: $10.1177 / 2167702616628523$

Beck, A. T., Steer, R. A., \& Brown, G. K. (1996). Manual for the Beck Depression Inventory-II. San Antonio, TX: Psychological Coporation.

Birditt, K. S., Fingerman, K. L., Almeida, D. M. (2005). Age differences in exposure and reactions to interpersonal tensions: A daily diary study. Psychology \& Aging, 20, 330 - 340. doi: $10.1037 / 0882-7974.20 .2 .330$

Brassen, S., Gamer, M., \& Buchel, C. (2011). Anterior cingulate activation is related to a positivity bias and emotional stability in successful aging. Biological Psychiatry, 70, 131 137. doi: 10.1016/j.biopsych.2010.10.013

Bremmer, M. A., Deeg, D. J. H., Beekman, A. T. F., Penninx, B. W. J. H., Lips, P., \& Hoogendijk, W. J. G. (2007). Major depression in late life is associated with both hypo- and hypercortisolemia. Biological Psychiatry, 62, 479 - 486. doi:

10.1016/j.biopsych.2006.11.033

Burke, H. M., Davis, M. C., Otte, C., \& Mohr, D. C. (2005), Depression and cortisol responses to psychological stress: A meta-analysis. Psychoneuroendocrinology, 30, 846 - 856. doi: 10.1016/j.psyneuen.2005.02.010 
Cameron, I. M., Cardy, A., Crawford, J. R., du Toit, S. W., Hay, S., Lawton, K., ... \& Reid, I. C. (2011). Measuring depression severity in general practice: discriminatory performance of the PHQ-9, HADS-D, and BDI-II. The British Journal of General Practice, 61(588), e419e426. http://doi.org/10.3399/bjgp11X583209

Campbell-Sills, L., \& Barlow, D. H. (2007). Incorporating emotion regulation into the conceptualizations and treatments of anxiety and mood disorders. In J. J. Gross (Ed.), Handbook of emotion regulation. (pp. 542 - 559). New York, NY: Guilford.

Canadian Psychological Association. (2014). "Psychology Works” Fact sheet: Depression Among Seniors. Retrieved from http://www.cpa.ca/docs/File/Publications/FactSheets/ PsychologyWorksFactSheet_DepressionAmongSeniors.pdf

Carlson, J. M., Dikecligil, G. N., Greenberg, T., \& Mujica-Parodi, L. R. (2012). Trait reappraisal is associated with resilience to acute psychological stress. Journal of Research in Personality, 46, 609-613. doi: 10.1016/j.jrp.2012.05.003

Carney, R. M., Freedland, K. E., \& Sheps, D. S. (2004). Depression is a risk factor for mortality in coronary heart disease. Psychosomatic Medicine, 66, 799 - 801. doi: 10.1097/01.psy.0000146795.38162.b1

Carstensen, L. L. (1995). Evidence for a life-span theory of socioemotional selectivity. Current Directions in psychological Science, 4, 151 - 156. doi: 10.1111/1467-8721.ep11512261

Carstensen, L. L., Isaacowitz, D. M., \& Charles, S. T. (1999). Taking time seriously: A theory of socioemotional selectivity. American Psychologist, 54, 165. doi: /10.1037/0003066X.54.3.165

Carstensen, L. L., Turan, B., Scheibe, S., Ram, N., Ersner-Hershfield, H., Samaez-Larkin, G. R., Brooks, K. P., \& Nesselroade, J. R. (2011). Emotional experience improves with age: 
Evidence based on over 10 years of experience sampling. Psychology \& Aging, 26, $21-33$. doi: $10.1037 / \mathrm{a} 0021285$

Carrion, V. G., Weems, C. F., Richert, K., Hoffman, B. C., \& Reiss, A. L. (2010). Decreased prefrontal cortical volume associated with increased bedtime cortisol in traumatized youth. Biological Psychiatry, 68, 491-493. doi: 10.1016/j.biopsych.2010.05.010

Charles, S. T., Piazza, J. R., Luong, G., \& Almeida, D. M. (2009). Now you see it, now you don't: Age differences in affective reactivity to social tension. Psychology \& Aging, 24, 645 - 653. doi: 10.1037/a0016673.

Ciesla, J. a, \& Roberts, J. E. (2007). Rumination, negative cognition, and their interactive effects on depressed mood. Emotion, 7, 555-565. doi: 10.1037/1528-3542.7.3.555

Chrousos, G. P., \& Gold, P. W. (1992). The concept of stress and stress system disorders: Overview of physical and behavioural homeostasis. The Journal of American Medical Association, 267, 1244 - 1252. doi: 10.1001/jama.1992.03480090092034

Cohen, S., Alper, C. M., Doyle, W. J., Adler, N., Treanor, J. J., \& Turner, R. B. (2008). Objective and subjective socioeconomic status and susceptibility to the common cold. Health Psychology, 27, 268 -274. doi: 10.1037/0278-6133.27.2.268

Cohen, S., Janicki-Deverts, D., Doyle, W. J., Miller, G. E., Frank, E., Rabin, B. S., \& Turner, R. B. (2012). Chronic stress, glucocorticoid receptor resistance, inflammation, and disease risk. PNAS, 109, 5995 - 5999. doi: 10.1073/pnas.1118355109

Cohen, S., \& Williamson, G. (1988). Perceived stress in a probability sample of the United States. In S. Spacapam \& S. Oskamp (Eds.), The Social Psychology of Health: Claremont Symposium on Applied Social Psychology. Newbury Park, CA: Sage. 
Cole, M. A., Kim, P. J., Kalman, B. A., \& Spencer, R. L. (2000). Dexamethasone suppression of corticosteroid secretion: evaluation of the site of action by receptor measures and functional studies. Psychoneuroendocrinology, 25, 151 - 167. doi: 10.1016/S0306-4530(99)00045-1

Conner, K. O., Copeland, V. C., Grote, N. K., Koeske, G., Rosen, D., Reynolds, C. F., \& Brown, C. (2010). Mental health treatment seeking among older adults with depression: the impact of stigma and race. The American Journal of Geriatric Psychiatry, 18, 531-543. doi:

10.1097/JGP.0b013e3181cc0366

Cowden Hindash, A. H., \& Amir, N. (2012). Negative interpretation bias in individuals with depressive symptoms. Cognitive Therapy and Research, 36, 502 - 501. doi: 10.1007/s10608011-9397-4

Crimmins, E. M., Johnston, M., Hayward, M., \& Seeman, T. (2003). Age differences in allostatic load: an index of physiological dysregulation. Experimental Gerontology, 38, 731 - 734. doi: 10.1016/S0531-5565(03)00099-8

Davalos, D., \& Akassoglou, K. (2012). Fibrinogen as a key regulator of inflammation in disease. Seminars in Immunopathology, 34, 43 - 62. doi: 10.1007/s00281-011-0290-8

Dedovic, K., Engert, V., Duchesne, A., Lue, S. D., Andrews, J., Efanov, S. I., Beaudry, T., \& Pruessner, J. C. (2010). Cortisol awakening response and hippocampal volume: vulnerability for major depressive disorder?. Biological Psychiatry, 68, 847 - 853. doi: 10.1016/j.biopsych.2010.07.025

Dienes, K. a., Hazel, N. a., \& Hammen, C. L. (2013). Cortisol secretion in depressed, and at-risk adults. Psychoneuroendocrinology, 38, 927-940. doi: 10.1016/j.psyneuen.2012.09.019

Edlund, B. J., Lauerer, J., \& Drayton, S. J. (2015). Recognizing depression in late life. The Nurse Practitioner, 40, 36 - 42. doi: 10.1097/01.NPR.0000459729.92650.ce 
Edwards, S., Evans, P., Hucklebridge, F., \& Clow, A. (2001). Association between time of awakening and diurnal cortisol secretory activity. Psychoneuroendocrinology, 26, 613-622. doi: $10.1016 / \mathrm{S} 0306-4530(01) 00015-4$

Ehring, T., Tuschen-Caffier, B., Schnülle, J., Fischer, S., \& Gross, J. J. (2010). Emotion regulation and vulnerability to depression: spontaneous versus instructed use of emotion suppression and reappraisal. Emotion, 10, 563-572. dio: 10.1037/a0019010

Ekman, P. (1992). An argument for basic emotions. Cognition and Emotion, 6, 169 - 200. doi: $10.1080 / 02699939208411068$

Etkin, E., Buchel, C., \& Gross, J. J. (2015). The neural bases of emotion regulation. Nature Reviews: Neuroscience, 16, 693 - 700. doi:10.1038/nrn4044

Everaert, J., Duyck, W., \& Koster, E. H. W. Attention, interpresetation, and memory biases in subclinical depression: A proof-of-principle test of the combined cognitive biases hypothesis. Emotion, 14, 331 - 340. doi: 10.1037/a0035250

Ezzati, Al., Jiang, J., Katz, M. J., Sliwinski, M. J., Zimmerman, M. E., \& Lipton, R. B. (2014). Validation of the Perceived Stress Scale in a community sample of older adults. International Journal of Geriatric Psychiatry, 29, 645 - 652. doi: 10.1002/gps.4049

Farrer, L., Leach, L., Griffiths, K. M., Christensen, H., \& Jorm, A. F. (2008). Age differences in mental health literacy. BMC Public Health, 8, 125. doi: 10.1186/1471-2458-8-125

Fiocco, A. J., Wan, N., Weekes, M., Pim, H., \& Lupien, S. J. (2006). Diurnal cycle of salivary cortisol in older adult men and women with subjective complaints of memory deficits and/or depressive symptoms: Relation to cognitive functioning. Stress, 9, 143 - 152. doi: $10.1080 / 10253890600965674$ 
Fisket, A., Wetherell, J. L., \& Gatz, M. (2009). Depression in older adults. Annual Review in Clinical Psychology, 5, 363 - 389. doi: 10.1146/annurev.clinpsy.032408.153621

Gallo, J. J., \& Rabins, R. V. (1999). Depression without sadness: alternative presentations of depression in late life. American Family Physician, 60, 820 - 826.

Gallo, J. J., Rebok, G. W., Tennsted, S., Wadley, V. G., \& The Advanced Cognitive Training for Independent and Vital Elderly (Active) Study Investigators. (2003). Linking depressive symptoms and functional disability in late life. Aging and Mental Health, 7, 469 - 480. doi: $10.1080 / 13607860310001594736$

Garnefski, N., Kraaij, V., \& Spinhoven, P. (2001). Negative life events, cognitive emotion regulation and emotional problems. Personality and Individual Differences, 30, 1311-1327. doi: 10.1016/S0191-8869(00)00113-6

Gianferante, D., Thoma, M. V, Hanlin, L., Chen, X., Breines, J. G., Zoccola, P. M., \& Rohleder, N. (2014). Post-stress rumination predicts HPA axis responses to repeated acute stress. Psychoneuroendocrinology, 49C, 244-252. doi: 10.1016/j.psyneuen.2014.07.021

Gelfand, > A. Mensinger, J. L., \& Tenhave, T. Mediation analysis : A retrospective snapshot of practice and more recent directions. Journal of General Psychology, 136, 153 - 176. doi : 10.3200/GENP.136.2.153-178

Goeleven, E., De Raedt, R., Baert, S., \& Koster, E. H. W. (2006). Deficient inhibition of emotional information in depression. Journal of Affective Disorders, 93, 149-157. doi: 10.1016/j.jad.2006.03.007

Gohier, B., Ferracci, L., Surguladze, S. a., Lawrence, E., El Hage, W., Kefi, M. Z., ... Le Gall, D. (2009). Cognitive inhibition and working memory in unipolar depression. Journal of Affective Disorders, 116, 100-105. doi: 10.1016/j.jad.2008.10.028 
Golden, S. H., Lazo, M., Carnethon, M., Bertoni, A. G., Schreiner, P. J., Diez Roux, A. V, ... Lyketsos, C. (2008). Examining a bidirectional association between depressive symptoms and diabetes. Journal of American Medical Aassocation, 299, 2751-2759. doi: 10.1016/S1073-5437(09)79168-5

Goldman, N., Turra, C. M., Glei, D. a, Lin, Y.-H., \& Weinstein, M. (2006). Physiological dysregulation and changes in health in an older population. Experimental Gerontology, 41, 862-870. http://doi.org/10.1016/j.exger.2006.06.050

Goldney, R. D., Fisher, L. J., Dal Grande, E. Taylor, A. W. (2004). Subsyndromal depression: Prevalence, use of health serivces and quality of life in an Australian population. Social Psychiatry and Psychiatric Epidemiology, 39, 293 - 298. doi: 10.1007/s00127-004-0745-5

Gotlib, I. H., \& Joormann, J. (2010). Cognition and depression: Current status and future directions. Annual Review in Clinical Psychology, 6, 285-312. doi: 10.1146/annurev.clinpsy.121208.131305

Gross, J. J. (1998a). The emerging field of emotion regulation: an integrative review. Review of General Psychology, 2, 271-299. doi: 10.1017.S0048577201393198

Gross, J. J. (1998b). Antecedent- and response-focused emotion regulation: divergent consequences for experience, expression, and physiology. Journal of Personality and Social Psychology, 74, 224-237. doi: 10.1037/0022-3514.74.1.224

Gross, J. J. (2015). Emotion regulation: current status and future prospects. Psychological Inquiry, 26, 1 - 26. doi: 10.1080/1047840X.2014.940781

Gross, J. J., \& Jazaieri, H. (2014). Emotion, emotion regulation, and psychopathology: An affective science perspective. Clinical Psychological Science, 2, 387-401. doi: $10.1177 / 2167702614536164$ 
Gross, J. J., \& Levenson, R. W. (1997). Hiding feelings: the acute effects of inhibiting negative and positive emotion. Journal of Abnormal Psychology, 106, 95 - 103. doi: 10.1037/0021843X.106.1.95

Gross, J. J., \& Levenson, R. W. (1993). Emotional suppression: physiology, self-report, and expressive behavior. Journal of Personality and Social Psychology, 64, 970 - 986. doi: $10.1037 / 0022-3514.64 .6 .970$

Gross, J. J., \& Munoz, R. F. (1995). Emotion regulation and mental health. Clinical Psychology: Science and Practice, 2, 151-164. doi: 10.1111/j.1468-2850.1995.tb00036.x

Gruenewald, T. L., Karlamangla, A. S., Hu, P., Stein-Merkin, S., Crandall, C., Koretz, B., \& Seeman, T. E. (2012). History of socioeconomic disadvantage and allostatic load in late life. Socioal Science \& Medicine, 74, 75 - 83. doi: 10.1016/j.socscimed.2011.09.037

Gruenewald, T. L., Seeman, T. E., Karlamangla, A. S., \& Sarkisian, C. A. (2009). Allostatic load and frailty in older adults. Journal of the American Geriatrics Society, 57, 1525-1531. doi: 10.1111/j.1532-5415.2009.02389.x

Gunn, J. M., Ayton, D. R., Densley, K., Pallant, J. F., Chondros, P., Herrman, H. E., \& Dowrick, C. F. (2012). The association between chronic illness, multimorbidity and depressive symptoms in an Australian primary care cohort. Social Psychiatry and Psychiatric Epidemiology, 47, 175-184. doi: 10.1007/s00127-010-0330-z

Gyurak, A., Goodkind, M. S., Kramer, J. H., Miller, B. L., \& Levenson, R. W. (2012). Executive functions and the down-regulation and up-regulation of emotion. Cognitive \& Emotion, 26, 103 - 118. doi: 10.1080/02699931.2011.557291 
Harris, C. R. (2001). Cardiovascular responses of embarrassment and effects of emotional suppression in a social setting. Journal of Personality and Social Psychology, 81, $886-897$ doi: $10.1037 / 0022-3514.81 .5 .886$

Hasher, L., Quig, M. B., May, C. P. (1997). Inhibitory control over no-longer-relevant information: adult age differences. Memory \& Cognition, 25, 286 - 295. doi: 10.3758/BF03211284

Hasher, L., Zacks, R. T., \& May, C. P. (1999). Inhibitory control, circadian arousal, and age. In D. Gopher \& A. Koriat (Eds.), Attention and Performance XVII, Cognitive Regulation of Performance: Interaction of Theory and Application (pp. 653-675). Cambridge, MA: MIT Press.

Hennessy, J. W., \& Levine, S. (1979). Stress, arousal and the pituitary-adrenal system: A psychoendocrine model. Progress in Psychobiology and Physiological Psychology, 8, 133 178.

Hellhammer, J., Schlotz, W., Stone, A. A., Pirke, K. M., \& Hellhammer, D. (2004). Allostatic load, perceived stress, and health: a prospective study in two age groups. Annals of the New York Academy of Sciences, 1032, 8-13. doi: 10.1196/annals.1314.002

Héraud-Bousquet, V., Larsen, C., Carpenter, J., Desenclos, J-., C., \& Le Strat, Y. (2012). Practical considerations for sensitivity analysis after multiple imputation applied to epidemiological studies with incomplete data. BMC Medical Research Methdology, 12. doi: 10.1186/1471-2288-12-73

Herman, J. P., \& Cullinan, W. E. (1997). Neurocircuitry of stress: Central control of the hypothalamo-pituitary-adrenocortical axis. Trends in Neurosciences, 20, 78 - 84. doi: 10.1016/S0166-2236(96)10069-2 
Hinkelmann, K., Muhtz, C., Dettenborn, L., Agorastos, A., Moritz, S., Wingenfeld, K., ... Otte, C. (2013). Association between cortisol awakening response and memory function in major depression. Psychological Medicine, 43, 2255-63. doi: 10.1017/S0033291713000287

Holzenberger, M., Dupont, J., Ducos, B., Leneuve, P., Geloen, A., Even, P. C., Cervera, P., \& Le Bouc, Y. (2003). IGF-1 receptor regualtes lifespan and resistance to oxidative stress in mice. Nature, 421, 182 - 187. doi: 10.1038/nature01298

Howland, R. H., Schettler, P. J., Rapaport, M. H., Mischoulon, D., Schneider, T., Fasiczka, A., Delrahiem, K., ... Nierenberg, A. A. (2008). Clinical feature, functioning of pateints with minor depression. Psychotherapyand Psychosomatics, 77, 384 - 389. doi: $10.1159 / 000151519$

Hu, P., Adler, N. E., Goldman, N., Weinstein, M., \& Seeman, T. E. (2005). Relationship between subjective social status and measures of health in older Taiwanese persons. Journal of the American Geriatrics Society, 53, 483 - 488. doi: 10.1111/j.1532-5415.2005.53169.x

Jamieson, J. P., Nock, M. K., \& Mendes, W. B. (2012). Mind over matter: Reappraising arousal improves cardiovascular and cognitive responses to stress. Journal of Experimental Psychology: General, 141, 417-422. doi: 10.1037/a0025719

Johnson, J. a., Lavoie, K. L., Bacon, S. L., Carlson, L. E., \& Campbell, T. S. (2012). The effect of trait rumination on adaptation to repeated stress. Psychosomatic Medicine, 74, 258-262. doi: 10.1097/PSY.0b013e31824c3ef2

Joormann, J. (2010). Cognitive inhibition and emotion regulation in depression. Current Directions in Psychological Science, 19, 161-166. doi: 10.1177/0963721410370293 
Joormann, J., \& Gotlib, I. H. (2008). Updating the contents of working memory in depression: interference from irrelevant negative material. Journal of Abnormal Psychology, 117, 182192. doi: 10.1037/0021-843X.117.1.182

Joormann, J., \& Gotlib, I. H. (2010). Emotion regulation in depression: relation to cognitive inhibition. Cognition \& Emotion, 24, 281-98. doi: 10.1080/02699930903407948

Joormann, J., \& Siemer, M. (2011). Affective processing and emotion regulation in dysphoria and depression: Cognitive biases and deficits in cognitive control. Social and Personality Psychology Compass, 5, 13-28. doi: 10.1111/j.1751-9004.2010.00335.x

Juster, R. P., Marin, M. F., Sindi, S., Nair, N. P. V., Ng, Y. K., Pruessner, J. C., \& Lupien, S. J. (2011). Allostatic load associations to acute, 3-year and 6-year prospective depressive symptoms in healthy older adults. Physiology and Behavior, 104, 360-364. doi: 10.1016/j.physbeh.2011.02.027

Juster, R. P., McEwen, B. S., \& Lupien, S. J. (2010). Allostatic load biomarkers of chronic stress and impact on health and cognition. Neuroscience and Biobehavioral Reviews, 35, 2-16. doi: 10.1016/j.neubiorev.2009.10.002

Karlamangla, A. S., Singer, B. H., McEwen, B. S., Rowe, J. W., \& Seeman, T. E. (2002). Allostatic load as a predictor of functional decline. Journal of Clinical Epidemiology, 55, 696-710. doi: 10.1016/S0895-4356(02)00399-2

Kendler, K. S., Karkowski, L. M., Ph, D., \& Prescott, C. a. (1999). and the Onset of Major Depression. Psychiatry Interpersonal and Biological Processes, 156, 837-841. doi: 10.1176/ajp.156.6.837 
Knight, M., Seymour, T. L., Gaunt, J. T., Baker, C., Nesmith, K., \& Mather, M. (2007). Aging and goal-directed emotional attention: Distraction revses emotional biases. Emotion, 7, 705 - 714. doi: 10.1037/1528-3542.7.4.705

Kobrosly, R. W., Seplaki, C. L., Cory-Slechta, D. A., Moynihan, J., \& van Wijngaarden, E. (2013). Multisystem physiological dysfunction is associated with depressiv symptoms in a population-based sample of older adults. Internaltional Journal of Geriatric Psychiatry, 28, 718 - 727. doi: $10.1002 / \mathrm{gps} .3878$

Kobrosly, R. W., van Wijngaarden, E., Seplaki, C. L., Cory-Slechta, D. A., \& Moynihan, J. (2014). Depressive symptoms are associated with allostatic load among communitydwelling older adults. Physiology \& Behaviour, 123, 223 - 230. doi: 10.1016/j.physbeh.2013.10.014

Koenig, A. M., Bhalla, R. K., \& Butters, M. A. (2014). Cognitive functioning and late-life depression. Journal of International Nueorpsychological Society, 20461 - 467. doi: $10.1017 / \mathrm{S} 1355617714000198$

Koster, E. H. W., De Raedt, R., Leyman, L., \& De Lissnyder, E. (2010). Mood-congruent attention and memory bias in dysphoria: Exploring the coherence among informationprocessing biases. Behaviour Research and Therapy, 48, 219-225. doi:

10.1016/j.brat.2009.11.004

Koster, E. H. W., Leyman, L., De Raedt, R., \& Crombez, G. (2006). Cueing of visual attention by emotional facial expressions: The influence of individual differences in anxiety and depression. Personality and Individual Differences, 41, 329 - 339. doi:

10.1016/j.paid.2005.12.022 
Kovacs, M., Joormann, J., \& Gotlib, I. H. (2008). Emotion (dys)regulation and links to depressive disorder. Child Development Persepctives, 2, 149-155. doi: 10.1111/j.17508606.2008.00057.x.

Kraaij, V., Pruymboom, E., \& Garnefski, N. (2002). Cognitive coping and depressive symptoms in the elderly: a longitudinal study. Aging \& Mental Health, 6, 275-281. doi: $10.1080 / 13607860220142387$

Kubzansky, L. D., Kawachi, I., \& Sparrow, D. (1999). Socioeconomic status, hostility, and risk factor clustering in the Normative Aging Study: any help from the concept of allostatic load?. Annals of Behavioral Medicine, 21, 330-338. doi: 10.1007/BF02895966

Kudielka, B. M., Broderick, J. E., \& Kirschbaum, C. (2003). Compliance with saliva sampling protocols: electronic monitoring reveals invalid cortisol daytime profiles in noncompliant subjects. Psychosomatic Medicine, 65, 313 - 319. doi:

10.1097/01.PSY.0000058374.50240.BF

Lam, S., Dickerson, S. S., Zoccola, P. M., \& Zaldivar, F. (2009). Emotion regulation and cortisol reactivity to a social-evaluative speech task. Psychoneuroendocrinology, 34, 1355-1362. doi: 10.1016/j.psyneuen.2009.04.006

Landfield, P. W., Waymire, J. C., \& Lynch, G. (1978). Hippocampal aging and adrenocorticoids: quantitative correlations. Science, 202, 1098 - 1102. doi: 10.1126/science. 715460

Lazarus, R. S. (1966). Psychological stress and the coping porocess. New York, US: McGrawHill.

Lazarus, R. S., \& Folkman, S. (1984). Stress, appraisal, and coping. New York, NY: Springer Publishing. 
Lee, B. K., Glass, T. A., McAtee, M. J., Wand, G. S., Bandeen-Roche, K., Bolla, K. I., \& Schwartz, B. S. (2007). Associations of salivary cortisol with cognitive function in the Baltimore memory study. Archives of General Psychiatry, 64, 810-818. doi: 10.1001/archpsyc.64.7.810

Li, C., Ford, E. S., Strine, T. W., \& Mokdad, A. H. (2008). Prevalence of depression among US adults with diabetes Findings from the 2006 Behavioral Risk Factor Surveillance System. Diabetes Care, 31, 105-107. doi: 10.2337/dc07-1154

Lin, F., Suhr, J., Diebold, S., \& Heffner, K. L. (2014). Associations between depressive symptoms and memory deficits vary as a function of insulin-like growth factor (IGF-1) levels in healthy older adults. Psychoneuroendocrinology, 42, 118 - 123. doi: 10.1016/j.psyneuen.2014.01.006

Liverant, G. I., Brown, T. a., Barlow, D. H., \& Roemer, L. (2008). Emotion regulation in unipolar depression: The effects of acceptance and suppression of subjective emotional experience on the intensity and duration of sadness and negative affect. Behaviour Research and Therapy, 46, 1201-1209. doi: 10.1016/j.brat.2008.08.001

Lockwood, K. A., Alexopoulos, G. S., van Gorp, W. G. (2002). Executive dysfunction in geriatric depression. The American Journal of Psychiatry, 159, 1119 - 1126. doi: 10.1176/appi.ajp.159.7.1119

Lorant, V., Deliege, D., Eaton, W., Robert, A., Philippot, P., \& Ansseau, M. (2003). Socioeconomic inequalities in depression: A meta-analysis. American Journal of Epidemiology, 157, 98 - 112. doi: 10.1093/aje/kwf182 
Lupien, S. J., de Leon, M., de Santi, S., Convit, A., Tarshish, C., Nair, N. P. V., Thakur, M., ... \& Meaney, M. J. (1998). Cortisol levels during human aging predict hippocampal atrophy and memory deficits. Nature Neuroscience, 1, 69 - 73. doi: 10.1038/271

Lupien, S. J., Gillin, C. J., \& Hauger, R. L. (1999). Working memory is more sensitive than declarative memory to the acute effects of corticosteroids: A dose-repsonse study in humans. Behavioural Neuroscience, 113, $420-430$.

Lyons, D. M., Lopez, J. M., Yang, C., \& Schatzberg, A. F. (2000). Stress-level cortisol treatment impairs inhibitory control of behavior in monkeys. Journal of Neuroscience, 20(20), 78167821.

Malooly, A. M., Genet, J. J., \& Siemer, M. (2013). Individual differences in reappraisal effectiveness: The role of affective flexibility. Emotion, 13, $302-313$. doi: $10.1037 / \mathrm{a} 0029980$

Mason, J. W. (1968). A review of psychoendocrine research on the pituitary-adrenal cortical system. Psychosomatic Medicine, 30, 576-607.

Mather, M., \& Carstensen, L. L. (2005). Aging and motivated cognition: The positivity effect in attention and memory. Trends in Cognitive Science, 9, 496 - 502. doi:

10.1016/j.tics.2005.08.005

Mather, M., \& Knight, M. (2005). Goal-directed memory: the role of cognitive control in older adults' emotional memory. Psychology and aging, 20, 554. doi: 10.1037/08827974.20 .4 .554

Mathews, A., \& MacLeod, C. (2005). Cognitive vulnerability to emotional disorders. Annual Review in Clinical Psychology, 1, 67 - 95. doi: 10.1146/annurev.clinpsy.1.102803.143916 
McGonagle, K. A., \& Kessler, R. C. (1990). Chronic stress, acute stress, and depressive symptoms. American Journal of Community Psychology, 18, 681-706. doi:

\subsection{7/BF00931237}

McEwen, B. S. (1998). Stress, adaptation, and disease: Allostasis and allostatic load. Annals of the New York Academy of Sciences, 840, 33-44. doi: 10.1111/j.1749-6632.1998.tb09546.x

McEwen, B. S. (2003). Interacting mediators of allostasis and allostatic load: Towards an understanding of resilience in aging. Metabolism, 52, 10 - 16. doi: 10.1053/S00260495(03)00295-6

McEwen, B. S. (2008). Central effects of stress hormones in health and disease: Understanding the protective and damaging effects of stress and stress mediators. European Journal of Pharmacology, 583, 174-185. http://doi.org/10.1016/j.ejphar.2007.11.071

McEwen, B. S., Gould, E. A., \& Sakai, R. R. (1992). The vulnerability of the hippocampus to protective and destructive effects of glucocorticoids in relation to stress. The British Journal of Psychiatry, 160 (Suppl. 15), 18 - 23.

McEwen, B. S., \& Stellar, E. (1993). Stress and the individual: mechanisms leading to disease. Archives of internal medicine, 153, 2093-2101. doi:

10.1001/archinte.1993.00410180039004

McRae, K., Jacobs, S. E., Ray, R. D., John, O. P., \& Gross, J. J. (2012). Individual differences in reappraisal ability: Links to reappraisal frequency, well-being, and cognitive control. Journal of Research in Personality, 46, 2 - 7. doi: 10.1016/j.jrp.2011.10.003

Meeks, T., Vahia, I., Lavretsky, H., Kulkarni, G., \& Jeste, D. (2011). A tune in “A Minor” can "B Major": A review of epidemiology, illness course, and public health implications of 
subthreshold depression in older adults. Journal of Affective Disorder, 129, 126-142. doi: 10.1016/j.jad.2010.09.015.A

Meiran, N., Diamond, G. M., Toder, D., \& Nemets, B. (2011). Cognitive rigidity in unipolar depression and obsessive compulsive disorder: Examination of task switching, Stroop, working memory updating and post-conflict adaptation. Psychiatry Research, 185, 149 156. doi: 10.1016/j.psychres.2010.04.044

Miklosi, M., Martos, T., Szabo, M., Kocsis-Bogar, K., Forintos, D. P. (2014). Cognitive emotion regulation and stress: A multiple mediation approach. Translational Neuroscience, 5, 6471. doi: $10.24788 / \mathrm{s} 13380-014-0207-9$

Mogg, K., Bradbury, K. E., \& Bradley, B. P. (2006). Interpretation of ambiguous information in clinical depression. Behaviour Research and Therapy, 44, 1411-1419. doi: 10.1016/j.brat.2005.10.008

Moriya, J., \& Takahashi, Y. (2013). Depression and interpersonal stress: The mediating role of emotion regulation. Motivation and Emotion, 37, 600-608. doi: 10.1007/s11031-012-93234

Morris, J. S., Friston, K. J., Buchel, C., Frith, C. D., Young, A. W., Calder, A. J., \& Dolan, R. J. (1998). A neuromodulatory role for the human amygdala in processing emotional facial expressions. Brain, 121, 47 - 57. doi: 10.1093/brain/121.1.47 47-57

Mortiz, S., Glascher, J., \& Brassen, S. (2005). Investigation of mood-congruent false and true memory recognition in depression. Depression and Anxiety, 21, 9 - 17. doi: 10.1002/da.20054 
Moussavi, S., Chatterji, S., Verdes, E., Tandon, A., Patel, V., \& Ustun, B. (2007). Depression, chronic diseases, and decrements in health: results from the World Health Surveys. The Lancet, 370, 8 - 14. doi: 10.1016/S0140-6736(07)61415-9

Murphy, R. A., Hagaman, A. K., Reinders, I., Steeves, J. A., Newman, A. B., Rubin, S. M., Satterfield, S., ... \& Harris, T. B. (2016). Depressive trajetories and risk of disability and mortality in older adults: Longitudinal findings fro the Health, Aging, and Body Composition Study. Journals of Gerontology: Medical Sciences, 71, 228 - 235. doi: 10.1093/gerona/glv139

Murri, M. B., Pariante, C., Mondelli, V., Masotti, M., Atti, A. R., Mellacqua, Z., Antonioli, M., ... Amore, M. (2014). HPA axis, aging in depression: Systematic review and meta-analysis. Psychoneuroendocrinology, 41, 46 - 62. doi: 10.1016/j.psyneun.2013.12.004

Nebes, R. D., Butters, M. A., Mulsant, B. H., Pollock, B. D., Zmuda, M. D., Houck, P. R., \& Reynolds, F. (2000). Decreased working memory and processing speed mediate cognitive impairment in geriatric depression. Psychological Medicine, 30, 679 - 691. doi: $10.1017 / \mathrm{S} 0033291799001968$

Nolen-Hoeksema, S. (1991). Responses to depression and their effects on the duration of depressive episodes. Journal of Abnormal Psychology, 100, 569-582. doi: 10.1037/0021843X.100.4.569

Nolen-Hoeksema, S., Morrow, J., \& Fredrickson, B. L. (1993). Response styles and the duration of episodes of depressed mood. Journal of Abnormal Psychology, 102, 20-28. doi: $10.1037 / 0021-843 X .102 .1 .20$

O’Hara, R., Schroder, C. M., Mahadevan, R., Schatzberg, A. F., Lindley, S., Fox, S., Weiner, M., ... \& Hallmayer, J. F. (2007). Serotonin transporter polymorphism, memory and 
hippocampal volume in the elderly: association and interaction with cortisol. Molecular Pyschiatry, 12, 544 - 555. doi: 10.1038/sj.mp.4001978

Olatunji, B. O., Naragon-Gainey, K., \& Wolitzky-Taylor, K. B. (2013). Specificity of rumination in anxiety and depression: A multimodal meta-analysis. Clinical Psychology: Science and Practice, 20, 225-257. doi: 10.1111/cpsp.12037

Oldehinkel, A. J., van den Berg, M. D., Flentge, F., Bouhuys, A. L., ter Horst, G. J., \& Ormel, J. (2001). Urinary free cortisol excretion in elderly persons with minor and major depression. Psychiatry Research, 104, 39-47. doi: 10.1016/S0165-1781(01)00300-6

Opitz, P. C., Rauch, L. C., Terry, D. P., \& Urry, H. L. (2012). Prefrontal mediation of age differences in cognitive reappraisal. Neurobiology of Aging, 33, 645-655. doi: 10.1016/j.neurobiolaging.2010.06.004

Pariante, C. M., \& Lightman, S. L. (2008). The HPA axis in major depression: classical theories and new developments. Trends in Neurosciences, 31, 464 - 468. doi: 10.1016/j.tins.2008.06.006

Park, M., Katon, W. J., \& Wolf, F. M. (2013). Depression and risk of mortality in individuals with diabetes: a meta-analysis and systematic review. General Hospital Psychiatry, 35, 217 - 225. doi: 0.1016/j.genhosppsych.2013.01.006

Parker, G., Roy, K., Hadzi-Pavlovic, D., Wilhelm, K., \& Mitchell, P. (2001). The differential impact of age on the phenomenology of melancholia. Psychological Medicine, 31, 1231 1236. doi: $10.1017 / \mathrm{S} 0033291701004603$

Penninx, B. W., Beekman, A. T., Corsi, A. M., Bremmer, M., Hoogendijk, W. J., Guralnik, J. M., ... \& Bandinelli, S. (2007). Late-life depressive symptoms are associated with both 
hyperactivity and hypoactivity of the hypothalamo-pituitary-adrenal axis. The American Journal of Geriatric Psychiatry, 15, 522-529. doi: 10.1097/JGP.0b013e318033ed80

Pek J., \& Hoyle, R. H. (2015). On the (in)validity of tests of simple mediation: Threats and solutions. Social and Personality Psychology Compass, 10, 150 - 163. doi: $10.1111 / \mathrm{spc} 3.12237$

Piazza, J. R., Almeida, D. M., Dmitrieva, N. O., \& Klein, L. C. (2010). Frontiers in the use of biomarkers of health in research on stress and aging. Journals of Gerontology - Series B Psychological Sciences and Social Sciences, 65B, 513-525. doi: 10.1093/geronb/gbq049

Potter, G. G., McQuoid, D. R., Payne, M. E., Taylor, W. D., \& Steffens, D. C. (2012). Association of attentional shift and reversal learning to functional deficits in geriatric depression. Interational Journal of Geriatric Psychiatry, 27, 1172 - 1179. doi: 10.1002/gps.3764

Preacher, K. J., \& Hayes, A. F. (2008). Asymptotic and resampling strategies for assessing and comparing indirect effects in multiple mediator models. Behaviour Research Methods, 40, 879 - 891. doi: 10.3758/BRM.40.3.879

Qin, S., Hermans, E. J., van Marle, H. J. F., Luo, J., Fernandez, G. (2009). Acute psychological stress reduces working memory-related activity in the dorsolateral prefrontal cortex. Biological Psychiatry, 66, 25 - 32. doi: 10.1016/j.biopsych.2009.03.006

Radstaak, M., Geurts, S. A. E., Brosschot, J. F., Cillessen, A. H. N., \& Kompier, M. A. J. (2011). The role of affect and rumination in cardiovascular recovery from stress. International Journal of Psychophysiology, 81, 237 - 244. doi: 10.1016/j.ijpsycho.2011.06.017 
Rapaport, M. H., Judd, L. L., Schettler, P. J., Yonkers, K. A., Thase, M. E., Kupfer, J. D., Frank, E., ... \& Rush, A. J. (2002). A descriptive analysis of minor depression. American Journal of Psychiatry, 159, 637 - 643. doi: 10.1176/appi.ajp.159.4.637

Reed, A. E., Chan, L., \& Mikels, J. A. (2014). Meta-analysis of the age-related positivity effect: Age differences in preferences for positive over negative information. Psychology \& Aging, 29, 1 - 5. doi: 10.1037/a0035194

Roberti, J. W., Harrington, L. N., \& Storch, E. A. (2006). Further psychometric support for the 10-item version of the Perceived Stress Scale. Journal of College Counseling, 9, 135 - 147. doi: 10.1002/j.2161-1882.2006.tb00100.x

Roozendaal, B., Barsegyan, A., \& Lee, S. (2007). Adrenal stress hormones, amygdala activation, and memory for emotionally arousing experiences. Progress in Brain Research, 167, 79-97. doi: 10.1016/S0079-6123(07)67006-X

Rydstedt, L. W., Cropley, M., \& Devereux, J. (2011). Long-term impact of role stress and cognitive rumination upon morning and evening saliva cortisol secretion, Ergonomics, 54, 430 - 435. doi: 10.1080/00140139.2011.558639

Sandi, C. (2013). Stress and cognition. WIREs: Cognitive Science, 4, 245 - 261. doi: $10.1002 /$ wcs. 1222

Sapolsky, R. M. (2000). The possibility of neurotoxicity in the hippocampus in major depression: A primer on neuron death. Biological Psychiatry, 48, 755 - 765. doi: 10.1016/S0006-3223(00)00971-9

Sapolsky, R. M. (1999). Glucocorticoids, stress, and their adverse neurological effects: Relevance to aging. Experimental Gerontology, 34, 721 - 732. doi: 10.1016/S0531$5565(99) 00047-9$ 
Saxbe, D. E. (2008). A field (researcher's) guide to cortisol: Tracking HPA axis functioning in everyday life. Healthy Psychology Review, 2, 163 - 190. doi: 10.1080/17437190802530812

Schule, C., Baghai, T., Rackwitz, C., \& Laakmann, G. (2003). Influence of mirtazapine on urinary free cortisol excretion in depressed patients. Psychiatry Research, 120, 257-264. doi: 10.1016/S0165-1781(03)00204-X

Schulkin, J. (2003). Allostasis: a neural behavioral perspective. Hormones and Behavior, 43, 2127. doi: 10.1016/S0018-506X(02)00035-1

Schmeichel, B. J., Volokhov, R. N., \& Demaree, H. A. (2008). Working memory capacity and the self-regulation of emotional expression and experience. Journal of Personality and Social Psychology, 95, 1526 - 1540. doi: 10.1037/a0013345

Seeman, T. E., McEwen, B. S., Rowe, J. W., \& Singer, B. H. (2001). Allostatic load as a marker of cumulative biological risk: MacArthur studies of successful aging. Proceedings of the National Academy of Sciences of the United States of America, 98, 4770-4775. doi: 10.1073/pnas.081072698

Segal, D. L., Coolidge, F. L., Cahill, B. S., \& O' Riley, A. A. (2008). Psychometric properties of the Beck Depression Inventory-II (BDI-II) among community-dwelling older adults. Behavior Modification, 32, 3-20. doi: 10.1177/0145445507303833

Seplaki, C. L., Goldman, N., Weinstein, M., \& Lin, Y.-H. (2006). Measurement of cumulative physiological dysregulation in an older population. Demography, 43, 165-183. doi: 10.1353/dem.2006.0009

Shields, G. S., Bonner, J. C., \& Moons, W. G. (2015). Does cortisol influence core executive functions? A meta-analysis of acute cortisol administration effects on working memory, 
inhibition, and set-shifting. Psychoneuroendocrinology, 58, 91-103. doi:

10.1016/j.psyneuen.2015.04.017

Siemer, M., Mauss, I., \& Gross, J. J. (2007). Same situation--different emotions: how appraisals shape our emotions. Emotion, 7, 592-600. doi: 10.1037/1528-3542.7.3.592

Singh-Manoux, A., Marmot, M., \& Adler, N. E. (2005). Does subjective social status predict health and chang in health status better than objective status? Psychosomatic Medicine, 67, 855-861. doi: 10.1097/01.psy.0000188434.52941.a0

Smoski, M. J., LaBar, K. S., \& Steffens, D. C. (2014). Relative effectiveness of reappraisal and distraction in regulating emotion in late-life depression. The American Journal of Geriatric Psychiatry, 22, 898-907. doi: 10.1016/j.jagp.2013.01.070

Snyder, H. R. (2013) Major depressive disorder is associated with broad impairments on neuropsychological measures of executive function: A meta-analysis and review. Psychological Bulletin, 139, 81 - 132. doi: 10.1037/a0028727

Stanners, M., Barton, C., Shakid, S., \& Winefield, H. (2013). The prevalence of depression amongst outpatients with multimorbidity. Health, 5, 805 - 810. doi:

10.4236/health.2013.54106

Statistics Canada. (2011). Projected population, by projection scenario, sex and age group as of July 1, Canada, provinces and territories, annual. (CANSIM table 052-0005). Retrieved from http://www5.statcan.gc.ca/cansim/a26?lang=eng\&id=520005

Stawski, R. S., Almeida, D. M., Sliwinski, M. J., Smyth, J. M. (2008). Reported exposure and emotional reactivity to daily stressors: The roles of adult age and global perceived stress. Psychology \& Aging, 23, 52 - 61. doi: 10.1037/0882-7974.23.1.52. 
Steer, R. A., Rissmiller, D. J., \& Beck, A. T. (2000). Use of the Beck Depression Inventory-II with depressed geriatric inpatients. Behaviour Research and Therapy, 38, 311-318. doi: 10.1016/S0005-7967(99)00068-6

Steffens, D. C., McQuoid, D. R., Payne, M. E., \& Potter, G. G. (2011). Change in hippocampal volume on magnetic resonance imaging and cognitive decline among older depressed and nondepressed subjects in the neurocognitive outcomes of depression in the elderly study. The American Journal of Geriatric Psychiatry, 19, 4-12. doi: 10.1097/JGP.0b013e3181d6c245

Sterling, P., \& Eyer, J. (1988). Allostasis: a new paradigm to explain arousal pathology. Fisher, Shirley (Ed); Reason, James (Ed), (1988). Handbook of life stress, cognition and health. (pp. 629-649). Oxford, England: John Wiley \& Sons, xxxiii, pp. 750.

Sterne, J. A. C., White, I. R., Carlin, J. B., Sprat, M., Royston, P., Kenward, M. G., Wood, A. M., \& Carpenter, J. R. (2009). Multiple imputation for missing data in epidemiological and clinical research: Potential and pitfalls. British Medical Journal, 339, 157 - 160. doi: 10.1136/bmj.b2393

Stetler, C., \& Miller, G. E. (2005). Blunted cortisol response to awakening in mild to moderate depression: regulatory influences of sleep patterns and social contacts. Journal of Abnormal Psychology, 114, 697-705. doi:10.1037/0021-843X.114.4.697

Stewart, J. G., Mazurka, R., Bond, L., Wynne-Edwards, K. E., \& Harkness, K. L. (2013). Rumination and impaired cortisol recovery following a social stressor in adolescent depression. Journal of Abnormal Child Psychology, 41, 1015-1026. doi: 10.1007/s10802013-9740-1 
St. Jaques, P., Dolcos, R., \& Cabeza, R. (2010). Effects of aging on functional connectivity of the amygdala during negative evaluation: A network analysis of fMRI data. Neurobiologicla Aging, 31, 315 - 327. doi: 10.1177/0963721410388395

Szczerbinska, K., Hirders, J. P., \& Zyczkowska, J. (2012). Good news and bad news: Depressive symptoms decline and undertreatment increases with age in home care and institutional settings. The American Journal of Geriatric Psychiatry, 20, 1045 - 1056. doi:

10.1097/JGP.0b013e3182331702

Tang, D. \& Schmeichel, B. J. (2014). Stopping anger and anxiety: Evidence that inhibitory ability predicts negative emotional responding. Cognition and Emotion, 28, 132 - 142. doi: $10.1080 / 02699931.2013 .799459$

Taverna, M., Marie, A.-L., Mira, J.-P., \& Guidet, B. (2013). Specific antioxidant properties of human serum albumin. Annals of Intensive Care, 3(4). doi: 10.1186/2110-5820-3-4

Taylor, W. D., McQuoid, D. R., Payne, M. E., Zannas, A. S., MacFall, J. R., \& Steffens, D. C. (2013). Hippocampus Atrophy and the Longitudinal Course of Late-life Depression. American Journal of Geriatric Psychiatry, 22, 1504-1512. doi: 10.1016/j.jagp.2013.11.004

Theirry, A. M., Javoy, F., Glowinski, J., \& Kety, S. S. (1968). Effects of stress on the metabolism of norepinephrine, dopamine, and serotonin in the central nervous systems of the rat. I. modifications of norepinephrine turnover. Journal of Pharmacology and Experimental Therapeutics, 163(1), $163-171$.

Thomas, A. J., \& O'Brien, J. T. (2008). Depression and cognition in older adults. Current Opinion in Psychiatry, 21, 8 - 13. doi: 10.1097/YCO.0b013e3282f2139b 
Troy, A. S., Wilhelm, F. H., Shallcross, A. J., \& Mauss, I. B. (2010). Seeing the silver lining: cognitive reappraisal ability moderates the relationship between stress and depressive symptoms. Emotion, 10, 783 - 795. doi: 10.1037/a0020262

Upchurch, D. M., Stein, J., Greendale, G., Chyu, L., Tseng, C-. H., Huang, M-. H., Lewis, T., ... \& Seeman, T. (2015). A longitudinal investigation of race, socioeconomic status, and psychosocial mediators of allostatic load in midlife women: Findings from the study of women's health across the nation. Psychosomatic Medicine, 77, 402 - 412. doi: 10.1097/PSY.0000000000000175

Ursin, H., \& Eriksen, H. R. (2004). The cognitive activation theory of stress. Psychoneuroendocrinology, 29, 567 - 592. doi: 10.1016/S0306-4530(03)00091-X

Urry, H. L., \& Gross, J. J. (2010). Emotion Regulation in Older Age. Current Directions in Psychological Science, 19, 352-357. doi: 10.1177/0963721410388395

Vieta, E., Popovic, D., Rosa, A. R., Solé, B., Grande, I., Frey, B. N., ... \& Kapczinski, F. (2013). The clinical implications of cognitive impairment and allostatic load in bipolar disorder. European Psychiatry, 28, 21-29. doi: 10.1016/j.eurpsy.2011.11.007

Vreeburg, S. A., Hoogendijk, W. J. G., van Pelt, J., DeRijk, R. H., Verhagen, J. C. M., van Dyck, R., ... Penninx, B. W. J. H. (2009). Major Depressive Disorder and Hypothalamic-PituitaryAdrenal Axis Activity: Results from a large cohort study. Archives of General Psychiatry, 66, 617-626. doi: 10.1001/archgenpsychiatry.2009.50

von Hippel, W., Vasey, M. W., Gonda, T., \& Stern, T. (2008). Executive function deficits, rumination and late-onset depressive symptoms in older adults. Cognitive Therapy and Research, 32, 474-487. doi: 10.1007/s10608-006-9034-9 
Watkins, E., \& Moulds, M. (2005). Distinct modes of ruminative self-focus: impact of abstract versus concrete rumination on problem solving in depression. Emotion, 5, 319-328. doi: $10.1037 / 1528-3542.5 .3 .319$

Werner, P., Stein-Shvachman, I., \& Heinik, J. (2009). Perceptions of self-stigma and its correlates among older audlts with depression: a preliminary study. International Psychogeriatrics, 21, 1180 - 1189. doi: 10.1017/S1041610209990470

Wilkins, V. M., Kiosses, D., \& Ravdin, L. D. (2010). Late-life depression with comorbid cognitive impairment and disaiblity: nonpharmacological interventions. Clinical Interventions in Aging, 5, 323-331. doi: 10.2147/CIA.S9088

Winecoff, A., LaBar, K. S., Madden, D. J., Cabeza, R., \& Huettel, S. A. (2011). Cognitive and neural contributors to emotion regulation in aging. Social Cognitive and Affective Neuroscience, 6, 165 - 176. doi: 10.1093/scan/nsq030

Wisco, B. E., \& Nolen-Hoeksema, S. (2010). Interpretation bias and depressive symptoms: The role of self-relevance. Behaviour Research and Therapy, 48, 1113-1122. doi: 10.1016/j.brat.2010.08.004

World Health Organization. (2012). Depression Fact Sheets. Retrieved from http://www.who.int/mediacentre/factsheets/fs369/en/

Wust, S., Wolf, J., Hellhammer, D. H., Federenko, I., Schommer, N., \& Kirschbaum C. (2000). Cortisol awakening response - normal values and confounds. Noise \& Health, 2, $79-88$.

Zelazo, P. D, \& Cunningham, W. A. (2006). Executive function: Mechanisms underlying emotion regulation. In J. J. Gross (Ed.), Handbook of emotion regulation (pp. 135-158). New York, NY: Guilford. 
Zobel, A. W., Nickel, T., Sonntag, A., Uhr, M., Holsboer, F., \& Ising, M. (2001). Cortisol response in the combined dexamethasone/CRH test as predictor of relapse in patients with remitted depression: a prospective study. Journal of Psychiatric Research, 35, 83-94. doi: 10.1016/S0022-3956(01)00013-9

Zoccola, P. M., Dickerson, S. S., \& Zaldivar, F. P. (2008). Rumination and cortisol responses to laboratory stressors. Psychosomatic Medicine, 70, 661 - 667. doi: 10.1097/PSY.0b013e31817bbc77

Zoccola, P. M., Figueroa, W. S., Rabideau, E. M., Woody, A., \& Benencia, F. (2014). Differential effects of poststressor rumination and distraction on cortisol and C-reactive protein. Health Psychology, 32, 1-4. doi: 10.1037/hea0000019

Zoccola, P. M., Quas, J. A., \& Yim, I. S. (2010). Salivary cortisol responses to a psychosocial laboratory stressor and later verbal recall of the stressor: The role of traits and state rumination. Stress, 13, 435 - 443. doi: 10.3109/10253891003713765 